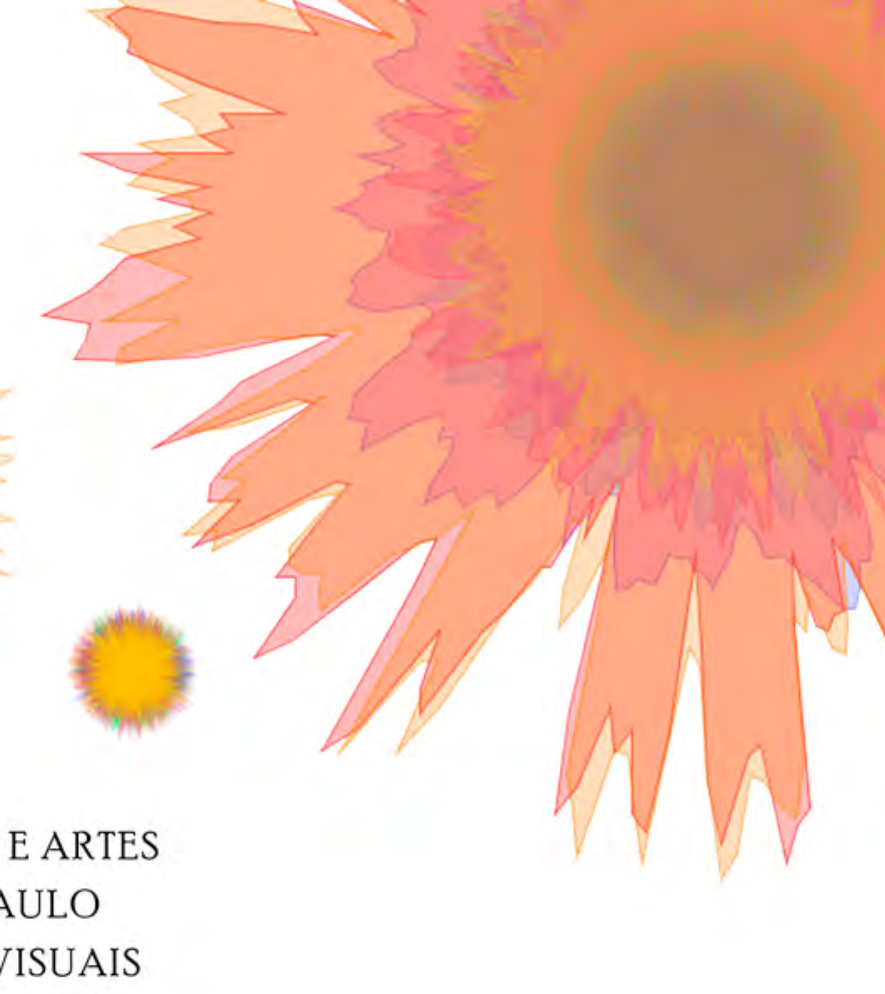

Loren Paneto Bergantini

Sinestesia mediada pela tecnologia

NA ARTE: A INTERAÇÃO ENTRE

VOZ E IMAGEM

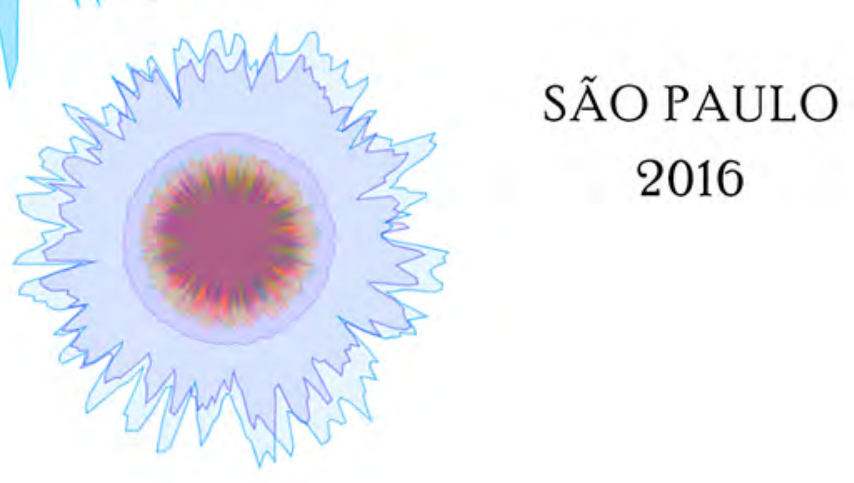


UNIVERSIDADE DE SÃO PAULO

ESCOLA DE COMUNICAÇÕES E ARTES

DEPARTAMENTO DE ARTES VISUAIS

LOREN PANETO BERGANTINI

\section{Sinestesia mediada pela tecnologia na arte: $a$ interação entre voz e imagem}

SÃO PAULO 
Sinestesia mediada pela tecnologia na arte: a interação entre voz e imagem

Dissertação apresentada ao Programa de Pós-graduação em Artes Visuais, da Escola de Comunicações e Artes da Universidade de São Paulo, como exigência parcial para a obtenção de título de Mestre em Artes Visuais.

Área de concentração: Poéticas Visuais.

Linha de pesquisa: Multimeios.

Orientadora: $\operatorname{Prof}^{\mathrm{a}} \operatorname{Dr}^{\mathrm{a}}$ Silvia Regina Ferreira de Laurentiz. 
Autorizo a reprodução e divulgação parcial deste trabalho, por qualquer meio convencional ou eletrônico, para fins de estudo e pesquisa, desde que citada a fonte.

Este trabalho recebeu apoio financeiro da FAPESP - Fundação de Amparo à Pesquisa do Estado de São Paulo, n do processo: 2014/11213-8.

Catalogação na Publicação

Serviço de Biblioteca e Documentação

Escola de Comunicações e Artes da Universidade de São Paulo

Dados fornecidos pelo(a) autor(a)

Bergantini, Loren Paneto

Sinestesia mediada pela tecnologia na arte: a interação

entre voz e imagem / Loren Paneto Bergantini. -- São Paulo:

L. P. Bergantini, 2016 .

$124 \mathrm{p}$, ; il.

Dissertação (Mestrado) - Programa de Pós-Graduação em Artes Visuais - Escola de Comunicações e Artes / Universidade de são Paulo.

Orientadora: Silvia Regina Ferreira de Laurentiz

Bibliografia

1. sinesteria 2 , voz 3, arte interativa 4, arte digital 5. neurociencia I. Laurentiz, Silvia Regina Ferreira de II. Título.

CDD 21. ed. - 700 
BERGANTINI, Loren. Sinestesia mediada pela tecnologia na arte: a interação entre voz e imagem. Dissertação apresentada ao Programa de Pós-graduação em Artes Visuais, da Escola de Comunicações e Artes da Universidade de São Paulo, como exigência parcial para a obtenção de título de Mestre em Artes Visuais, Área de concentração: Poéticas Visuais, linha de pesquisa: Multimeios

São Paulo, de de 2016

Banca Examinadora: 
Aos meus pais e ao Chu. 


\section{AGRADECIMENTOS}

À Universidade de São Paulo, Escola de Comunicações e Artes e ao Departamento de Artes Visuais, pela estrutura física e pelo apoio dos funcionários que permitiram o desenvolvimento e a continuidade dos meus estudos.

À Fundação de Amparo à Pesquisa do Estado de São Paulo pelo suporte financeiro para a realização desta pesquisa.

À minha orientadora Silvia Laurentiz, pela excelente orientação, apoio e confiança.

Às professoras Wania Storolli e Heloisa Valente pelas ótimas referências.

Ao professor Sérgio Basbaum pelos insights sobre sinestesia.

À professora Monica Batista Tavares por ter me iniciado apropriadamente na área acadêmica. Aos meus professores de canto Marta Dalila Mauler e Carlos Eduardo Marcos pela amizade e paciência nos ensinamentos sobre voz.

Aos pianistas correpetidores Nancy Bueno e Daniel Gonçalves pelo apoio musical e dicas de interpretação que destacaram a característica emocional da voz.

À Paloma Oliveira, Jaime Lobato e todos os participantes do Projeto Híbrida, em especial ao grupo do Simulador de Sinestesia (Rafael, Vinicius, Glória e Alex), pela colaboração e generoso compartilhamento de conhecimentos e experiências.

Ao Grupo de Pesquisa REALIDADES (Sílvia, Cássia, Gi, Vivi, Vick, Mariana, Marcus e Lali) pela amizade e companheirismo na busca pelo conhecimento.

A toda comunidade virtual do Processing por disponibilizar seus conhecimentos abertamente.

Ao Sean Day por disponibilizar livremente e de forma atualizada um grande número de artigos científicos sobre sinestesia em seu site.

À minha família que sempre me incentivou a ser o melhor de mim.

Ao meu marido Rodrigo, pelo apoio incondicional e pela minuciosa revisão do texto. 
Minha voz ouvida revela-me a mim mesmo, não menos embora de uma maneira diferente - que ao outro. 


\section{RESUMO}

BERGANTINI, Loren. Sinestesia mediada pela tecnologia na arte: a interação entre voz e imagem. 2016. 124 p. Dissertação (Mestrado) - Escola de Comunicações e Artes da Universidade de São Paulo, São Paulo, 2016.

Avanços tecnológicos recentes inauguraram novas possibilidades estéticas devido ao potencial de integração de diversos meios, códigos e linguagens. Consequentemente, as tradicionais fronteiras entre as áreas artísticas dissolveram-se e estímulos simultâneos a vários sentidos foram introduzidos. A inclusão do corpo e seus aspectos cognitivos em interação direta com códigos computacionais é fato irreversível na arte contemporânea e seus aspectos e consequências ainda não foram completamente compreendidos. Este trabalho tem como objetivo investigar, sistematizar e utilizar os conhecimentos sobre sinestesia na arte, destacando o caso das obras artísticas interativas que correlacionam voz e imagem. Em função disto, foram propostas: a) a realização de estudos sobre o fenômeno da sinestesia no contexto da ciência e da arte; b) a busca de uma definição para a voz; c) a pesquisa por referências estéticas que abordaram a questão; e d) a realização de trabalhos experimentais correlacionados ao tema. Os métodos de pesquisa utilizados foram: revisão bibliográfica - a partir de um enfoque multidisciplinar, englobando referências tanto da neurociência quanto de outras áreas -, seleção e análise de trabalhos artísticos interativos contemporâneos que abordaram a questão da sinestesia e da interação entre voz e imagem, e investigação estética a partir da realização de propostas poéticas experimentais. Os principais resultados obtidos foram: a compreensão da trajetória dos estudos sobre sinestesia na ciência e a atualização dos conhecimentos sobre o assunto; apontamentos sobre a contextualização da sinestesia na arte; a definição da voz como corporificada e relacionada a todos os sentidos incluídos na unidade do corpo; e a realização de três trabalhos experimentais, dois coletivos sobre sinestesia e um individual que explora a relação entre voz e visualidade.

Palavras-chave: sinestesia, voz, arte interativa, arte digital, neurociência. 


\begin{abstract}
BERGANTINI, Loren. Sinestesia mediated by technology in art: the interaction between voice and image. 2016. 124 p. Dissertation (Master's degree) - School of Comunication and Arts from University of São Paulo (ECA-USP), São Paulo, 2016.

Recent technological advances opened new aesthetic possibilities in art, due to its potentiality to integrate several medias, codes and languages. Consequently, the traditional boundaries between artistic areas were dissolved and simultaneous stimuli to various senses were introduced. The occurence of the body and its cognitive aspects in interaction with computer codes is an irreversible fact in contemporary art, and its aspects and consequences have not been fully understood. This work aims to investigate, systematize and use the information about synesthesia in arts, highlighting the case of interactive art works connecting voice and image. Therefore, it was proposed: a) the study of the synesthetic phenomenon and how it is treated in both science and arts; b) the definition of voice; c) the search for aesthetic references in interactive arts addressing this issue; and d) the development of experimental works related to this subject. The adopted methodology consisted of: bibliographical reviewwith a multidisciplinary approach, encompassing references from neuroscience and other areas -, selection and analysis of contemporary interactive artworks adressesing aspects of synesthesia and the voice-image interaction, and aesthetic research based on experimental artworks. Our main results were: understanding the trajectory of the studies about synesthesia in science and updating the knowledge on the subject; notes on the context of synesthesia in art; the definition of voice as an embodied entity, related to all the senses included in the body unit; and the development of three experimental works of art, two collective works about synesthesia, and an individual one that explores the relationship between voice and visuality.
\end{abstract}

Key-words: synesthesia, voice, interactive art, digital art, neuroscience. 


\section{LISTA DE ILUSTRAÇÕES}

Figura 1: O desenho esquemático compara a mesma palavra "sinestesia", impressa em preto, como visualizada por não sinestetas (acima) e por um suposto sinesteta (abaixo) com sinestesia grafema cor. Autoria própria

Figura 2: Quadro esquemático que compara o posicionamento dos monistas, pluralistas e separatistas quanto à definição de sinestesia. Tradução e adaptação da tabela em inglês (MARKS, 2011, p.68)

Figura 3: Rascunhos de David Hockney para a ópera Oedipus Rex de Stravinsky. Disponível em: $\quad<$ http://www.hockneypictures.com/stravinsky triple/stravinsky oedipus title.php $>$. Acesso em: 16 jun. 2016.

Figura 4: Escultura Déjeuner en Fourrure de Meret Oppenheim (1936). Disponível em: http://www.wikiart.org/en/meret-oppenheim/object-le-d-jeuner-en-fourrure-1936. Acesso em: 15 jun. 2016 p.39

Figura 5: Desenho indicando as estruturas anatômicas do pescoço e algumas das cavidades de ressonância presentes na cabeça humana. Disponível em: $<$ http://www.ebah.com.br/content/ABAAAggH4AH/anatomia-radiologica-pescoco $>$.

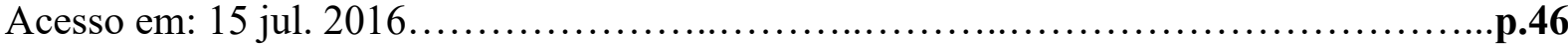

Figura 6: Imagem apresentando o aparelho/sistema fonador que abrange a relação entre o sistema respiratório, a laringe $\mathrm{e}$ as cavidades de ressonância. Disponível em: $<$ http://www.eav.eng.br/tech/fisiologia/Constituiodoaparelhofonadorhumano.html $>$.

Acesso em: 15 jul. 2016

.p. 47

Figura 7: Quadro esquemático apresentando resumidamente as principais diferenças entre as pregas vocais de crianças, mulheres e homens. Ilustração de Luciano Veronezi. Disponível em: $\quad<$ http://cantodellarte.blogspot.com.br/2012/06/o-que-faz-voz-ser-grossa-ou-fina.html $>$. Acesso em 15 jul. 2016 p.48

Figura 8: Frame do vídeo Composition Fukushima, composição musical criada a partir de dados imagens digitais. Disponível em: < http://www.kenjikojima.com/fukushima2011/>. Acesso em: 15 jun. 2016

Figura 9: Neil Harbisson, o cyborg que desenvolveu uma sinestesia artificial devido a um dispositivo eletrônico artificial acoplado em sua cabeça. Disponível em: $<$ http://www.harbisson.com/>. Acesso em 20 jul. 2016................................53

Figura 10: Foto de montagem de Very nervous System, de Rockeby, em uma rua de Postdam, 1993. Disponível em: <http://www.davidrokeby.com/vns.html $>$. Acesso em: 20 jun. 2016 . .p.55

Figura 11: Foto documentando a performance de Face Visualizer/Face Instrument na Harajuko Performance Plus $(+)$ em Tóquio, 2008. Disponível em: $<$ http://www.daito.ws/en/work/smiles.html $>$. Acesso em 20 jun. 2016 p.56

Figura 12: $O P \_A R T$ : Haptic Wall de Daniela Kutschat e Rejane Cantoni, instalação que transforma sons do ambiente em respostas táteis. Fonte: (GONTIJO, 2013, p.104). .p.57

Figura 13: Imagem de La Plume (1988) à esquerda, e a versão múltipla de Les Pissenlits (2005) à direita. Disponíveis em: <http://www.multimedialab.be/doc/images/index.php? 
album=art-numerique $\% 2$ Fbiological-systems-models-and-

algorithms\&image $=1996$ Edmond Couchot and Michel Bret Le Pissenlit 1996 03.jpg\&p

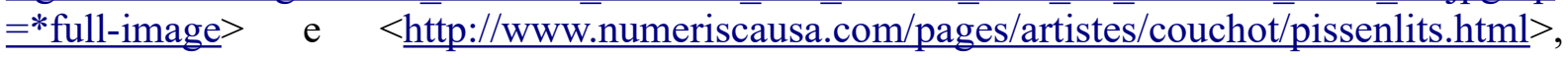
respectivamente. Acesso em 25 jun. 2016.

p.58

Figura 14: Instalação interativa Sopro/The Blow (2016) do grupo cAt. Frame do vídeo disponível em: $<$ https://vimeo.com/158800251 $>$. Acesso em: 20 jun. 2016.

Figura 15: Interação pela respiração na instalação Breathing de Guto Nóbrega, 2010. Disponível em: $<\underline{\text { http://file.org.br/interactive installation/guto-nobrega/?lang }=\mathrm{pt}>}>$. Acesso em 20 jun. 2016. .p.60

Figura 16: Frame do vídeo Meus passos ainda não foram dados de Sérgio Basbaum. Disponível em: $<$ https://vimeo.com/38563003 $>$. Acesso em 20 jun. 2016. p.61

Figura 17: Interação com a instalação Voice Tunnel em Nova York, durante o Summer Streets de 2013. Disponível em: <http://www.lozano-hemmer.com/showimage.php?

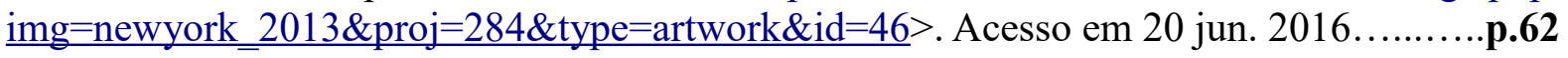

Figura 18: Documentação contemporânea da instalação Participatory TV de Nam June Paik (1969). Frame do video documentando a obra disponível em: < https://vimeo.com/49988167>. Acesso em 16 jul. 2016

Figura 19: Performance realizada com o modo fluids de Messa di Voce, performers: Jaap Blonk e Joanna La Barbara, 2003. Imagem disponível $\mathrm{em}:<$ http://www.tmema.org/messa/img/messa_fluid_ica_1698.jpg $>$. Acesso 20 jun. de 2016 .p.64

Figura 20: Documentação da primeira montagem de Syn²-Simulador de Sinestesia em 2014. Autoria própria. .p.66

Figura 21: Imagem de divulgação do Projeto Hibrida, que ocorreu entre 17 de março a 28 de julho de 2014 em parceria com a Universidade de São Paulo (USP-Brasil) e Universidad Nacional Autónoma de México (UNAM-México). Imagem disponível em: $<$ http://www2.eca.usp.br/hibrida/>. Acesso em: 20 jul. 2016.......................68

Figura 22: Esquema de montagem do protótipo do Simulador de Sinestesia a.k.a Syn². Autoria própria. .p.69

Figura 23: Interação com o protótipo de Simulador de Sinestesia na montagem da Exposição "Híbrida: Exposição e Performances"(2014). Autoria própria. p.70

Figura 24: Imagem obtida durante a interação com o Enigma 3.1 - $\Phi$ : Um enigma para Gibson (2015). Autoria própria.

Figura 25: Comparação entre a interação com as webcams no terceiro enigma e a variação das áreas luminosas delimitadas pelas linhas vermelha e preta. Repare na estampa da camiseta reconhecida pelas câmeras e sua movimentação em relação à interação do corpo. Autoria própria.

Figura 26: Figura esquemática representando a montagem da instalação interativa $\varphi$ um enigma para Gibson 3.1 (2015). Autoria própria. .p.75

Figura 27: Foto da montagem de $\Phi$ Um enigma para Gibson 3.1 na exposição internacional "Visual Music: Interações Música-Imagem" (arte computacional), Centro Cultural Banco do Brasil de Brasília (2015). Autoria própria. 
Figura 28: Foto da montagem de $\Phi$ Um enigma para Gibson 3.1 na exposição Lugares da Experiência, na Galeria da Universidade Estadual de São Paulo (2016). Autoria

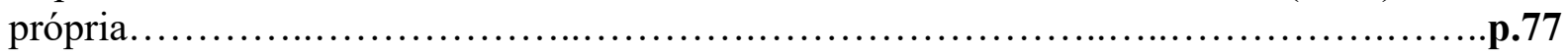

Figura 29: Uma das primeiras tentativas de relacionar voz e imagem, associando-se sons agudos a espaços altos da tela e sons graves a espaços baixos. Autoria própria p.79

Figura 30: Imagem representando a escala de cores final utilizada, com seus nomes e valores RGB, em relação às notas da escala cromática identificadas (nomenclatura inglesa: la-A, si-B, do-C, re-D, mi-E, fa-F, sol-G). Autoria própria.

Figura 31: Sequência que representa a interação com os testes relacionando linha e voz no Processing. A primeira linha apresentando a interação com a linha branca única, a segunda linha, a repetição das linhas e a terceira, a repetição com adição de cor. Autoria própria.

Figura 32: Imagem qe apresenta, em cada uma das linhas, sequências de interação dos testes realizados no Processing com o objetivo de criar texturas sinestésicas p.82

Figura 33: Teste para a visualização mais efetiva da voz em relação a tamanho de circunferências e o espaço da tela.

Figura 34: Representação do funcionamento da programação de Noise Circle de Peter Hoffman. Imagens retiradas do sketch disponível em: $<$ http://www.openprocessing.org/sketch/112858 $>$. Acesso em: 16 jul. 2016.............p.84

Figura 35: Representação dos resultados estéticos obtidos com a interação vocal e sua associação a cores e formas circulares nodosas. A parte superior apresenta o funcionamento somente com o contorno e a parte superior, com o preenchimento das cores identificadas. Autoria própria. .p.85

Figura 36: Interação com a versão apresentando um visual intermediário entre os dois testes anteriores, com contornos coloridos e preenchimento das cores com transparência. Autoria própria. p.86

Figura 37: Proposta de montagem para o estágio atual de Vozes Policromáticas dentro do Projeto Vendo Vozes (2014-2016). Autoria própria. ... 


\section{LISTA DE TABELAS:}

Tabela 1: Tipos de sinestesia catalogadas até o momento, e sua porcentagem de ocorrência dentro da atual amostra de sinestetas. Disponível em: <http:/www.daysyn.com/Types-ofSyn.html $>$. Acesso em: 16 jun. 2016. p. 17

Tabela 2: Tabela apontando as associações entre cor e notas musicais da escala cromática sugeridas por alguns indivíduos nos últimos séculos. Disponível

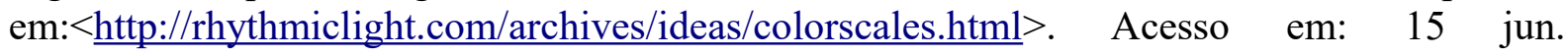

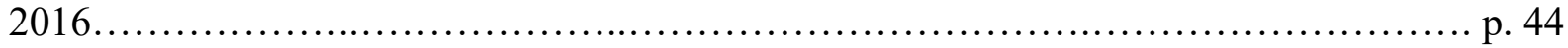




\section{LISTA DE SIGLAS}

CAP Departamento de Artes Visuais.

cAt ciência/ARTE/tecnologia.

ECA Escola de Comunicações e Artes.

EMESP Escola de Música do Estado de São Paulo - Tom Jobim.

EMMSP Escola Municipal de Musica da Fundação Theatro Municipal de São Paulo.

FAPESP Fundação de Amparo à Pesquisa do Estado de São Paulo.

FFT Fast Fourier Transform.

fMRI functional Magnetic Ressonance Imaging.

IME Instituto de Matemática e Estatística da Universidade de São Paulo

POLI Escola Politécnica da Universidade de São Paulo.

TOG Test of genuiness.

UNAM Universidad Nacional Autónoma de México.

UNESP Universidade do Estado de São Paulo.

USP Universidade de São Paulo. 


\section{SUMÁRIO}

INTRODUÇÃO.................................................................................................................................16

1. SINESTESIA NO CONTEXTO CIENTÍFICO..................................................19

1.1 Breve história dos estudos sobre sinestesia..................................................20

1.2 Diagnóstico e bases neurofisiológicas da sinestesia....................................22

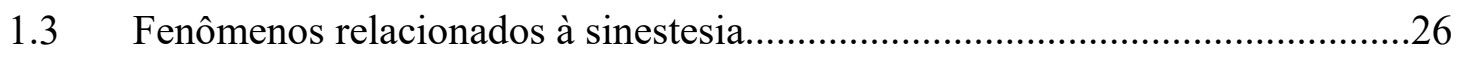

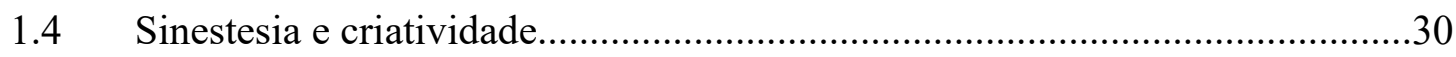

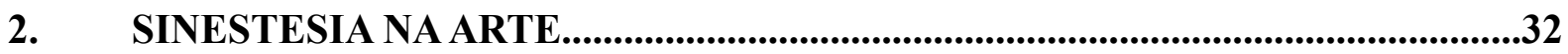

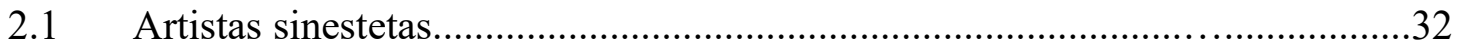

2.2 Apropriação do termo sinestesia pela arte......................................................37

2.3 Breve percurso histórico da sinestesia na arte.............................................41

3. A VOZ, O CORPO E SEU POTENCIAL SINESTÉSICO.................................46

4. SINESTESIA E TECNOLOGIA EM OBRAS ARTÍSTICAS.............................52

4.1 Sinestesia e processo criativo: dois estudos de caso.......................52

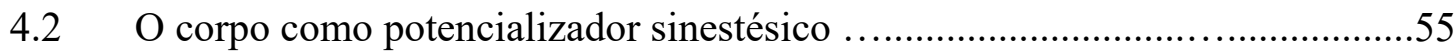

4.3 Do sopro à fala: a voz como mediação ......................................................58

5. TRABALHOS EXPERIMENTAIS....................................................................66

5.1 Projeto Hibrida: Syn ${ }^{2}$ - Simulador de Sinestesia...........................................66

5.2 Grupo Realidades: Enigma 3.1 - Ф: Um enigma para Gibson .....................71

5.3 Projeto Vendo Vozes: vozes policromáticas ....................................................77

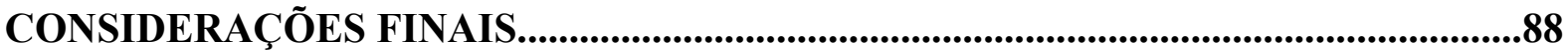

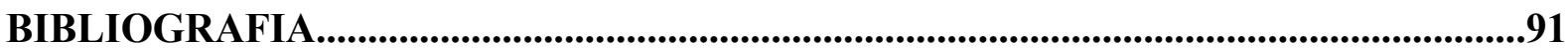

APÊNDICE............................................................................99

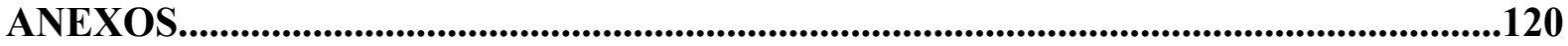




\section{INTRODUÇÃO}

A preocupação com os aspectos perceptivos e cognitivos de obras artísticas se intensificou nas últimas décadas. Isto ocorreu em especial no campo da arte interativa, devido às novas possibilidades de inclusão de diversas linguagens, códigos e meios artísticos. "As noções de interação, interatividade e multisensorialidade intersectam-se e retroalimentam as relações entre arte e tecnologia" (PLAZA, 2003, p. 17). Não se pode ignorar também a dependência do corpo que interage com a obra, e sua variabilidade individual, como a origem de todos os processos perceptivos. A voz, elemento primordial de expressão do corpo, tem um grande potencial de abordagem para esse tipo de interação. Tendo em vista a importância de investigar esses aspectos, tomou-se como objeto de pesquisa as relações possíveis entre voz e imagem no campo da arte interativa por duas vias: a teórica e a prática.

A delimitação do objeto de pesquisa estabeleceu o principal desafio teórico: a questão da sinestesia. Ultimamente, tem se tornado comum utilizar a palavra sinestesia para caracterizar grande parte das obras interativas. O fato não é surpreendente ao reconhecermos a origem etimológica grega da palavra (syn - união, ao mesmo tempo + aesthesis - sensação, percepção) e a facilidade com que novos aparatos tecnológicos podem utilizar simultaneamente informações sonoras, visuais e, mais recentemente, sistemas diversos de monitoramento corporal. Contudo, a utilização indiscriminada da palavra pelos mais diversos teóricos da arte sem uma sistematização exata de sua origem ou significado factual no campo das ciências cognitivas - de onde ela surgiu - pode ser uma armadilha conceitual de difícil resolução.

Foi necessária, portanto, a realização de uma extensa revisão bibliográfica nas áreas da psicologia e neurociência para compreender a trajetória dos estudos sobre o tema e as principais características conhecidas sobre o fenômeno na atualidade. Os principais resultados sobre o assunto estão descritos no primeiro capítulo: Sinestesia no contexto científico. $\mathrm{O}$ conteúdo se subdivide em quatro partes, as quais apresentam, respectivamente: a) concisas informações históricas sobre a trajetória do estudo da sinestesia na ciência e o contexto de criação da palavra "sinestesia"(1.1 Breve história dos estudos sobre sinestesia); b) 
informações necessárias para o atual diagnóstico da sinestesia e as duas principais teorias sobre a configuração neurológica do cérebro do sinesteta (1.2 Diagnóstico e bases neurofisiológicas da sinestesia); c) fenômenos que possuem características análogas à sinestesia e a discussão da comunidade científica acerca da expansão ou não do significado do termo para englobar outras manifestações (1.3 Fenômenos relacionados à sinestesia); e d) pesquisas que abordam a relação entre sinestesia e criatividade (1.4 Sinestesia e criatividade).

A associação entre arte e sinestesia e o problema da utilização da palavra para caracterizar obras artísticas foi abordada no segundo capítulo: Sinestesia na arte, que se organiza em três frentes: A primeira, Artistas sinestetas, aponta alguns artistas considerados sinestetas e como a condição influenciou seus processos criativos; a segunda, Apropriação do termo sinestesia pela arte, apresenta a discussão sobre os usos do termo sinestesia por autores diferentes no contexto artístico; e a terceira, Breve percurso histórico da sinestesia na arte, aborda historicamente alguns dos anseios de união sensorial na arte do passado.

Compreendidas as dificuldades de abordar a relação entre os sentidos, foi necessário que se definisse com rigor mais acentuado a voz. Foi esse o outro desafio teórico do presente trabalho, vistas a natureza múltipla da vocalidade e a frequente utilização de nomenclaturas subjetivas para descrevê-la. Estas informações foram constatadas inclusive por experiências pessoais, havendo o primeiro contato com esse tipo de terminologia no CoralUSP, durante o período da graduação. O convívio continuou nos próximos anos com o contato com regentes, pianistas, cantores e professores de canto tanto da Escola de Música do Estado de São Paulo - Tom Jobim (EMESP), entre 2013 e 2014, quanto da Escola Municipal de Musica da Fundação Theatro Municipal de São Paulo (EMMSP) a partir de 2015. Palavras como “pesado", “leve”, “aveludado", “estridente”, “pontudo”, “cheio", “pleno”, “escuro", “claro", "apoiado", entre outros, eram norteadas no senso comum como características vocais e nem sempre interpretadas da mesma forma. Provavelmente estes termos já sugeririam a existência de associações sinestésicas culturais interessantes entre voz, visualidade e tactilidade

No terceiro capítulo, A voz, o corpo e seu potencial sinestésico, tomamos partido de uma definição mais científica de voz a partir dos estudos fonoaudiológicos de Sundberg 
(SUNDBERG, 2015) evitando utilizar aspectos subjetivos para defini-la. No mesmo capítulo, apontamos também a relação entre voz, corpo e espaço, assim como o impacto da cultura ocidental e dos novos meios para a compreensão da vocalidade. Essa correlação foi incluída tanto pela natureza corporificada do fenômeno vocal quanto pela potencialidade sinestésica representada pelo corpo unificado (como ele é de fato na percepção).

Os dois últimos capítulos se referem ao aspecto prático da pesquisa, apresentando uma seleção de trabalhos artísticos realizados sobre o assunto e a documentação das experiências estéticas empreendidas durante o mestrado.

O quarto capítulo, denominado Sinestesia e tecnologia em obras artísticas, é dividido em três partes e apresenta uma seleção de obras com alguns resultados poéticos obtidos pela utilização de equivalências entre dois ou mais sentidos por meio de algoritmos computacionais. A primeira parte, Sinestesia e processo criativo: dois estudos de caso, descreve a influência da sinestesia nos processos criativos de dos artistas Kenji Kojima e Neil Harbisson; a segunda, O corpo como potencializador sinestésico, demonstra a importância do corpo na constituição de obras artísticas interativas potencialmente sinestésicas; e a terceira, Do sopro à fala: a voz como mediação, apresenta um apanhado de trabalhos artísticos que se utilizaram da voz como estímulo para interações iminentemente sinestésicas em obras interativas.

Por fim, o quinto e último capítulo, Trabalhos experimentais, apresenta a documentação dos experimentos poéticos, realizados parcial ou totalmente pela pesquisadora, e que abordam esteticamente o tema investigado. A primeira obra documentada, Syn ${ }^{2}$ - Simulador de Sinestesia, foi uma das propostas de trabalhos práticos coletivos promovidos pelo Projeto Hibrida, que aconteceu no Brasil entre 17 de março e 30 de abril de 2014; a segunda, $\Phi$ - Um enigma para Gibson 3.1, foi concebida e realizada colaborativamente pelo grupo de pesquisa Realidades; e a terceira e última, Vozes Policromáticas, faz parte das pesquisas experimentais que buscam relacionar voz e imagem neste projeto, organizados sob o nome de Projeto Vendo Vozes. 


\section{SINESTESIA NO CONTEXTO CIENTÍFICO}

Atualmente, a sinestesia é descrita de maneira geral em trabalhos científicos como a experiência, reportada por algumas pessoas, na qual estímulos específicos provocam automaticamente percepções atípicas. Ouvir música, ler um texto ou saborear um alimento não estimulam na população geral, por exemplo, repostas como a percepção de cores, formas, ou sensações de volume, o que pode acontecer no caso de sinestetas.

O fenômeno é diversificado e extenso. Até o momento, foram catalogados mais de 70 tipos de relações sinestésicas pelo pesquisador norte-americano Sean A. Day ${ }^{1}$, sendo o tipo mais comum e mais estudado na atualidade a sinestesia de grafemas relacionados à visão - caso em que pessoas associam letras, números ou caracteres a informações visuais, sejam elas formas, cores ou tonalidades -, perfazendo $61,26 \%$ dos casos listados por Day. Estas relações incluem desde associações entre modalidades distintas, como odores e sons, até respostas incomuns dentro da mesma modalidade, como a correlação entre grafemas e cores ilustrada pela figura abaixo.

\section{SINESTESIA SINESTESIA}

Figura 1: O desenho esquemático compara a mesma palavra "sinestesia", impressa em preto, como visualizada por não sinestetas (acima) e por um suposto sinesteta (abaixo) com sinestesia grafema cor. Autoria própria.

A Tabela 1, apresentada na página seguinte, mostra a compilação realizada por Sean Day dos tipos de sinestesia identificados atualmente, indicando a porcentagem dos tipos de sinestesia reconhecidos numa amostra de 1143 indivíduos sinestetas.

1 Site oficial do artista disponível em: $<\underline{\text { http:}: / / w w w . d a y s y n . c o m / T y p e s-o f-S y n . h t m l ~}>$. Acesso 15 jun. 2016. 


\begin{tabular}{|c|c|}
\hline emotions $->$ flavors & $0.26 \%$ \\
\hline emotions $\rightarrow$ odors & $0.35 \%$ \\
\hline emotions $->$ sounds & $0.09 \%$ \\
\hline emotions $\rightarrow>$ vision & $3.24 \%$ \\
\hline flavors $\rightarrow$ musical sounds & $0.09 \%$ \\
\hline flavors $\rightarrow$ sounds & $0.53 \%$ \\
\hline flavors -> temperatures & $0.09 \%$ \\
\hline flavors $->$ touch & $0.53 \%$ \\
\hline flavors $->$ vision & $5.78 \%$ \\
\hline general sounds $->$ vision & $16.21 \%$ \\
\hline grapheme personification (OLP*) & $4.65 \%$ \\
\hline grapheme $\rightarrow$ sound & $0.09 \%$ \\
\hline grapheme $>$ touch & $0.09 \%$ \\
\hline graphemes -> vision & $61.26 \%$ \\
\hline kinetics $>$ personality & $0.09 \%$ \\
\hline kinetics $\rightarrow$ sound & $1.05 \%$ \\
\hline kinetics -> vision & $0.53 \%$ \\
\hline lexemes $->$ flavors & $2.89 \%$ \\
\hline lexemes $\rightarrow$ odors & $0.61 \%$ \\
\hline lexemes $->$ temperature & $0.09 \%$ \\
\hline
\end{tabular}

\begin{tabular}{|c|c|}
\hline lexemes $->$ touch & $0.44 \%$ \\
\hline lexemes -> vision & $0.70 \%$ \\
\hline mirror speech & $0.18 \%$ \\
\hline mirror touch & ***** \\
\hline musical notes $\rightarrow$ vision & $7.80 \%$ \\
\hline musical sounds $\rightarrow$ flavors & $0.44 \%$ \\
\hline musical sounds $>>$ personality & $0.09 \%$ \\
\hline musical sounds $\rightarrow>$ spatial coordinates & $0.09 \%$ \\
\hline musical sounds -> temperatures & $0.09 \%$ \\
\hline musical sounds $->$ vision & $18.05 \%$ \\
\hline \multicolumn{2}{|c|}{ non-graphemic ordinal personification $* * * * *$} \\
\hline number $->$ flavor & $0.26 \%$ \\
\hline object personification & ****** \\
\hline odors $->$ flavors & $0.09 \%$ \\
\hline odors -> sounds & $0.44 \%$ \\
\hline odors $->$ temperatures & $0.09 \%$ \\
\hline odors $->$ touch & $0.70 \%$ \\
\hline odors -> vision & $6.13 \%$ \\
\hline orgasm $>$ flavors & $0.09 \%$ \\
\hline orgasm $->$ vision & $1.93 \%$ \\
\hline
\end{tabular}

\begin{tabular}{|c|c|}
\hline pain $\rightarrow$ flavors & $0.09 \%$ \\
\hline pain $\rightarrow$ odors & $0.09 \%$ \\
\hline pain $\rightarrow>$ sounds & $0.09 \%$ \\
\hline pain $>$ temperature & $0.09 \%$ \\
\hline pain $\rightarrow$ vision & $5.43 \%$ \\
\hline personalities -> flavors & $0.35 \%$ \\
\hline personalities $->$ odors & $0.70 \%$ \\
\hline personalities $->$ sound & $0.09 \%$ \\
\hline personalities $->$ touch & $0.09 \%$ \\
\hline personalities -> vision ("auras") & $6.49 \%$ \\
\hline phonemes -> flavors & ****** \\
\hline phonemes -> vision & $7.54 \%$ \\
\hline proprioception -> flavor & $0.09 \%$ \\
\hline proprioception -> vision & $0.09 \%$ \\
\hline sounds $->$ flavors & $5.00 \%$ \\
\hline sounds $\rightarrow$ kinetics & $0.96 \%$ \\
\hline sounds $->$ odors & $1.58 \%$ \\
\hline sounds $->$ temperatures & $0.53 \%$ \\
\hline sounds $->$ touch & $4.38 \%$ \\
\hline spatial sequence (number form) & ****** \\
\hline
\end{tabular}

\begin{tabular}{|c|c|}
\hline temperatures $->$ sounds & $0.09 \%$ \\
\hline temperatures $->$ vision & $1.84 \%$ \\
\hline ticker-tape & $* * * * *$ \\
\hline time units $\rightarrow$ flavors & $0.09 \%$ \\
\hline time units $->$ sounds & $0.09 \%$ \\
\hline time units $>$ spatial coordinates & $* * * * *$ \\
\hline time units $\rightarrow$ vision & $22.96 \%$ \\
\hline touch $>$ emotion & $0.26 \%$ \\
\hline touch $>$ flavors & $1.14 \%$ \\
\hline touch $\rightarrow$ odors & $0.35 \%$ \\
\hline touch $>$ sounds & $0.35 \%$ \\
\hline touch $>$ temperatures & $0.09 \%$ \\
\hline touch $\rightarrow$ vision & $3.94 \%$ \\
\hline vision $\rightarrow$ flavors & $2.98 \%$ \\
\hline vision $>$ graphemes & $* * * * *$ \\
\hline vision $\rightarrow$ kinetics & $0.09 \%$ \\
\hline vision $\rightarrow$ odors & $1.14 \%$ \\
\hline vision $\rightarrow$ sounds & $3.07 \%$ \\
\hline vision $->$ temperatures & $0.35 \%$ \\
\hline vision $\rightarrow$ touch & $1.58 \%$ \\
\hline
\end{tabular}

HTTP:I/WWW.DAYSYN.COM/TYPES-OF-SYN.HTML, acesso em junho de 2016.

Tabela 1: Tipos de sinestesia catalogadas até o momento, e sua porcentagem de ocorrência dentro da atual amostra de sinestetas. Disponível em: $<$ http://www.daysyn.com/Types-of-Syn.html $>$. Acesso em: 16 jun. 2016.

\subsection{Breve história dos estudos sobre sinestesia}

A primeira descrição médica de sinestesia foi elaborada por Georg Tobias Ludwig Sachs (1786-1814) em sua tese de doutorado sobre albinismo - do qual o próprio autor era portador - em 1812. Neste trabalho, ele descreve sua visão e preferências de cor, relacionando nuances cromáticas a letras do alfabeto, números, dias da semana, notas musicais, entre outras correlações incomuns (JEWANSKI et al., 2009, p. 296-298). O capítulo que apresenta a descrição sinestésica foi escrito como uma observação teórica sobre a visão. Sachs não parece ter julgado existir uma correlação direta entre as descrições e o albinismo, visto que ele indica, no final do capítulo, ter conhecido outra pessoa não-albina ("um homem muito famoso") que lhe relatou experiências similares (Ibidem, p. 298).

A descrição de Sachs foi recebida inicialmente como uma reunião curiosa de ideias. Somente em 1848 ela foi discutida cientificamente pelo médico francês Charles-Auguste Édouard Cornaz. Ele sugeriu a existência de uma condição anômala na estrutura ocular de Sachs, oposta ao daltonismo, como explicação para as associações atípicas, nomeando-a de hyperchromatopsia (Ibidem, p. 299). A partir de então, alguns trabalhos científicos 
começaram a discutir pela primeira vez as origens fisiológicas da sinestesia. A teoria de Cornaz, de que a sinestesia ocorreria devido a uma doença que causaria a hipersensibilidade da visão (JEWANSKI et al., 2012, p. 79), foi rebatida por outros pesquisadores. Deste debate resultou a predominância, desde 1860, da explicação do fenômeno como tendo origem cerebral (Idem, 2011, p. 288).

A palavra synesthésie ou synopsia foi utilizado pela primeira vez no sentido moderno somente em 1893, quando Theodore Flournoy (1854 - 1920) a emprega para descrever exemplos diversificados de associações visuais anormais com experiências tácteis, gustativas, olfativas e visuais em seus estudos específicos sobre sinestesia óptica (MARKS, 2011, p. 48). Desde então o termo se popularizou no jargão científico, tendo seu significado ampliado por novas possibilidades associativas. O conteúdo etimológico da palavra sugere a interpretação da existência da união ou associação direta entre dois ou mais sentidos.

O interesse filosófico durante os séculos XVII e XVIII em relação a qualquer tipo de fenômeno que pudesse gerar conhecimento através dos sentidos, unido ao grande interesse pós-newtoniano na correspondência som-cor na ciência e nas artes, influenciou a popularidade de eventos que apresentassem intercruzamentos sensoriais (JEWANSKIETAL et al., 2009, p. 296). As consequências desse grande interesse foram o abundante número de publicações sobre temas relacionados à sinestesia entre 1860 e 1930 e a designação de uma comissão no Congresso Internacional de Psicologia Fisiológica em 1890 com o objetivo de estabelecer uma terminologia padrão para dirigir os estudos do campo (BASBAUM, 2002, p.23). Surpreendentemente, as pesquisas relacionadas à sinestesia diminuíram drasticamente entre 1932 e 1974 (Ibidem, p.23). A explicação para tal acontecimento é dada pela forte influência behaviorista na ciência durante o século XX, quando "médicos eliminaram com sucesso o papel da observação subjetiva do homem na coleta de dados empíricos ${ }^{2 "}$ (CYTOWIC, 2002, p.8).

Novas pesquisas sobre sinestesia foram retomadas pela comunidade científica somente a partir da década de 1970. Elas foram especialmente impulsionadas: a) pelas publicações de

2 Tradução nossa. Trecho original: "During the twentieth century, physicists successfully eliminated the subjective role of a human observer in gathering empirical data." 
estudos de revisão bibliográfica sobre o cruzamento de padrões e constantes entre vogais, sons e cores realizados por Lawrence E. Marks; b) pelo desenvolvimento de testes de consistência por Baron-Cohen e Harrison; e c) pela proposta de existência de paradigmas comuns ao diagnóstico da sinestesia a partir de casos clínicos, apontados na primeira edição de Sinesthesia: a union of the senses por Cytowic em 1989 (BASBAUM, 2002, p. 39). Nas últimas décadas, o campo continua fascinando a comunidade científica, principalmente após a constatação factual da veracidade de relatos sinestésicos a partir de pesquisas com imagens de ressonância magnéticas fMRI (functional magnetic ressonance imaging) do cérebro (SPECTOR; MAURER, 2009, p.176-177) e proporciona, ainda hoje, uma farta e popular fonte de estudos para muitos pesquisadores (SIMNER, 2012, p.1).

\subsection{Diagnóstico e bases neurofisiológicas da sinestesia}

Estudos sugerem que a sinestesia idiopática - a qual se manifesta naturalmente, sem qualquer tipo de indução ou aquisição por lesão cerebral, epilepsia, drogas ou outras atividades possui algum tipo de hereditariedade, embora o gene responsável por este fator ainda não tenha sido identificado (HUBBARD; RAMACHANDRAN, 2005 p. 509). Possivelmente, ela depende também de fatores ambientais e/ou epigenéticos, visto que pesquisas recentes indicam que a sinestesia possui incidência simultânea de apenas 73,9\% em gêmeos monozigóticos (BOSLEY; EAGLEMEN, 2015, p.93). Além disso, a sinestesia idiopática inicia-se na infância, de forma que muitos sinestetas consideram suas experiências "naturais" e surpreendem-se ao descobrir que elas não são comuns a todas as pessoas (CYTOWIC, 2002, p.13).

Richard E. Cytowic propôs em seu livro "Synesthesia: a union of the senses" (2002, 2a ed.) cinco critérios para o diagnóstico da sinestesia idiopática, os quais são resumidos a seguir:

1. Sinestesia é involuntária mas elegível: A experiência é automática, mas pode ser mais intensa ou branda de acordo com o foco de atenção do sinesteta.

2. Sinestesia é espacialmente estendida: é projetada no espaço circundante ao corpo, mas de 
forma que o sujeito consiga diferenciá-la de suas experiências não-sinestésicas.

3. Percepções sinestésicas são consistentes e discretas: As associações de um sinesteta é consistente e se mantém ao longo de sua vida. A percepção sinestésica é genérica (cenas de formatos, cores ou sensações elementares) e restrita (as formas, sensações ou cores são muito específicas de acordo com cada estímulo e/ou contexto).

4. Sinestesia é memorável: As percepções sinestésicas são facilmente memoráveis, de tal forma que em alguns casos ela é utilizada como recurso mnemônico.

5. Sinestesia é emocional: percebida como real e com senso de validação da realidade, experiência as vezes descrita como precedida de uma sensação de "eureka" (CYTOWIC, 2002, p.67-69).

A consistência da experiência sinestésica foi utilizada nas últimas décadas por inúmeros psicólogos e neurocientistas com o objetivo de testar a genuinidade dos sujeitos que se denominavam sinestetas, visto que a maior parte do diagnóstico dependia estritamente de descrições pessoais. O teste e reteste da consistência (TOG - Test of genuiness) foi criado por Baron-Cohen e seus colaboradores (Baron-Cohen et al., 1987), e aprimorado por outros pesquisadores ao longo do tempo. O TOG consiste no levantamento das características sinestésicas a partir de descrições verbais do avaliado, seguido pelo reteste dessas associações algum tempo depois, sem aviso prévio e em ordem aleatória. Vários estudos demonstraram que sinestetas apresentam consistência de mais de $90 \%$ no teste e reateste com intervalo de mais de um ano e apresentam grande especificidade relacional em suas correspondências (HUBBARD; RAMACHANDRAN, 2005, p. 509).

O TOG foi de tal forma difundido e aceito na comunidade científica que é considerado como o "padrão de ouro" para determinar a genuinidade da condição, sendo pré-requisito para a inclusão de qualquer indivíduo na grande maioria dos estudos científicos sobre o tema na atualidade (SIMNER, 2012, p. 7). Contudo, Julia Simner apresenta a ressalva de que talvez somente esse quesito não possa ser absoluto no reconhecimento do fenômeno, visto que uma porcentagem pequena de indivíduos: a) falham no teste, b) reportam desde o início que suas associações sinestésicas não são constantes, e c) mesmo depois de compreender o significado estrito do fenômeno, continuam alegando que fazem parte dele (Ibidem, p.7). A conclusão 
deste debate exige futuras investigações, que eventualmente podem se valer de equipamentos eletrônicos mais avançados para a averiguação, como por exemplo, os experimentos com fMRI. Este novo tipo de tecnologia tem sido responsável pela obtenção de novas informações chaves para o campo, indisponíveis nas décadas passadas (CYTOWIC, 2014, p.13). Atualmente, as técnicas de imageamento cerebral demonstram claramente a coativação de duas ou mais áreas sensoriais no córtex cerebral de sinestetas (SACKS, 2007, p. 178), e não existe a possibilidade de dúvida a respeito da realidade psicológica e fisiológica da sinestesia (Ibidem, p.179).

Outro requisito apresentado por Cytowic, que foi contestado nos últimos anos, foi o de que a experiência sinestésica seria estendida espacialmente, de forma que sua localização pudesse ser identificada claramente a partir do campo de visão dos sinestetas. Nos dias de hoje, considera-se a existência de dois tipos de sinestetas quanto a esta questão: os "projetores" e os “associadores". Os "projetores" descrevem suas experiências como localizadas externamente - reconhecendo-as visualmente no espaço como se, por exemplo, formas, cores ou elementos visuais se sobrepusessem aos objetos da área ao redor. Já os "associadores" reconhecem o aspecto de suas associações através dos "olhos da mente" - como se imaginassem, ou simplesmente soubessem as associações sinestésicas intuitivamente, sem qualquer relação espacial (DIXON et al., 2004, p. 336).

Atualmente, existem duas correntes dominantes quanto à explicação das bases neurofisiológicas da sinestesia:

a) The disinhibited feedback theory (A teoria da experiência desinibida, tradução nossa), na qual alguns pesquisadores sugerem que a sinestesia seria o resultado de uma "falha" no circuito inibitório do cérebro, que impediria o inter-cruzamento de informações entre as áreas cerebrais de pessoas não-sinestetas. Essa corrente parece considerar a igualdade de estruturas cerebrais entre sujeitos com e sem sinestesia, embasando algumas pesquisas sobre sinestesia induzida e/ou adquirida;

b) The cross-activation theory (A teoria da ativação-cruzada, tradução nossa) - que propõe como a origem da experiência sinestésica, a existência física de hiper-conectividade neural entre áreas cerebrais (CHIOU; RICH, 2014, p.2). 
Apesar da predominância destas duas correntes, com variações dependendo do modelo cerebral proposto por cada pesquisa, os cientistas ainda não concordam quanto aos tipos e perfis neurológicos que favorecem o desenvolvimento da sinestesia, e nem porque e quando as respostas sensoriais se tornam conscientes no fenômeno sinestésico (DEROY; SPENCE, 2013, p.645).

Múltiplos estudos apontam que a sinestesia é mais comum em crianças e as ocorrências vão diminuindo durante a adolescência (SACKS, 2007, p. 180). Algumas pesquisas indicam, inclusive, que todo recém-nascido seria potencialmente um sinesteta, visto que o desenvolvimento de áreas de especialização do cérebro ainda não aconteceu (CAMPEN, 2007, p. 30-31). Em raras ocasiões experiências sinestésicas podem ocorrer após a infância, de forma fugaz, em convulsões do lóbulo temporal, sob a influência de alucinógenos (SACKS, 2007, p.180), ou mesmo em mudanças do estado de consciência em praticantes de meditação (CAMPEN, 2007, p.113). Contudo, os únicos casos conhecidos de sinestesia adquirida permanentemente após a infância são os de pessoas que perderam a visão. Nesta situação, alguns indivíduos ocasionalmente apresentam a intensificação de imagens mentais e o desenvolvimento de variados tipos de conexões intersensoriais (SACKS, 2007, p.180-181).

Duas hipóteses ainda persistem quanto ao desenvolvimento espontâneo da sinestesia desde a infância: a explicação congênita (atualmente mais aceita e defendida na comunidade científica), na qual todos nascemos sinestetas e perdemos esta qualidade durante o desenvolvimento cerebral; e a de que as relações sinestésicas são aprendidas e absorvidas a partir da repetição modular implícita de elementos presentes na linguagem durante a infância (KADOSH et al., 2009, p. 484).

Apesar do caráter individual e heterogêneo das associações descritas por diferentes sinestestas em relação a um mesmo estímulo, alguns estudos indicam que as experiências reportadas tendem a replicar associações intra-modais sentidas pela maioria das pessoas, como por exemplo a relação entre a frequência do som agudo com correspondência a uma tonalidade "clara", de dimensão "pequena" e com formato "pontudo" (MARKS, 2011, p.53). Diante 
deste fato, é possível que exista um mecanismo humano comum para representar associações intra-modais, que simplesmente pode ser mais pronunciado em sinestetas que nas pessoas normais (SIMNER, 2012, p.2).

\subsection{Fenômenos relacionados à sinestesia}

Alguns fenômenos, como as metáforas presentes na linguagem apresentam interessantes proximidades com os mecanismos da sinestesia. Lawrence E. Marks e Catherine M. Mulvenna indicaram, no artigo Synesthesia, at and near its borders (2013), seis fenômenos com características que se relacionam ao fenômeno sinestésico:

a) Correspondências intermodais - são as associações entre modalidades já descritas, encontradas em culturas diversas. Embora possuam um caráter universal, elas não contêm a experiência da qualidade vívida da associação em si e nem são tão específicas como no caso dos sinestetas;

b) Imaginação intermodal - inclui qualquer tipo de associação mental com controle voluntário da imaginação e provável influência cultural, como por exemplo as inúmeras metáforas poéticas da linguagem ou relações sinestésicas artificiais propostas em obras de arte;

c) Memórias sensoriais autobiográficas (Fenômeno Proust) - consistem em sensações desencadeadas por memórias que evocam sons, sabores, cheiros e imagens a partir de associações com acontecimentos da infância. Possuem uma qualidade vívida, e automática para alguns indivíduos, de uma forma mais "semântica" do que "episódica";

d) Percepções empáticas (dor, toque e Síndrome de Couvard) - consistem em sensações estimuladas a partir da empatia com situações sofridas por outras pessoas. $\mathrm{O}$ fato de ver ou ouvir pessoas em situações de dor e desconforto pode induzir sensações análogas em alguns sujeitos. O mesmo pode ocorrer quando alguém assiste um indivíduo tocando outro, e a pessoa que observa a situação identifica-se e acaba vivenciando uma sensação equivalente. A Síndrome de Couvard - na qual homens experimentam náusea, vômito e dores abdominais a partir da percepção empática da gravidez de suas parceiras - é exemplar para ilustrar esse tipo de ocorrência; 
e) Alucinações - são percepções aproximadas que ocorrem na ausência de qualquer estímulo. Possuem impacto e força correspondentes à realidade e não podem ser amenizadas por controle direto ou voluntário de quem tem a experiência. Podem ser desencadeadas por alucinógenos ou enxaquecas. Alguns tipos de alucinações aproximam-se da sinestesia na possibilidade de evocar vários sentidos ao mesmo tempo e diversas formas de padrões visuais, mas geralmente vêm acompanhadas por aflição e angústia relacionadas a seu conteúdo; e f) Ilusão Doppler - é um fenômeno perceptivo que ocorre quando uma fonte de som aumenta constantemente seu volume e, mesmo mantendo sua frequência constante, é percebida como mais aguda pelo ouvinte (MARKS; MULVENNA, 2013, p.1-2).

Nas últimas décadas, a discussão sobre se a sinestesia e fenômenos que se assemelham a ela teriam ou não as mesmas bases perceptivas, e se fariam parte de uma mesma conjuntura, tem dividido cientistas. Este debate iniciou-se com a ousada proposta publicada no artigo "Synesthesia: Strong and Weak" (MARTINO; MARKS, 2001), que propõe considerar correspondências intermodais como um tipo de "sinestesia fraca" que manifestaria de forma mais branda os mesmos mecanismos perceptivos da "sinestesia forte" (sinestesia canônica).

De um lado, a corrente assimilacionista (também denominada monista) considera o fenômeno sinestésico sob um prisma fenomenológico. Defende, desta forma, a ideia de que a sinestesia representaria o ápice de um modelo de percepção contíguo que conteria desde correlações culturais, metafóricas e criativas entre modalidades, até as sensações vívidas dos sinestetas (MARKS; MULVENNA, 2013, p.3).

Em oposição, os separatistas (também denominados dualistas) consideram a sinestesia como uma experiência idiossincrática, ou seja, uma ocorrência exclusiva dos sinestetas e não comum a um grande número de indivíduos ou característica de uma cultura determinada. Consequentemente, recusam veementemente incluir quaisquer fenômenos aproximados no estudo da sinestesia. Para eles, existiriam somente duas categorizações possíveis dentro do campo: os sinestésicos e os não-sinestésicos. Como embasamento para sua posição, eles alegam não existir evidências suficientes para comprovar que a sinestesia e fenômenos que apresentam características similares tenham as mesmas origens e nem que a própria 
ocorrência de tipos distintos de sinestesia sejam decorrentes do mesmo princípio desencadeador (DEROY; SPENCE, 2013, p. 645).

Entre os dois opostos existem os pluralistas que, de um lado, concordam com os separatistas na distinção e categorização clara entre sinestesia e fenômenos que apresentem características análogas; e de outro, concordam com os monistas em relação à natureza plural do fenômeno sinestésico. Ao destacar que alguns casos específicos de sinestesia podem, sim, apresentar correlações mais diretas com fenômenos relacionados que outros, defendem a possível expansão da utilização do termo sinestesia a partir da inclusão de subcategorias que pudessem favorecer os estudos cruzados entre fenômenos sinestésicos e não sinestésicos (MARKS, 2011, p.68).

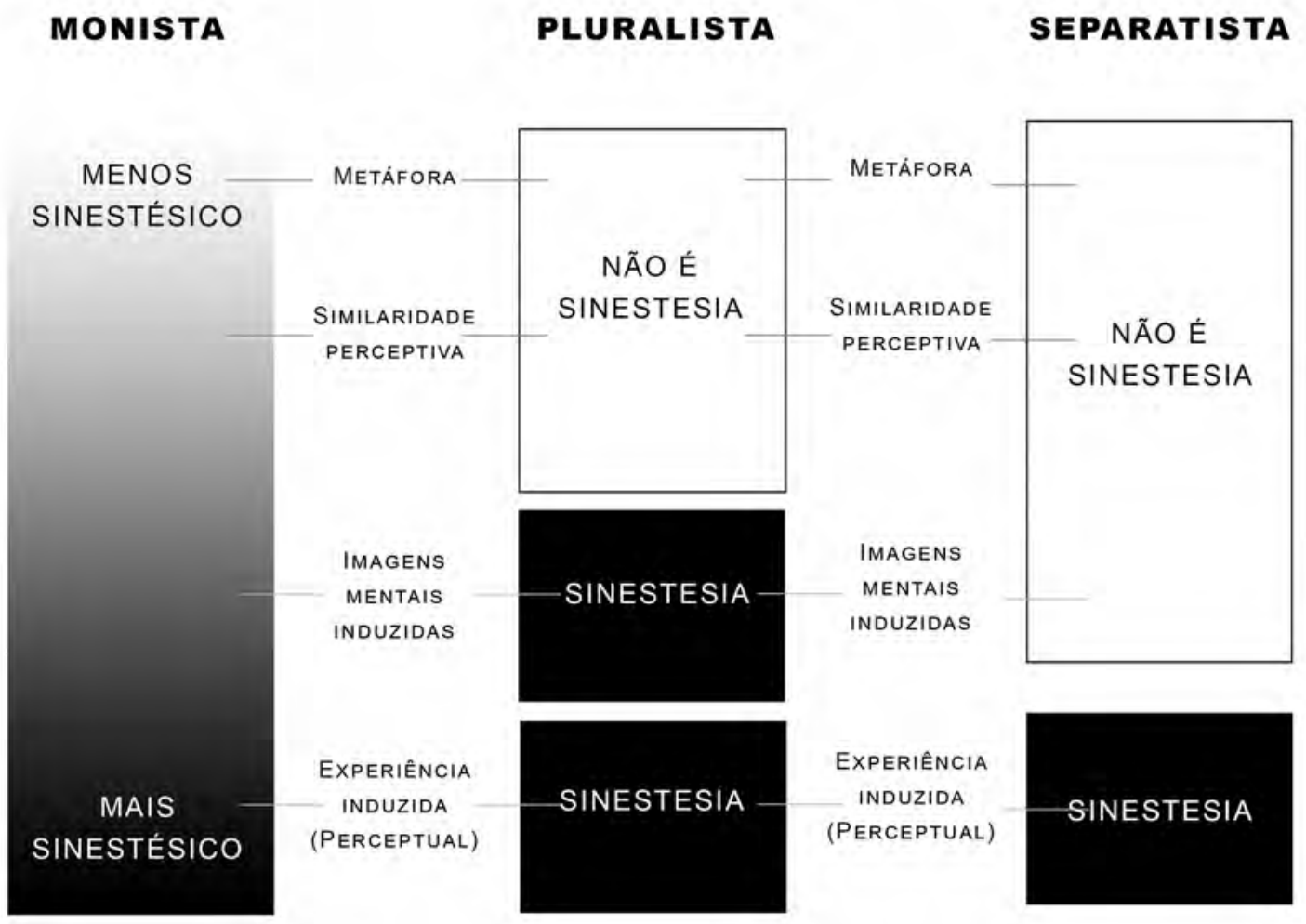

Figura 2: Quadro esquemático que compara o posicionamento dos monistas, pluralistas e separatistas quanto à definição de sinestesia. Tradução e adaptação da tabela em inglês (MARKS, 2011, p.68). 
Pode-se observar na Figura 2 a esquematização, proposta por Lawrence E. Marks, da diferença entre os três pontos de vista apresentados: monismo à esquerda, dualismo à direita $\mathrm{e}$ pluralismo no centro. Assim como na figura original, mantivemos os exemplos críticos apontados, os quais não representam uma lista completa de todos os exemplos de sinestesia formulados por cada uma das correntes.

Os exemplos indicados por Marks incluem: a) Experiência perceptual induzida - a experiência sinestésica vívida, consistente e automática da sinestesia canônica (por exemplo, quando uma nota musical, caracteres monocromáticos ou dores induzem a sensação de cor); b) Imagens mentais induzidas - imagens mentais cross-modais induzidas por estímulos específicos que não são necessariamente automáticas e constantes (quando a música, por exemplo, remete a cores ou padrões visuais); c) Similaridades perceptivas - percepção de similaridades que ocorre quando pessoas identificam correlações entre modalidades, mas sem a experiência vivida em si (por exemplo, relacionar o timbre de um tamborim a cores claras e amarelas e o timbre de um violino a cores escuras e amarronzadas); e d) Metáforas semelhanças cross-modais na linguagem (por exemplo, quando indivíduos interpretam metaforicamente palavras como "guincho" e "espirro" como claras e palavras como "trovão" e “tosse" como escuras) (MARKS, 2011, p.68).

Ao considerar uma provável relação entre sinestesia e linguagem, V. S. Ramachandran e E. M. Hubbard defenderam a possibilidade de que correspondências sinestésicas universais entre sentidos e movimentos corporais poderiam ser um dos fatores que influenciaram a emergência primitiva da linguagem. Tais autores citam o exemplo familiar da dança, na qual elementos rítmicos corporais imitam o ritmo captado pelo aparelho auditivo (RAMACHANDRAN; HUBBARD, 2001, p.19-22). A teoria tem como princípio que "movimentos de língua e outras vocalizações podem estar sinestesicamente ligados a objetos e eventos aos quais se referem de forma muito mais próxima do que usualmente assumimos" ${ }^{3 \%}$ (Ibidem, p.20). Os autores sugerem, inclusive, que o estudo da sinestesia poderia auxiliar no entendimento dos mecanismos neurológicos da metáfora e da criatividade, visto a incidência de sinestetas que se dedicam às áreas artísticas (Ibidem, p. 29).

3 Tradução nossa. Texto original: “... lip and tongue movements and other vocalizations may be synaesthetically linked to objects and events they refer to in closer ways than we usually assume..."(RAMACHANDRAN;HUBBARD, 2001, p.20). 


\subsection{Sinestesia e criatividade}

Algumas pesquisas apontam a tendência de sinestetas se envolverem mais frequentemente com o setor de indústrias criativas do que a média na população geral, além de dedicarem mais tempo tocando instrumentos, produzindo artes visuais, e visitando exposições artísticas (WARD et al., 2008, p. 134). Dados também indicam uma maior proporção de sinestetas em amostras de estudantes de artes do que na população geral (ROTHEN; MEIER, 2010, p.720). Estudos comparativos realizados por Catherine E. Mulvenna, em sua tese de doutorado (2012) sobre a relação entre sinestesia e criatividade, indicam que sinestetas possuem destacada habilidade em gerar novas ideias quando comparada a dos não-sinestetas. Entretanto, quando se trata de transformar criativamente essas ideias em objetos artísticos, os sinestetas não demonstraram nenhuma vantagem em relação aos não-sinestetas (MULVENNA, 2012, p.97). Além de tudo, existem indícios de que algumas figuras criativas famosas são ou foram sinestetas. Essa lista é composta, entre outros, pelos músicos Oliver Messiaen e Alexander Scriabin, pelos pintores Wassily Kandinsky e David Hockney, pelo nobel da física Richard Feynman e pelo escritor Vladmir Nabokov (WARD et al, 2008, p.128).

A criatividade pode ser definida como a habilidade adaptativa de criar novas associações, que se diferenciam do aleatório pelo fato de serem originais, significativas ou apreciadas por outrem (Ibidem, p.127). Embora um certo nível de conhecimento seja necessário para a ocorrência da criatividade, a presença de informações em si não garantem sua manifestação (Ibidem, p.129). O que a caracteriza são as formas como esses conhecimentos são acessados e avaliados para a criação de novas associações (Ibidem, p.137). Nesse caso, o contraponto proposto por Jamie Ward e seus colaboradores - à teoria de Ramachandran e Hubbard de que a criatividade e a sinestesia teriam bases neurológicas comuns, seria a de que os sinestetas simplesmente teriam acesso a uma base de conhecimento diferenciada, que inspiraria o exercício de suas capacidades criativas (Ibidem, p. 129).

De qualquer forma - sejam encontrada ou não as bases neurológicas para a sinestesia, 
metáfora ou mesmo para a criatividade - a relação entre sensações e as mais diversas modalidades tem inspirado a criação artística, seja na literatura, poesia, artes visuais ou música desde a antiguidade. A relação entre a visualidade e a sonoridade, em especial, pode ser destacada como o mar no qual desembocam diversas correntes. Desde as teorias pitagóricas de relações entre símbolos matemáticos e notas musicais (DAY, 2002, p.2), passando pelas aspirações simbolistas de Charles Baudelaire (1821-1867) na literatura (BASBAUM, 2003, p. 2), às ambições de plenitude sensorial de Richard Wagner (1813-1883) em sua "obra de arte total", até as aspirações sinestésicas da arte e tecnologia em busca por novas percepções digitais (Ibidem, p. 15). 


\section{SINESTESIA NA ARTE}

A sinestesia aparece no âmbito artístico em três contextos diferentes: a) com os artistas sinestetas, que podem ou não utilizar sua condição como inspiração criativa ou mesmo como parte de sua poética individual; b) com os sinestetas não-artistas que, dependendo do tipo de sinestesia de que são portadores, apreciam obras de arte diversas sobre prismas bem particulares; c) com as obras artísticas sinestésicas, as quais são apresentadas - por artistas e/ou pesquisadores tanto das ciências como das artes - como relacionadas à "ideia" de sinestesia, por buscar expressar ou induzir a união e/ou correspondência entre dois ou mais sentidos abertamente. Serão abordados neste capítulo somente o primeiro e o último tópico, visto que a experiência de apreciação de qualquer obra de arte por sinestetas pode ser demasiadamente pessoal e, portanto, demandaria estudos de caso específicos que não estão no escopo desta pesquisa.

\subsection{Artistas sinestetas}

Embora o desenvolvimento de testes para identificar sinestetas só tenha surgido no século $\mathrm{XX}$, e o próprio reconhecimento do fenômeno neurológico tenha se dado predominantemente nos últimos três séculos, declarações de alguns sujeitos criativos famosos respaldam o pressuposto de que eles foram sinestetas. Em casos mais recentes, alguns artistas acabaram sendo diagnosticados com sinestesia oficialmente por pesquisadores da área.

Suspeita-se, por exemplo, que Vincent van Gogh (1853-1890) possuía algum grau de sinestesia, a partir de informações sobre sua infância e declarações em cartas pessoais ao seu irmão. Conta-se que quando criança, o artista teve algumas aulas de piano, mas o professor idoso mandou-o embora já nas primeiras tentativas porque o pupilo comparava constantemente as notas do piano com azul prussiano, verde escuro, ocre escuro, amarelo de cádmio e outras cores (CAMPEN, 2007, p.59). Outro exemplo pode ser encontrado na carta de 31 de dezembro de 1882 a Théo, na qual ele atribui correspondências entre os estilos de traçado de alguns artistas e alguns timbres de instrumentos musicais: 
[...] Este é também o caso do o preto e branco, é a mesma situação afinal - é preciso ser capaz de variar da mais clara luz ao sombreado mais profundo, e fazer isso utilizando poucos ingredientes. Alguns artistas têm uma mão nervosa ao desenhar, o que confere a sua técnica algo próximo do som peculiar de um violino, como por exemplo, Lemud, Daumier, Lançon outros, como Gavami e Bodmer, lembram mais o tocar de um piano. Você também sente isso? - Millet é talvez um majestoso órgão ${ }^{4}[\ldots]$ (Carta de Van Gogh a Theo -The Hague, 31-2, dez - jan, 1882)

Além de Wassily Kandinsky (1866-1944) ser um dos grandes divulgadores da relação entre música e artes visuais em seus livros, e de demonstrar grande interesse em desenvolver e ensinar novas formas de expansão individual da sensibilidade entre "formas visuais, cores, tato, calor, som e energia" (CAMPEN, 2007, p.56). Desconfia-se que ele era também um sinesteta devido ao fato do artista esmiuçar o tema de forma quase científica em seus escritos, e à afinidade que o pintor tinha com a música - ele estudou música desde a tenra infância, e tocava violino e violoncelo. Apesar de muitos pesquisadores interpretam seu posicionamento por um prisma mais metafórico do que necessariamente sinestésico, algumas evidências de suas práticas e colaborações artísticas, declarações de pessoas que o conheceram em vida e episódios apresentados em sua autobiografia parecem indicar a ocorrência de experiências sinestésicas vívidas durante sua trajetória (IONE; TYLER; 2003, p. 224). Sua esposa, por exemplo, escreveu ter testemunhado a paixão de Kandinsky pelas suas cores de infância, revelando que ele tinha uma correspondência sonora e olfativa para cada matiz (Ibidem, p.224). Além do mais, a descrição pessoal de seus sentimentos ao assistir a montagem do Lohengrin de Wagner em Moscou em 1896, é notoriamente sinestésica:

[...] Os violinos, a tonalidade profunda dos baixos, e especialmente os instrumentos de sopro naquele momento encarnaram para mim todo o poder daquela hora pré noturna. Eu vi todas as minhas cores na minha mente; elas se posicionaram diante dos meus olhos. Selvagens, quase loucas linhas foram desenhadas diante de $\mathrm{mim}^{6}$. [...] (IONE;TYLER, 2003, p.224 apud

4 Tradução nossa, original: "This is also the case with Black and White, it is the same after all - one must be able to go from the highest light to the deepest shadow, and this with only a few simple ingredients. Some artists have a nervous hand at drawing, which gives their technique something of the sound peculiar to a violin, for instance, Lemud, Daumier, Lançon - others, for example, Gavarni and Bodmer, remind one more of piano playing. Do you feel this too? - Millet is perhaps a stately organ." texto na integra disponível em: http://www.webexhibits.org/vangogh/letter/11/256.htm, em junho de 2016.

5 Tradução nossa, original: "In his lessons at the Bauhaus he taught his students to experiment with the relationships between visual form, color, touch, warmth, sound, and energy."

6 Tradução nossa, original: "The violins, the deep tones of the basses, and especially the wind instruments at that time embodied for me all the power of that prenocturnal hour. I saw all my colors in my mind; they stood before my eyes. Wild, almost crazy lines were 
KANDINSKY, 1913, p. 364)

O pintor David Hockney (1937-) foi um dos que foi pessoalmente diagnosticado como sinesteta por Richard Cytowic. Ele possui associações sinestésicas de cores e formas desencadeadas por sons. Sua sinestesia não é evidente em suas pinturas mais famosas, mas sim em seus trabalhos para figurino e cenário dos ballets de Marseille e Glynbourne e para as óperas do Metropolitan. Nessas ocasiões, suas percepções sinestéticas em relação à música dos espetáculos precederam a correlação com o roteiro da trama em seu processo criativo (CYTOWIC, 2002, p.312). O fato pode ser verificado nestas declarações do artista:

[...] Eu acredito que as equivalências visuais para a música revelam a si mesmas. Em Ravel, certas passagens pareciam todas azuis e verdes para mim, e certas formas começavam a se insinuar quase naturalmente. É a música que me atrai para realizar o projeto do cenário ao invés do enredo. [...] Em todas as óperas que fiz, a música me forneceu o cenário - a cor e a forma. No Oedipus Rex (de Stravinsky) não havia muita cor, mas linhas 7 .[...] (Ibidem, p. 312-313)

Dois rascunhos de Hockney para o cenário e o figurino da ópera Oedipus Rex de Stravinsky, apresentadas em 1981 no Metropolitan Opera House, podem ser conferidos na figura abaixo:

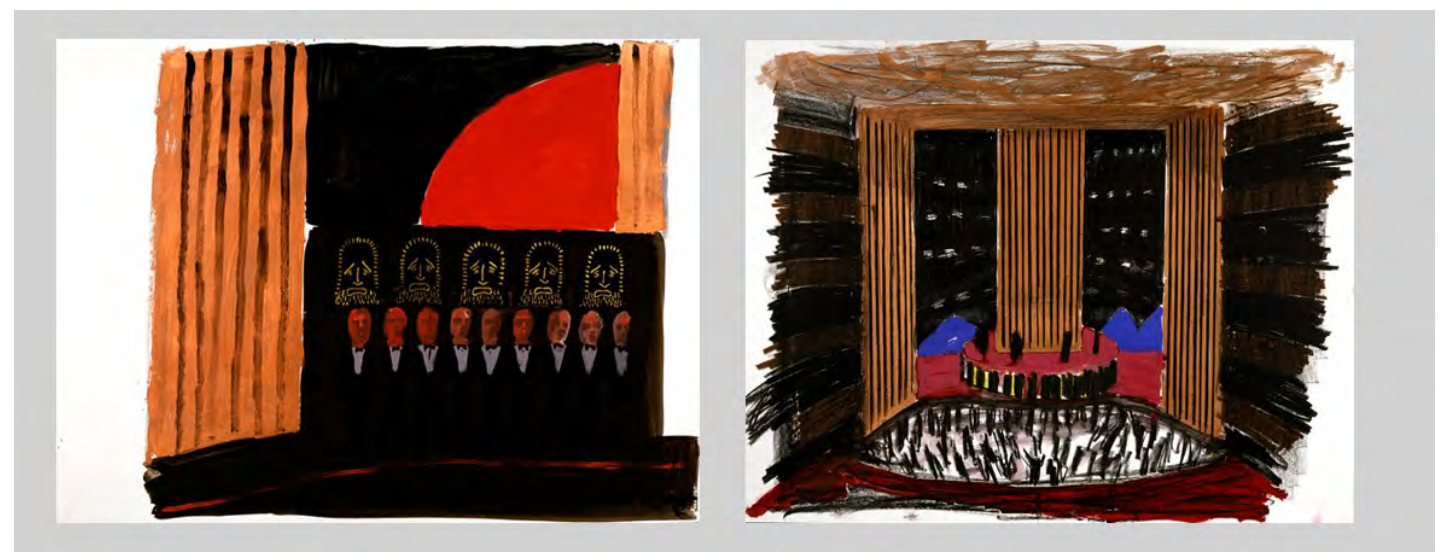

Figura 3: Rascunhos de David Hockney para a ópera Oedipus Rex de Stravinsky. Disponível em: $<$ http://www.hockneypictures.com/stravinsky triple/stravinsky_oedipus title.php $>$. Acesso em: 16 jun. 2016.

O escritor Vladmir Nabokov (1899-1977) indica, em sua autobiografia: Speak, Memory - An

sketched in front of me."

7 Tradução nossa, original: “ I find that visual equivalents for music reveal themselves. In Ravel, certain passages seem to me all blue and green, and certain shapes begin to suggest themselves almost naturally. It's the music that attracts me to doing the set designs rather than the plot'(...)'In all operas I've done, the music gives me the set—-the color and shape. In the [Stravinsky's] Oedipus Rex there was not much color but lines and sharp things that suggested cross hatchings."' 
autobiography revisited ( $1^{\mathrm{a}}$ edição publicada em 1947), todas as nuances de cores que ele associava a caracteres e fonemas. Ele aponta grupos de letras em categorias de cores. A palavra que, de acordo com ele, mais se aproximava do colorido de um arco-íris "decididamente turvo, mas ainda assim um arco-íris" (NABOKOV, 1989, p.51), era quase impronunciável: kzspygv. Entre os matizes muito específicos que ele descreve esta, por exemplo, a diferenciação entre a letra " $a$ " do alfabeto inglês (que ele denomina como " $a$ longo" e de cor de madeira úmida) e o " $a$ francês" (que indica ter a tonalidade do ébano polido) (Ibidem, p.48). Depois de relatar suas percepções sinestésicas, ele descreve o momento em que descobre que sua mãe possuía sensações sinestésicas parecidas:

[...] As confissões de um sinesteta devem soar tediosas e pretensiosas àqueles que são protegidos de tais vazamentos e projeções por muralhas mais sólidas do que as minhas. Para minha mãe, porém, tudo isso parecia bastante normal. $\mathrm{O}$ assunto surgiu um dia no meu sétimo ano quando eu estava usando uma pilha de antigos blocos alfabéticos velhos para construir uma torre. Casualmente comentei com ela que todas as cores estavam erradas. Nós descobrimos então que algumas letras para ela tinham a mesma cor que para mim e que, além disso, ela era afetada oticamente por notas musicais. Estas não evocavam nenhum tipo de cromatismo para $\operatorname{mim}^{8}$.[...] (Ibidem, p.52)

O compositor Oliver Messiaen (1908-1992) apresentava sinestesia bidirecional (escutava sons ao ver cores e vice-versa), o que foi marcante para seu método de composição. Ele chegou a inventar uma ferramenta composicional denominada "modos de transposição limitada", na qual conjuntos de intervalos musicais ordenados hierarquicamente se relacionavam a grupos de cores. Desta forma, ele podia transmitir música em termos de cor (CYTOWIC, 2002, p.310). As variações cromáticas dentro do azul, violeta e púrpura eram correspondentes ao Modo 2, por exemplo, enquanto o Modo 3 apresentava grande variação de matizes, desde o vermelho, laranja e verde, até pontos dourados e um branco leitoso com reflexos iridescentes como uma pedra opala (Ibidem, p. 310). Os modos criados por Messiaen foram estruturados de tal forma, dentro das 12 notas cromáticas tradicionais do sistema temperado ocidental, que a lógica harmônica só possibilita um número limitado de transposições (como deixa evidente

8 Tradução nossa, original: "The confessions of a synesthete must sound tedious and pretentious to those who are protected from such leakings and drafts by more solid walls than mine are. To my mother, though, this all seemed quite normal. The matter came up, one day in my seventh year, as I was using a heap of old alphabet blocks to build a tower. I casually remarked to her that their colors were all wrong. We discovered then that some of her letters had the same tint as mine and that, besides, she was optically affected by musical notes. These evoked no chromatisms in me whatsoever." 
o nome da técnica), o que garante a preservação dos matizes de cor específicos de cada modo (CYTOWIC, 2002, p.309). A composição Des canyons aux étoiles (Dos desfiladeiros até as estrelas, tradução nossa) foi inspirada durante uma experiência que ele teve em uma visita aos EUA, quando presenciou o voo de um gaio-de-steller (espécie americana de pássaro azul e preta de rabo longo) sob o Bryce Canyon em Utah. No sétimo movimento dessa composição, intitulado Bryce Canyon, ele tentou capturar musicalmente o conjunto de cores que viu naquele dia. Segue abaixo as instruções, referindo-se a seus modos coloridos, que ele disponibiliza para a interpretação musical dessa parte:

[...] Sopros e metais, o tema massivo de rochas vermelho-alaranjadas. 'Ressonância de acorde contraído' (vermelho e laranja), modo três 1 (laranja e ouro), 'Inversão de acorde transposto' (amarelo, lilás, vermelho, branco e preto) transmitem as diferentes cores das pedras ${ }^{9}[\ldots]$.

(CAMPEN, 2007, p.21).

György Ligeti (1923-2006) utilizava sua sinestesia - em conjunto com referências literárias, científicas e situações cotidianas - como fonte de inspiração para suas composições. Apesar disso, alegava não compor música programática, visto que não queria expressar musicalmente um pensamento ou uma imagem específica. Ele justificava que simplesmente pensava de forma sinestésica (CAMPEN, 2007, p.22). Ligeti relata que frequentemente recebia respostas acústicas a partir de estímulos visuais e táteis, assim como, inversamente, toda a sensação acústica evocava forma, cor e qualidades materiais. Mesmo conceitos abstratos como relacionamento, quantidade, evento e coesão tinham uma forma sensitiva e localização em seu espaço imaginário (Ibidem, p.22). Segue abaixo a descrição das sensações do compositor acerca do conceito de tempo:

[...] Para mim, o tempo é de um branco enevoado; ele flui lenta e continuamente da esquerda para a direita, enquanto solta um suave hhh sussurrado. Nessa impressão, 'esquerda' é um ponto colorido violeta com qualidade e som de latão; 'direita' tem uma cor laranja, uma superfície de madeira e som abafado ${ }^{10}[\ldots]$ (CAMPEN, 2007, p.23).

9 Tradução nossa, original: original: "Woodwind and brass, the massive theme of red-orange rocks. "Contracted chordal resonance"(red and orange), mode three 1 (orange and gold), "transposed chord inversions" (yellow, mauve, red, white and black) convey the different colors of the stones."

10 Tradução nossa, original: "For me, time is misty white; it fl ows slowly and continuously from left to right, while it raises a very soft hhh-like whispering. In this impression, "left" is a violet-colored spot with a tin quality and ditto sound; "right" has an orange color with a wooden surface and a muffled sound.”. 
Em sua composição Atmospheres (Atmosferas, tradução nossa) ele não só utiliza indicações com palavras como agudo e grave ou forte e fraco, mas também termos como timbres leves/rasos e pesado/profundo. Essa obra, assim como outras do compositor, carrega qualidades táteis facilmente percebidas mesmo para não-sinestetas, como passagens mais leves e frágeis em contraposição a momentos robustos e pesados.

Nas décadas passadas, alguns pesquisadores consideravam Alexander Scriabin (1872-1915) como um possível sinesteta, devido à proeminência com que as relações intermodais entre som e cor foram abordadas em suas composições. B. M. Galeyev e I. L.Vanechkina apontaram a natureza teórica das associações propostas, contudo, com base nos textos originais em russo do compositor e de seu crítico e biógrafo Leonid Sabaneyev (1881-1968) (GALEYEV;VANECHKINA, 2001, p.357-361).

Ainda na lista de famosos que possivelmente têm ou tiveram sinestesia, disponível no site do pesquisador Sean Day, estão: os artistas Charles Blanc-Gatti (1890-1966), Joan Mitchell (1925-1992) e Sandy Schimmel (1954 -); os músicos Franz Liszt (1811-1886), Jean Sibelius (1865-1957), Amy Beach (1867-1944), Elvin Jones (1927-2004) Michael Torke (1961-) e Lady Gaga(1986-); e os escritores Ellen Thornetcroft Fowler (1860 - 1929), Orhan Pamuk (1952-), Julie Myerson (1960-) e Joanne Harris (1964-). Devido à já abordada tendência de sinestetas adentrarem o mundo da arte, o número de casos de sinestetas na arte é provavelmente ainda maior.

\subsection{Apropriação do termo sinestesia para descrever obras de arte}

É evidentemente comum o fato de alguns pesquisadores, historiadores da arte e público geral se apropriarem do termo sinestesia para se referir a obras de arte. Geralmente ele é utilizado para aludir a obras que propõem uma relação direta e explícita entre dois ou mais sentidos (obras entremeios que apresentam mais de um sentido interconectados) ou que buscam induzir esteticamente um sentido pelo outro (por exemplo, uma pintura que remeta a um ritmo 
sonoro ou que utilize texturas para relacionar-se ao tato). Contudo, como o capítulo anterior buscou detalhar, o conceito científico de sinestesia é bem mais preciso e focado em respostas sensitivas típicas de um grupo restrito de pessoas.

O quadro se torna ainda mais complexo diante da abordagem (utilizada por alguns cientistas) de mencionar obras de arte em uma perspectiva histórica como introdução para o fenômeno da sinestesia. A divergência entre os próprios pesquisadores sobre o fenômeno acaba gerando confusão e a criação de diversos termos para se referir ao mesmo objeto, como é o caso crítico das correspondências entre sentidos presentes na linguagem, e nas similaridades e interações perceptuais que ocorrem durante o processamento de informação. Estes casos já foram denominados em diferentes trabalhos como: sinestesia fraca, associações sinestésicas, correspondências sinestésicas, correspondências cross-modais, correspondências intermodais, correspondências, equivalências cross-modais, mapeamentos naturais cross-modais, mapas metafóricos, associações cross-modais (DEROY; SPENCE, 2013, p. 644) e pseudo-sinestesia (BASBAUM, 2002, p.27).

A utilização do termo sinestesia para descrever obras de arte geralmente leva mais em consideração o significado etimológico da palavra do que o real objetivo para o qual o termo foi cunhado (descrição de uma peculiaridade médica por Flournoy no séc. XIX). Não é por menos, visto que a ideia de união sensorial é muito mais antiga do que a criação da palavra, o que fez com que o estudo da sinestesia eventualmente também herdasse um contexto filosófico e cultural. É possível que essa herança tenha influenciado a recusa da comunidade científica em reconhecer este campo de estudo entre as décadas de 1930 e 1970, e a discussão que existe até os dias de hoje em relação à classificação e nomenclatura na área.

Diante da armadilha que pode se tornar o estudo da sinestesia devido a essa imbricada relação entre ciência, filosofia e cultura, destacamos a seguir o posicionamento de alguns pesquisadores da arte que se aventuraram a abordar o tema.

O artista belga Dr. Hugo Heyrman utiliza duas categorias para tratar do tema da sinestesia: a "sinestesia de ocorrência natural" (sinestesia canônica) e a "sinestesia na arte". Ele se vale da 
hipótese de que os fenômenos sinestésicos estão na raiz de toda a prática artística, e portanto considera a própria arte como uma experiência sinestésica que cria conexões entre os sentidos (HEYRMAN, 2005). Ele emprega na arte a sinestesia em seu sentido etimológico, indicando potencialmente todo e qualquer trabalho artístico como exemplo de obra sinestésica. Heyman contextualiza, como pertencentes ao fenômeno, inclusive obras que não utilizam mais de um meio de expressão ou que não tenham declarada intenção artística de união sensorial. Dois dos exemplos mencionados são Le Déjeuner en Fourrure de Meret Oppenheim (1936), que abordaria o potencial visual-tátil-gustativo - e Broadway Boogie Woogie (1942-43) de Piet Mondrian, que indicaria ritmos visual-sonoros.

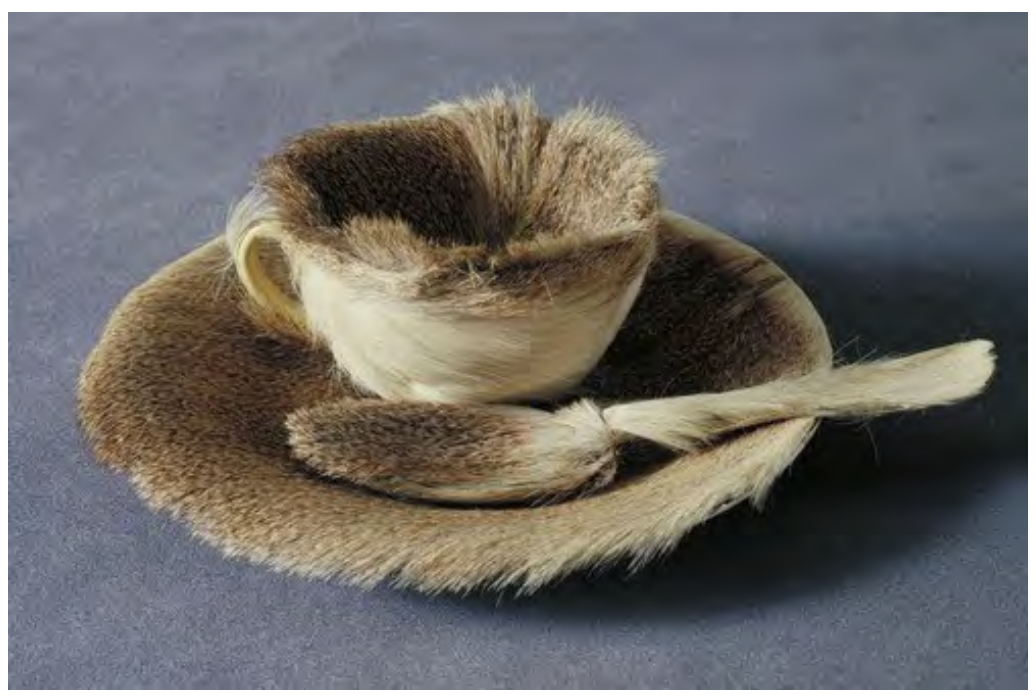

Figura 4: Escultura Déjeuner en Fourrure de Meret Oppenheim (1936). Disponível em: http://www.wikiart.org/en/meret-oppenheim/object-le-d-jeuner-en-fourrure-1936. Acesso em: 15 jun. 2016.

Cretien van Campen, por sua vez, utiliza no seu histórico sobre a sinestesia na arte somente obras de artistas sinestetas ou de artistas que se interessaram pela ideia de união sensorial. Estes artistas, em sua maior parte, apresentaram declarações e pesquisas poéticas explícitas sobre o tema (CAMPEN, 2007). Entretanto, ele define a sinestesia no contexto artístico de forma bastante abrangente: como um conjunto de fenômenos perceptivos simultâneos engatilhados por dois ou mais estímulos como uma experiência gestalt (CAMPEN, 2009, p.1). 
Sérgio Basbaum (2002) e Yara Borges Caznók (2008) seguem uma linha de tratamento próxima à de Campen, abordando primeiro a sinestesia como definida na ciência e depois considerando-a na arte. A sinestesia no contexto artístico aparece, então, como "propostas ou realizações artísticas que buscaram de alguma forma, e deliberadamente as fusões de dois ou mais sentidos" (BASBAUM, 2002, p.28). Basbaum destaca o campo particular da visual music como trazendo em seu cerne a sinestesia a partir de um caráter metafórico, evocando um sentido em termos de outro (Ibidem, p. 57). Caznók cita a busca pela correspondência entre sons e cores na música, na poesia e nas artes visuais, descrevendo obras artísticas da mesma natureza também como multissensoriais.

Alexandre Siqueira de Freitas estende o conceito de sinestesia na arte para o campo da estética comparada, apontando que diferentes campos artísticos possuem atributos que compartilham uma condição qualitativa imensurável. Ele defende, desse modo, a existência de uma "sinestesia generalizada, que admite uma comunhão entre sujeito e objeto, se reflete e é refletida no entendimento das semelhanças entre as artes" (FREITAS, 2012, p.69). Não causa surpresa a relação entre sinestesia e tradução intersemiótica (PLAZA, 2010) observada por Freitas em seu artigo de 2009, "Apontamentos sobre tradução e sinestesia", visto que ele interpreta a sinestesia como a própria qualidade de primeiridade (semiótica peirceana) comum aos campos artísticos ${ }^{11}$.

Rosângela Leote, por outro lado, contrapõe-se à utilização do termo sinestesia para descrever obras artísticas. A autora alega que o termo carrega em si um prisma essencialmente perceptivo e só deveria ser aplicado à arte quando relacionada às experiências sensíveis únicas proporcionadas pelas configurações e estados cerebrais do interator (LEOTE, 2014, p.56). Desta forma, ela afirma que, apesar da intenção de trabalhos artísticos tecnológicos de abordar experimentações multissensoriais imersivas como sinestésicos, o grau de interação ou imersibilidade não seriam, necessariamente, pré-requisitos para a experiência sinestésica (Ibidem, p.57). Ela propõe a utilização do termo pseudo sinestesia como aproximado à terminologia multissensorial, destacando a possibilidade poética de "indução do interator a

11 Necessário destacar que o próprio Júlio Plaza utiliza explicitamente a palavra sinestesia para se referir ao estado natural de mistura sensorial que origina nossa percepção do mundo (PLAZA, 2010, p.46). 
estados alterados de consciência, portanto perceptivos, para uma impressão pseudo sinestésica de um determinado evento, porém, sem a utilização de drogas de efeito alucinógeno" (Ibidem, p.59). Portanto, Leote considera a pseudo sinestesia como a ocorrência episódica de sensações análogas à sinestesia em não-sinestetas por obras artísticas multissensoriais.

Alexandra Cristina Moreira Caetano também intercala os conceitos de multissensorialidade e sinestesia em sua tese (2015). Ela toma partido das definições de sinestesia na arte de Campen, Caznók e Basbaum, abordando, em geral, obras nas quais os artistas apresentaram historicamente o interesse entre a relação entre sons e cores. Curiosamente, em 2013, Caetano apresenta uma perspectiva de sinestesia na arte um pouco mais próxima da de Leote, ao considerar como sinestésicos trabalhos multissensoriais com utilização de tecnologias de dados de biofeedback do público (CAETANO, 2013, p.1). Por conseguinte, ela defende que a tecnologia resgataria em primeira mão parte das percepções do usuário (pelo monitoramento de suas respostas corporais) e possibilitaria, então, uma leitura sinestésica.

\subsection{Breve percurso histórico da sinestesia na arte}

O surgimento da ideia de união entre vários sentidos na filosofia ocidental surgiu na concepção pitagórica de "Música das Esferas". Tal formulação sugere a existência de uma espécie de harmonia geométrica divina, que estaria presente em todos os fenômenos naturais, em que vibrações de proporções matemáticas permitiriam a união cósmica do Universo (BASBAUM, 2002, p.19-20). A formulação de união perceptiva é tão antiga quanto o entendimento da divisão e especificação dos sentidos. Aristóteles, apesar de concordar com a compartimentação sensível a partir dos órgãos sensoriais de sua época, considera a existência do que ele nomeia como sensus communis, um sentido que perceberia a qualidade (qualia) comum do fenômeno apresentado pelos diversos sentidos externos (VAN CAMPEN, 2009, p.2). Aristóteles e seus alunos tentaram continuar as pesquisas sobre a relação entre a altura dos sons e intensidade luminosa iniciada por Pitágoras, propondo a existência de uma proporção matemática que garantisse a relação de correspondência entre o espectro de cor do mais claro ao mais escuro - e o espectro sonoro - do mais grave ao mais agudo (VAN 
CAMPEN, 2007, p.45).

Por volta de 1492, a música modal grega foi reintroduzida por Franchino Gaffurio (14511522) na Europa, com associações entre corpos celestes, cores e modos (Dórico - cristalino, Frígio - laranja, Lídio - vermelho e Mixolídio - cor misturada indefinida) (DAY, 2002, p.3). No final do século XVI, o pintor Giuseppe Arcimboldo (1527-1593) experimentou testar a hipótese da correspondência entre sons e cores a partir da fixação de tiras de papéis pintados com cores diferentes para cada tecla de um gravicembalo (instrumento precursor do piano moderno). Influenciado por Aristóteles, Arcimboldo relacionou cores mais claras a notas mais graves e cores mais escuras a notas agudas - o que soa bastante curioso para nosso ouvido ocidental contemporâneo, que tende a relacionar o oposto (VAN CAMPEN, 2007, p.46). Leonardo Da Vinci (1452-1519) também foi motivado pelas ideias de misturas sensoriais de seu colega Arcimboldo. Ele promoveu espetáculos de luz, som e cor para a corte italiana, inaugurando a aplicação da ideia de sinestesia a espetáculos e obras artísticas (BASBAUM, 2002, p.20).

Os jesuítas Marin Mersenne (1588-1648), Athanasium Kircher (1601-1680) e Luis-Bertrand Castel (1688-1757) também pesquisaram a relação entre cores e frequências musicais. Os três se utilizavam, ao mesmo tempo, de influências místicas e religiosas acentuadas e da responsabilidade com o conhecimento científico da época (CAZNÓK, 2008, p.29). Castel, em especial, foi muito influenciado pelas pesquisas de Isaac Newton (1642-1727) - divulgada em Optiks (1704) - a respeito do paralelismo entre espectro luminoso e séries harmônicas (sons parciais). Ele também foi, junto com Mersenne, um dos primeiros a propor a relação entre graves e tons escuros e agudos e tons claros, predominante até hoje na escuta musical ocidental (Ibidem, p. 37). Em 1735, Castel inventou o harpsicórdio ocular, instrumento que associava diretamente a escala cromática musical a variações de cores, produzindo segunda versão do instrumento em 1754. Nos anos seguintes, foram publicados mais três trabalhos que propuseram relações entre matizes de cor e notas musicais: Herder, em 1772; L. Hoffman, em 1786; e Erasmus Darwin em 1790 (BASBAUM, 2002, p.21).

Acredita-se que o início do século XIX tenha sido marcado por várias considerações acerca da 
comparação entre cores e sons, visto que Goethe considera tais relações como comuns em sua Doutrina das Cores (Ibidem, p.22), publicada nesse período. Na poesia, a fusão dos sentidos é característica dos escritos de poetas simbolistas, com casos encontrados, por exemplo, em trechos dos poemas Correspondances (1857) de Charles Baudelaire e em Le Sonnet des Voyelles (1837) de Arthur Rimbaud (Ibidem, p.58-59). Na música, Richard Wagner propôs em 1849 a colaboração e a continuidade entre as artes, na experiência estética integrada e potencialmente sinestésica de sua "obra de arte total" (Gesamtkunstwerk). A partir da década de 1890, inúmeros artistas plásticos, músicos, cineastas e cientistas se interessaram em construir ou obter instrumentos musicais coloridos (CAZNÓK, 2008, p.37), os estudos sobre sinestesia ganharam destaque nas pesquisas da área de psicologia (BASBAUM, 2002, p.23) e o nascimento do cinema inaugurou novas possibilidades criativas de intercruzamento entre imagem e som.

A transformação das linguagens artísticas e musicais no século XX se deu a partir da recusa da tradição romântica, caracterizada pelo rompimento com o tonalismo na música e o figurativismo na pintura (CAZNÓK, 2008, p.103). Apesar dessas novas poéticas proporem a autorreferencialidade e a especificação das artes, alguns artistas, como Arnold Schoenberg (1874-1951) e Kandinsky, flertaram com a sinestesia mesmo às custas de duras críticas de teóricos como Clement Greenberg (1909-1994) e Pierre Boulez (1925-2016) (BASBAUM, 2003, p.15).

Nas primeiras décadas do século passado, Alexander Scriabin (1872-1915) e Nicolay RimskyKorsanov (1844-1908), na Rússia, propuseram relações entre cores e tonalidades musicais (CAZNÓK, 2008, p.43-48), levando em consideração o ciclo das quintas musicais e influências místicas que buscavam a regeneração da união cósmica (Ibidem, p.115). Scriabin foi o primeiro compositor a escrever uma sinfonia para som e cor de fato, em seu Prometeus, o poema do fogo (1910) para orquestra e teclado de luzes (BASBAUM, 2002, p.83). Ainda na Rússia pré-revolucionária, Nicolai Kublin sob influência da teosofia, do pós-simbolismo francês e do futurismo, propôs seu formato de arte sinestésica a partir de uma nova música micro-tonal e abolição do pentagrama, além de ter iniciado a construção de um alfabeto sinestésico pessoal (Ibidem, p.60). Após a Revolução Russa, o ator e diretor Mikhail Tchecov 
(1891-1955) constituiu as bases de um teatro sinestésico onde fonemas, movimentos e sentimentos se inter-relacionariam com cores no palco, alcançando relativo sucesso em sua montagem inovadora de Hamlet em 1924 (Ibidem, p.60-63).

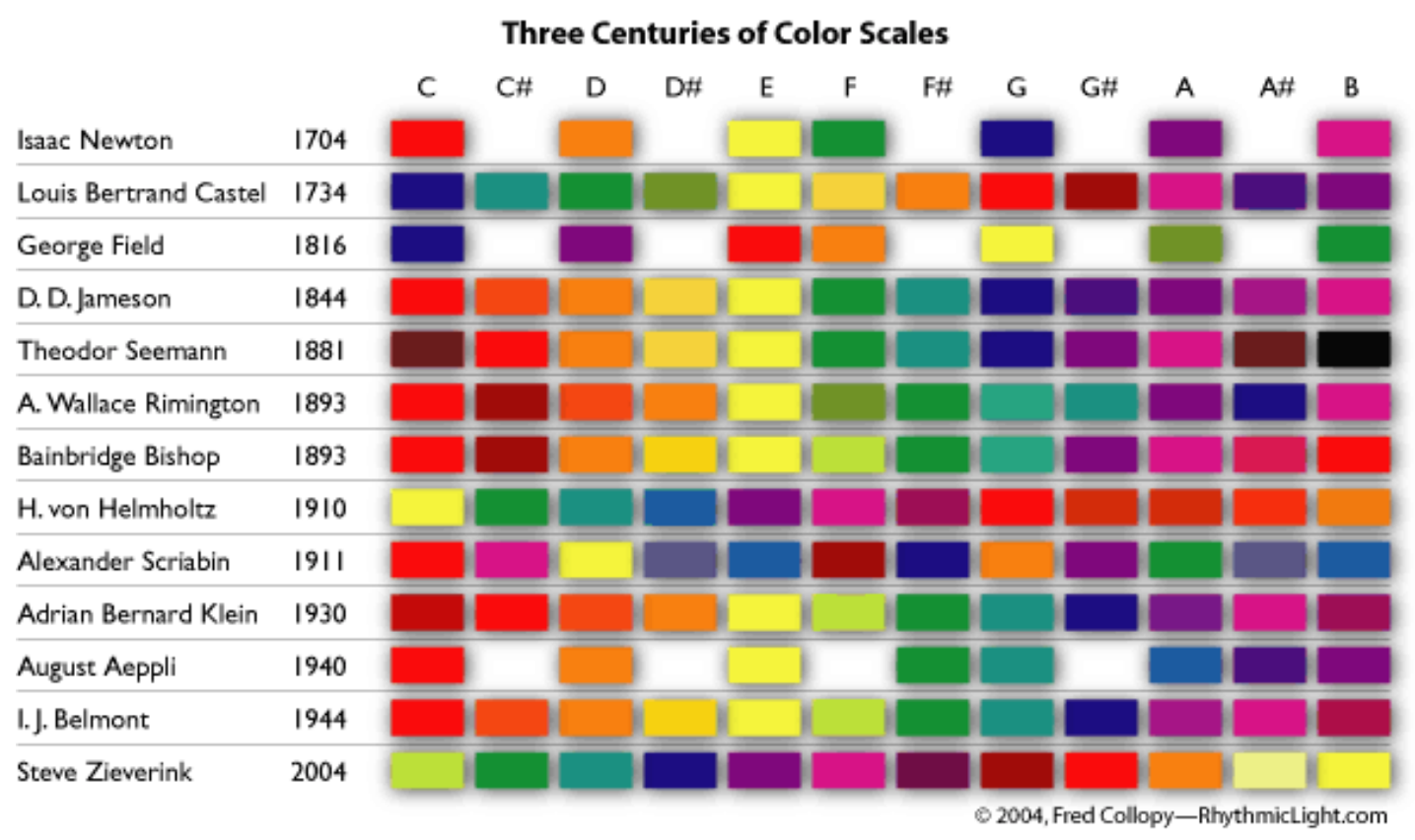

Tabela 2: Tabela apontando as associações entre cor e notas musicais da escala cromática sugeridas por alguns indivíduos nos últimos séculos. Disponível

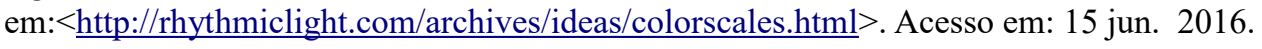

O compositor austríaco Arnold Schoenberg utiliza variadas relações entre cores e sentidos em seus escritos, teorias e sistemas musicais, sem ter entretanto desenvolvido as consequências dessa linha de pensamento em sua teoria (Ibidem, p.66). Apesar deste fato, as elaborações de Schoenberg sobre dodecafonismo, cor e som influenciaram a "melodia de timbres" de Anton Webern (1883-1945) e Wayne Slawson (1932 -). Messiaen, artista sinesteta já referenciado, divulgou bastante suas ideias sinestésicas a partir de anotações sobre indicações de interpretação em suas composições. Jorge Antunes (1942 -) lança, na década de 1960, suas primeiras "músicas cromofônicas" e se torna um dos pioneiros na pesquisa sobre sinestesia no Brasil. 
No campo das artes visuais, inúmeros artistas buscaram a relação entre som e visualidade em suas poéticas durante o século XX. Os futuristas já no início do século incluíram o ruído, o ritmo e a velocidade na pintura, além de utilizar a tipografia de palavras e fonemas como ponte entre olho e ouvido. Um exemplo do uso destes elementos pode ser encontrado no Zang Tumb Tumb (1914) de Filipo T. Marinetti (1876-1944). Kandisky é, sem dúvida, um dos artistas que mais abordaram o tema, seja em suas pinturas abstratas, permeadas de ritmo e cor, seja em seus livros: Ponto e Linha sobre Plano (1923) e Do espiritual na arte (1966). Piet Mondrian (1872-1944) e Paul Klee (1879-1940) se inspiraram em gêneros musicais como a fuga e o jazz. Eles buscaram na vivência musical inspirações para dinâmicas temporais dissociadas de quaisquer narrativas para suas pinturas (CAZNÓK, 2008, p.108-110). Uma vertente denominada "musicalismo", fundada na França em 1932 por Henri Valensi (18831960), Gustave Bourgogne (1888-1968), Charles Blanc-Gatti (1890-1966) e Vito Stracquadaini (1891-1955), buscava exprimir em obras pictóricas "o dinamismo e o ritmo do espaço-tempo e produzir a sensação de equilíbrio semelhante àquela que a harmonia musical realiza"(Ibidem, p.112).

Ainda na primeira metade do século $\mathrm{XX}$, interesses de vários artistas em espetáculos multissensoriais de luz e som, misturando diversas tecnologias (cinema, iluminação e teclados coloridos) em produções não-figurativas conhecidas genericamente como son et lumière, possibilitaram poéticas potencialmente sinestésicas. Entre os principais precursores destes eventos multimidia estão: Morgan Russel (1886-1953), Stanton MacDonald-Wright (18901972), Leopold Sauvage (1879-1968), Walter Ruttman (1887-1941), Hans Richter (18881976), Thomas Wilfrid (1889-1968), Oskar Fischinger (1900-1967), Mary Ellen Bute (19061983), Cecil Strokes (1910-1956), Frank J. Malina (1912-1981), John Whitney (1917-1995) e Harry Everet Smith (1923-1995) (Ibidem, p.116). A partir da inclusão do corpo - unificador dos órgãos sensoriais - em obras artísticas, desde os happenings da década de 1960 até as performances e instalações, hoje aliadas às novas possibilidades tecnológicas, a sinestesia pôde estar potente em grande parte das obras contemporâneas. 


\section{A VOZ, O CORPO E SEU POTENCIAL SINESTÉSICO}

É difícil definir a voz por causa da multiplicidade de fatores que influem em sua manifestação e em sua recepção. Optamos, então, por iniciar a aproximação do fenômeno vocal pelo prisma fisiológico. A palavra voz pode ser empregada para designar quaisquer sons vocais emitidos pelos seres humanos. São considerados sons vocais todas as possibilidades de produção sonora advindas da relação entre o fluxo de ar que vem dos pulmões, a vibração das pregas vocais, as configurações anatômicas do trato vocal - espaço constituído pelas cavidades faríngea e oral - e da influência da cavidade nasal (SUNDBERG, 2015, p.19). A localização anatômica das estruturas que compõem o trato vocal está esquematizada na figura abaixo:

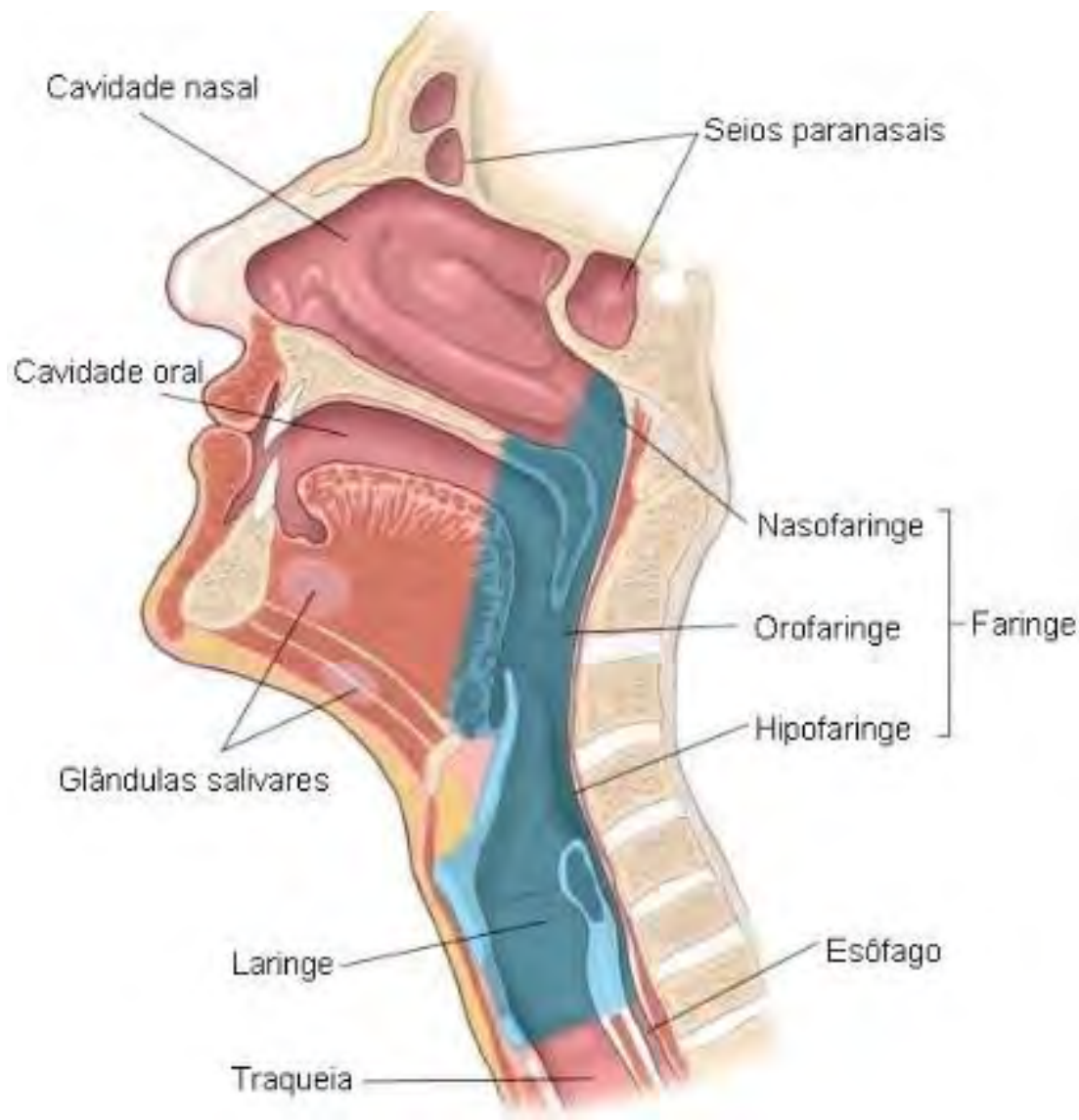

Figura 5: Desenho indicando as estruturas anatômicas do pescoço e algumas das cavidades de ressonância presentes na cabeça humana. Disponível em: $<$ http://www.ebah.com.br/content/ABAAAggH4AH/anatomia$\underline{\text { radiologica-pescoco }>}$. Acesso em: 15 jul. 2016. 


\section{FISIOLOGIA DA VOZ}
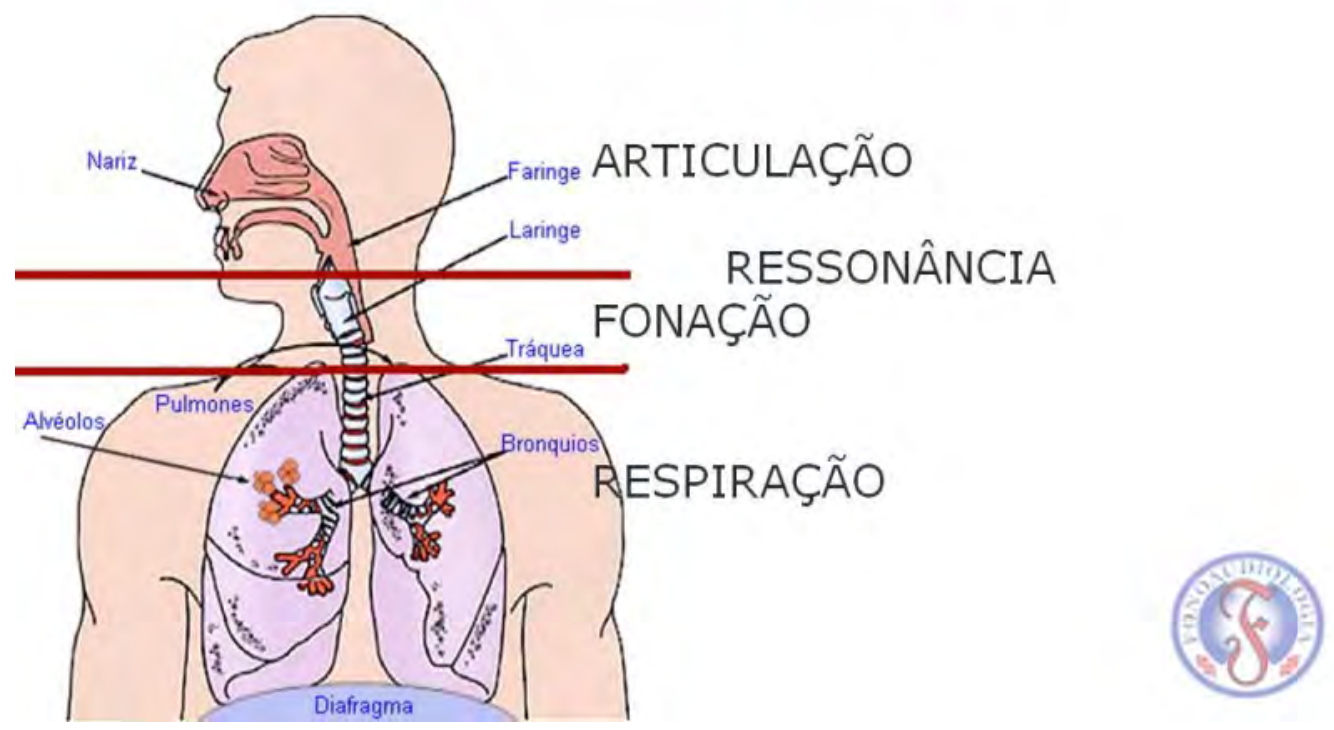

Figura 6: Imagem apresentando o aparelho/sistema fonador que abrange a relação entre o sistema respiratório, a laringe $\mathrm{e}$ as cavidades de ressonância. Disponível em: $<$ http://www.eav.eng.br/tech/fisiologia/Constituiodoaparelhofonadorhumano.html $>$. Acesso em: 15 jul. 2016.

Pode-se subdividir o sistema fonador em três partes com funções diferentes e complementares. A primeira é composta pelo sistema respiratório, que inclui diversas estruturas (tais como alvéolos, brônquios pulmonares, pulmões, pleura e traqueia), controladas pela ação do diafragma e dos músculos abdominais e intercostais. A segunda é composta pelas pregas vocais, que são estruturas musculares de poucos milímetros revestidas por mucosas em forma de dobra ou prega, que se localizam na laringe e respondem à ação de forças aerodinâmicas (pressão do ar) e dos músculos laríngeos. Finalmente, a terceira é composta pelas cavidades de ressonância, que abrangem diversos buracos cranianos incluindo as cavidades nasal e oral, as quais sofrem a ação dos músculos da faringe, da laringe e dos articuladores da fala (lábios, mandíbula, língua, palato, etc.) (SUNDBERG, 2015, p. 2529). Johan Sundberg usa as metáforas do compressor, oscilador e ressoador para se referir às funções das três partes que compõem o sistema de fonação. O compressor age reduzindo e controlando o volume do ar (respiração), originando então a pressão que incide sobre o 
oscilador. Este, por sua vez, vibra e gera um sinal sonoro (fonação), o qual é amplificado, propagado e filtrado pelo ressoador (articulação) (Ibidem, p. 29-34). As três partes que compõem esse sistema estão esquematizadas na Figura 6.

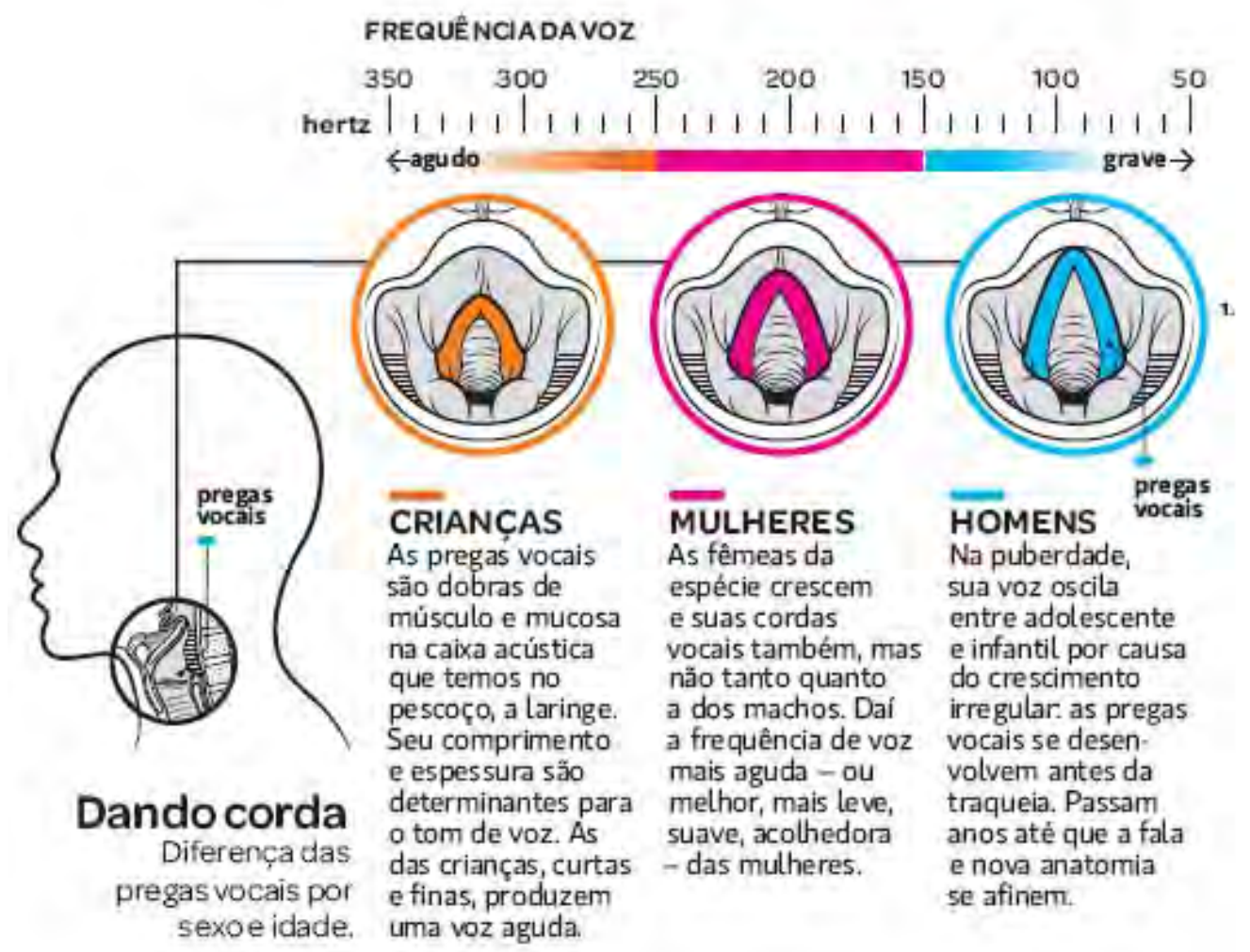

Figura 7: Quadro esquemático apresentando resumidamente as principais diferenças entre as pregas vocais de crianças, mulheres e homens. Ilustração de Luciano Veronezi. Disponível em: $<$ http://cantodellarte.blogspot.com.br/2012/06/o-que-faz-voz-ser-grossa-ou-fina.html $>$. Acesso em 15 jul. 2016.

A qualidade vocal produzida por um indivíduo depende das características morfológicas que compõem as estruturas de seu sistema fonador (capacidade respiratória, tamanho das pregas vocais e propriedades estruturais e dimensionais dos ressoadores) e do modo como ele está treinado para utilizar estas estruturas (SUNDBERG, 2015, p.21). As características de vozes infantis, femininas e masculinas são determinadas por alguns desses fatores, e mesmo dentro de cada um desses grupos existem, obviamente, indivíduos que apresentam qualidades vocais distintas da usual. A Figura 7 esquematiza a relação existente entre as características das 
cordas vocais e as frequências alcançadas pela oscilação dessas estruturas em crianças, mulheres e homens.

Outro fator que influencia as características de uma voz é o estado emocional com que ela é emitida. A emoção é tão importante que pode, inclusive, afetar a saúde vocal de indivíduos. É comum, por exemplo, a constatação por laringologistas da contribuição do estresse para o surgimento de alterações vocais (SUNDBERG, 2015, p.201). Somos capazes de identificar as qualidades emocionais de uma voz com naturalidade. Algumas pesquisas indicam a existência de gestos vocais universais, que podem ser associados a percepções emocionais mesmo por indivíduos que não compreendam uma palavra da língua falada (Ibidem, p.203). Este talvez seja um dos fatores que tornaram tão rentável a gravação e a veiculação de registros vocais pela indústria fonográfica.

O surgimento de aparatos que possibilitam a gravação, a reprodução e o armazenamento sonoro na Revolução Elétrica do século XX inaugurou uma nova relação entre som, tempo e espaço denominada esquizofonia. O termo, criado por R. Murray Schafer a partir da junção das palavras gregas schizo (cortar, separar) e phone (voz), refere-se ao "rompimento entre um som original e sua transmissão ou reprodução eletroacústica" (SCHAFER, 2001, p.133). Dissociou-se, dessa forma, o som da fonte sonora, do tempo e do espaço onde ele foi criado. Schafer explica as consequências dessa cisão exatamente com o caso da voz:

[...] O som vocal, por exemplo, já não está ligado a um buraco na cabeça, mas está livre para sair de qualquer lugar na paisagem. No mesmo instante, ele pode sair de milhões de buracos em milhões de lugares públicos e privados, em todo o mundo, ou pode ser estocado para ser reproduzido em data posterior, talvez centenas de anos depois de ter sido originalmente produzido. Uma coleção de discos e fitas pode conter informações de culturas e períodos históricos completamente diversos, que pareceriam, a qualquer pessoa de outro século que não o nosso, uma justaposição surrealista e sem sentido [...] (Ibidem, p.134)

A mediação eletrônica, ao fixar e tornar a voz reiterável, também a tornou abstrata, abolindo sua efemeridade característica (ZUMTHOR, 2014, p.18), e eliminando sua corporeidade: "o peso, o calor, o volume real do corpo do qual a voz é apenas expansão" (Ibidem, p.19). A 
tecnologia permitiu então o isolamento factual da voz de seu corpo, influenciando a concepção de que a voz é um elemento abstrato e externo; algo que se tem, em vez de algo que se é. Assim como a voz, outros elementos foram segregados do corpo e a própria quantificação e diferenciação dos sentidos que formam a percepção são consequência desse fatiamento.

A tendência de separação dos elementos que compõem a unidade corporal não é novidade na cultura do ocidental, e existe desde a antiguidade grega. Neste período, filósofos como Heráclito e Aristóteles já defendiam a distinção entre os sentidos, indicando a preferência pela visão como fonte de conhecimento (IHDE, 2007, p.7). O conceito de mundo das ideias de Platão, aliado à concepção abstrata do atomo de Demócrito, inauguraram a ideia de divisão da experiência humana em física (disponível através dos cinco sentidos) e metafísica (construções imaginativas baseadas em hipóteses não-constatáveis) (IHDE, 2007, p.9-10). A cisão filosófica definitiva entre mente e corpo ocorreu somente no século XVII, com a subdivisão do homem em duas substâncias opostas por René Descartes: res extensae - corpo físico, e res cogitans - alma pensante de substância imaterial (SIBILIA, 2002, p.66). Marcouse então a diferença entre o cadáver e o corpo vivo ("penso, logo existo"). A dessacralização subsequente do corpo abriu caminho para as investigações anatômicas europeias, que realizaram um extenso e exaustivo inventário da constituição física humana no início do século XIX. Os fisiologistas incumbiram-se de transferir aspectos subjetivos e mentais para planos empíricos e quantitativos (de modo a localizar a memória, a inteligência e as emoções em órgãos internos do corpo), fragmentando o sujeito físico em sistemas orgânicos e mecânicos com funções e atividades específicas (CRARY, 2008, p.113). O cérebro passou a ser o reduto absoluto da mente.

Atualmente, apesar de estudar o protagonismo dos circuitos neurais para a atividade do pensamento, as ciências cognitivas remendaram o corpo e a mente, apontando a importância de toda a unidade corpórea e de sua interação com o mundo para a configuração do conteúdo essencial da mente (DAMASIO, 1996, p.256-257). Não existiria mais, portanto, uma existência central que alocaria a essência definitiva dos indivíduos, mas sim "estados (redes) emergentes que respondem a uma auto-organização, a estados biológicos constantemente 
reconstruídos" (NUNES, 2010, p.112). Estudos antropológicos também indicam a arbitrariedade cultural da subdivisão clássica dos sentidos em cinco (VAN CAMPEN, 2007, p. 99), e proposições médicas recentes propõem a categorização de, pelo menos, mais quinze sentidos, sem considerar os de outros animais (Ibidem, p.100).

A tradição ocidental de fatiamento do corpo e da experiência humana resultou na negligência de aspectos importantes da voz, como sua relação com o ouvido e com o espaço. A audição é um sentido privilegiado ${ }^{12}$, que apresenta as primeiras experiências do feto com o mundo (ZUMTHOR, 2014, p.84), e capta informações espaciais de forma multidirecional. A partir dela, o corpo mostra indícios de sua presença espacial e íntima: "Ouvindo-me, eu me autocomunico. Minha voz ouvida revela-me a mim mesmo, não menos - embora de uma maneira diferente - que ao outro" (Ibidem, p.84).

Apesar de Marshall McLuhan excluir o aspecto oral do texto fonético, indicando sua disseminação pela imprensa como o estopim para a configuração de uma sociedade fragmentada e predominantemente visual, ele vislumbra a potencialidade sinestésica da voz ao reconhecer a fala como o enunciado e exteriorização de todos os sentidos ao mesmo tempo (McLUHAN, 1994, p.6). Não é por menos, a voz percebida como o lugar do sujeito permite a expansão dos limites corporais, ampliando-o temporal e espacialmente (STOROLLI, 2009, p.157). A voz é expressão natural do corpo; vibra-o e o entorno, evidencia aspectos físicos e emocionais do indivíduo e conecta suas percepções ao mundo. Por esta razão, a utilização do corpo e da voz em obras artísticas interativas pode servir como uma matriz poderosa para abordar a sinestesia na arte.

12 Nascer surdo é infinitamente pior do que nascer cego, porque a ausência da experiência acústica pode impedir indivíduos de adquirirem linguagem, e é por meio da língua que o ser humano adquire seu estado de cultura (SACKS, 2010, p.19). Por séculos foram negados direitos humanos fundamentais para os natissurdos, considerados equivocadamente como "incapazes" e "estúpidos". Somente com o desenvolvimento do primeiro sistema de sinais no século XVIII, pelo abade De l'Epeé na França, que indivíduos nessa condição puderam adquirir símbolos próprios, desenvolver raciocínio lógico, comunicar-se e, a partir de associações com as palavras do alfabeto fonético, aprender a ler (Ibidem, p. 20-27). O conhecimento da história dos surdos e a relação existente entre audição, voz e texto negam a dicotomia definitiva entre oral e escrito, proposta por McLuhan e defendida por Walter Ong nos anos 1970 (ZUMTHOR, 2014, p.16). 


\section{SINESTESIA E TECNOLOGIA EM OBRAS ARTÍSTICAS}

Nos séculos anteriores, o antigo sonho artístico de abordar a união sensorial, especialmente a relação entre som e visualidade, esbarrou em algumas limitações tecnológicas do passado. Não foram poucas a tentativas de criar máquinas e instrumentos que pudessem relacionar automaticamente sons e cores, por exemplo. O desenvolvimento das novas mídias, em especial o computador, impulsionou não somente a criação de obras artísticas multissensoriais, mas acabou resultando também em uma cultura digital intrinsecamente relacionada à ideia de sinestesia (BASBAUM, 2003, p.17). A intermediação mecânica presente em máquinas de aspiração sinestésica do passado foi substituída pela lógica algorítmica e matemática do computador, que é capaz de traduzir simultaneamente dados de um sentido em termos de outro. Contudo, nem todo trabalho multissensorial tem como tema as questões perceptivas relativas à equivalência entre os sentidos, apesar de utilizar ferramentas que favoreçam essa abordagem. A seguir serão analisados alguns exemplos de obras artísticas que incitam questionamentos sobre o potencial da tecnologia para ampliar percepções humanas e para estimular e simular experiências sinestésicas. Entre eles, destacase também a presença do corpo e da voz como fonte de dados para interação com outros sentidos.

\subsection{Sinestesia e processo criativo: dois estudos de caso}

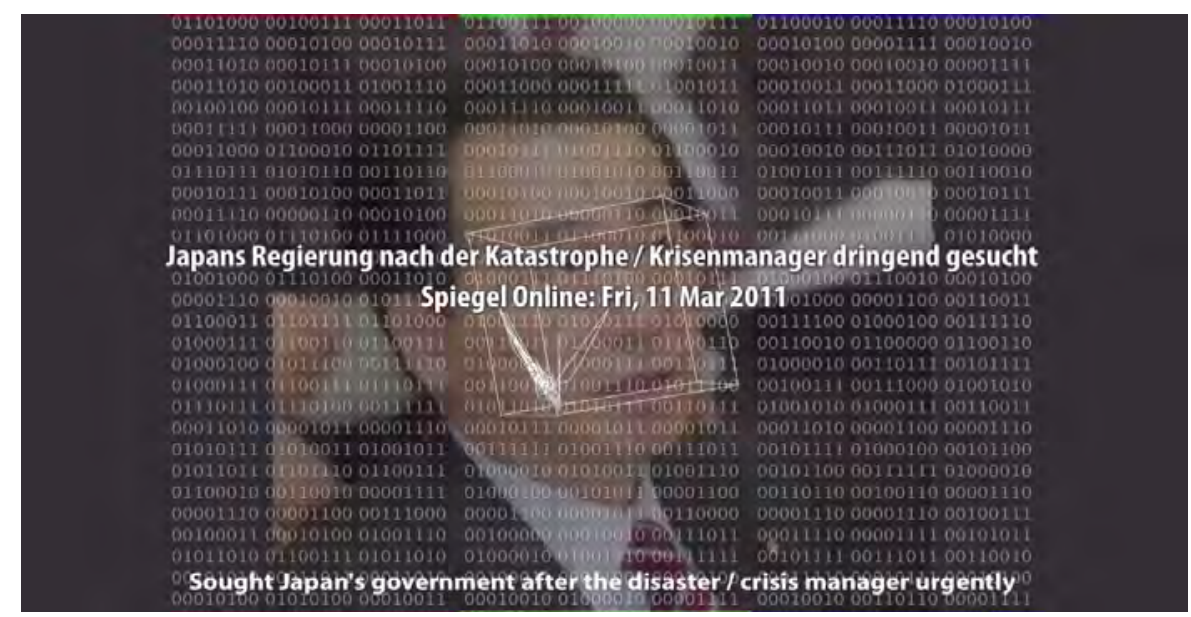

Figura 8: Frame do vídeo Composition Fukushima, composição musical criada a partir de dados imagens digitais. Disponível em: < http://www.kenjikojima.com/fukushima2011/>. Acesso em: 15 jun. 2016. 
Composition Fukushima $(2011)^{13}$ de Kenji Kojima é um dos trabalhos que levantam questões acerca do potencial do computador como máquina sinestésica de tradução entre linguagens, e da abertura de novas maneiras de criar música a partir de dados visuais. Trata-se de uma composição musical, apresentada em exposições em formato de vídeo. Ela foi realizada a partir de imagens disponibilizadas por jornais sobre o acidente nuclear de Fukushima I que ocorreu em 2011, considerado o maior desastre nuclear desde Chernobil (1986). Para compor a obra, Kojima utilizou o RGB Experimental Music Laboratory - software criado por ele que converte dados RGB de uma imagem em sons da escala cromática ocidental. Assim como a altura dos sons é determinada pelos valores tridimensionais de matiz, a duração advém do valor de luminosidade dos pixels. O artista utiliza, desta forma, as imagens digitais como partituras que podem ser decodificadas algoritmicamente pelo computador, gerando composições sinestésicas artificiais.

Um dos casos mais curiosos de expansão sensorial por meio da tecnologia que ocorreu no contexto artístico dos últimos anos foi o de Neil Harbisson. O artista, hoje ativista e cofundador da Cyborg Foundation ${ }^{14}$, nasceu com um tipo raro de daltonismo - acromatopsia - que impede totalmente a percepção de cor, e só permite que ele enxergue em preto e branco. Contudo, a partir dos 21 anos o artista se tornou capaz de ouvir cores a partir de um "olho eletrônico" em forma de uma antena, acoplado em sua cabeça.

O dispositivo está há mais de 10 anos em sua cabeça. Ele é composto por um sensor (na ponta da antena) que capta as frequências das cores mais próximas e envia as informações para um chip instalado atrás de sua cabeça. Um software gera sons eletrônicos de acordo com a cor informada, transmitindo-os através da reverberação óssea em seu crânio.

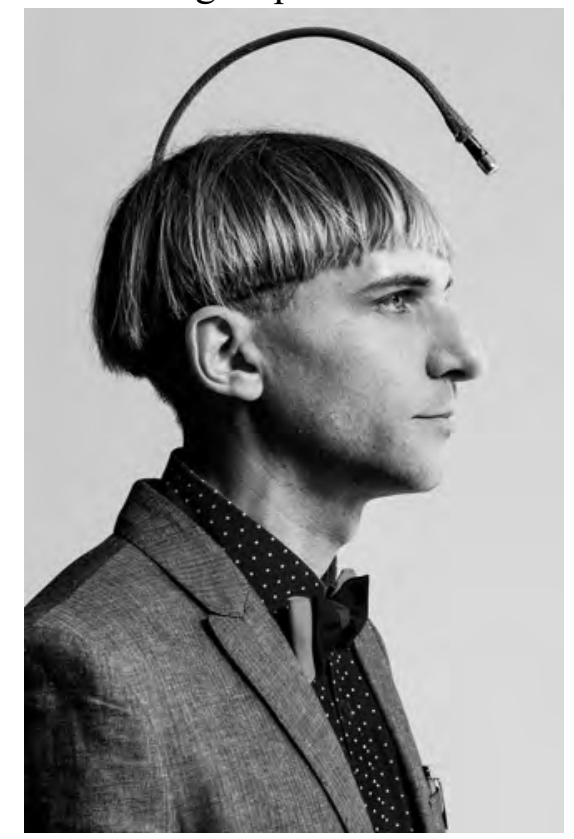

Figura 9: Neil Harbisson, o cyborg que desenvolveu uma sinestesia artificial devido a um dispositivo eletrônico artificial acoplado em sua cabeça. Disponível em: $<$ http://www.harbisson.com/>. Acesso em 20 jul. 2016.

13 Disponível em: $<$ http://www.kenjikojima.com/fukushima2011/>.Acesso em: 20 jun. de 2016.

14 Fundação internacional que tem como objetivo ajudar humanos a se tornarem cyborgs, defender os direitos dos cyborgs e promover o cyborgismo como movimento social e artístico. 
O artista relata que no início teve que decorar o nome que se dava para cada cor e o som de cada nota musical. Após algum tempo, no entanto, as informações se tornaram percepções e passaram a incitar nele respostas empáticas. Seu corpo se adaptou de tal forma à situação que ele começou inclusive a sonhar em cores. Foi então que ele se percebeu como um cyborg, visto que seu cérebro estava produzindo os sons eletrônicos em seus sonhos, e não o software. O dispositivo havia se tornado uma extensão de seu corpo, e sua vida se transformou drasticamente. Além de ter desenvolvido uma espécie de sinestesia artificial, seu estilo e sua prática artística se modificaram completamente. Ele começou a vestir-se como "soava" melhor; a ouvir rostos das pessoas e compor retratos musicais deles (o que alterou, inclusive, sua percepção estética, pois alguns rostos que ele considerava bonitos soavam mal, e alguns rostos antes feios soavam bem); a ouvir pinturas; a pintar músicas e discursos de políticos famosos; e, inclusive, desenvolveu um ouvido absoluto (ou seja, passou a reconhecer acuradamente cada nota da escala cromática ocidental) visto que hoje quando ouve qualquer som externo associa-o automaticamente à sua cor correspondente. Seu olho artificial também permite que ele "ouça" o infravermelho e o ultravioleta, que são frequências luminosas as quais o olho humano não pode perceber. Sua percepção e sua forma de sentir o mundo foram modificados a partir das limitações e potencialidades da tecnologia ${ }^{15}$.

Tanto em Composition Fukushima quanto no cyborgismo de Neil Harbisson a sinestesia é mais influente no processo de produção individual dos artistas do que, necessariamente, no resultado final apresentado. Nas obras que serão apresentadas a seguir ocorre o inverso: a sinestesia está latente, mas só pode ser experimentada a partir da interação com a obra, e pode ou não ser interpretada como sinestésica dependendo da percepção e do grau de engajamento do usuário. $\mathrm{O}$ mecanismo comum na maioria dos trabalhos selecionados está na proposta oferecida pela tecnologia de conexão entre a ação do usuário (estímulo) e as respostas automáticas em modalidades distintas, pré-determinadas pela programação. Esta conexão cria um sistema input e output, que de certa forma simula a conexão entre áreas cerebrais que ocorre no sinesteta.

15 Informações recolhidas de seu site e de seu TEDTalk. Disponíveis em: <http://www.harbisson.com/> e

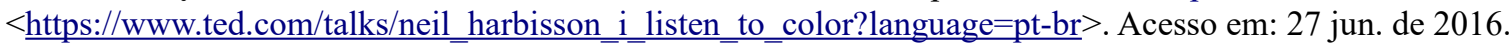




\subsection{O corpo como potencializador sinestésico}

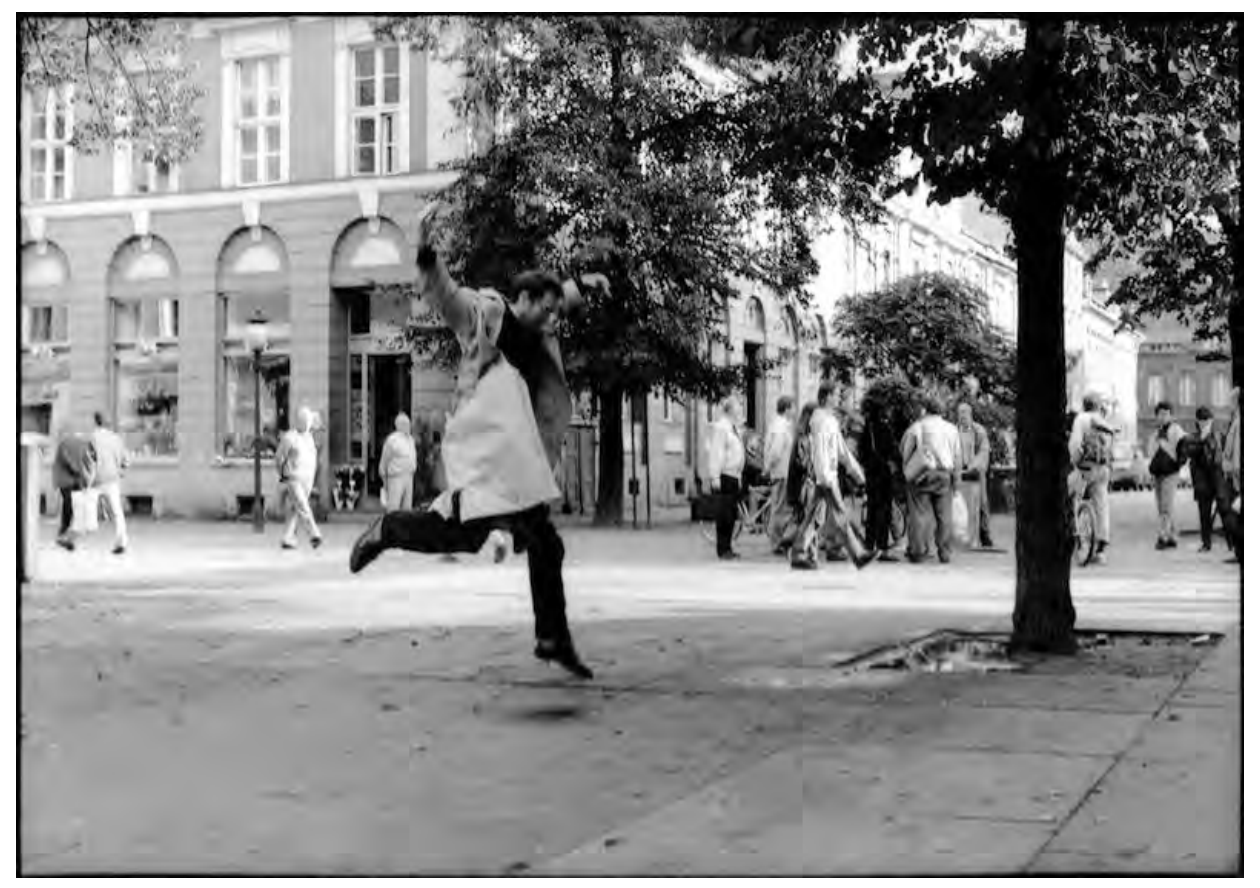

Figura 10: Foto de montagem de Very nervous System, de Rockeby, em uma rua de Postdam, 1993. Disponível

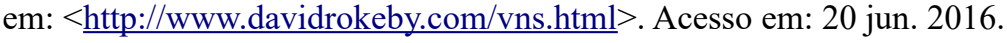

Very Nervous System ${ }^{16}$ (1986-1990) de David Rockeby é um trabalho emblemático que une corpo e som. A obra - que já foi apresentada como instalação e como performance em diferentes ocasiões - utiliza câmeras de vídeo, processamento de imagem, sintetizadores e sistemas de amplificação sonora para preparar um espaço no qual movimentos do corpo geram sons ou música. Cria-se, dessa forma, uma interface invisível e expandida no espaço físico, onde a movimentação corporal e os sons que são associados a ela se retroalimentam esteticamente.

A experiência direta entre movimento e som incentiva a fruição intuitiva da obra, e somente a prática faz conhecer as associações entre os movimentos corporais específicos e as respostas sonoras desencadeadas. A amplitude, o ritmo e a localização espacial do indivíduo perante a

16 Descrição da obra pelo artista e vídeos disponíveis em: $<$ http://www.davidrokeby.com/vns.html $>$. Acesso em 28 jun. 2016. 
câmera, por exemplo, influenciam a leitura e a interpretação computacional do movimento. $\mathrm{O}$ aprofundamento da propriocepção corporal em resposta (e em busca) dos sons gerados possibilita a criação de pontes sensoriais sinestésicas entre os sentidos, tanto para quem realiza o gesto quanto para quem observa o processo de reconhecimento da obra. Durante o processo, o corpo passa a ter e receber novos sons e se adapta perceptivamente a eles.

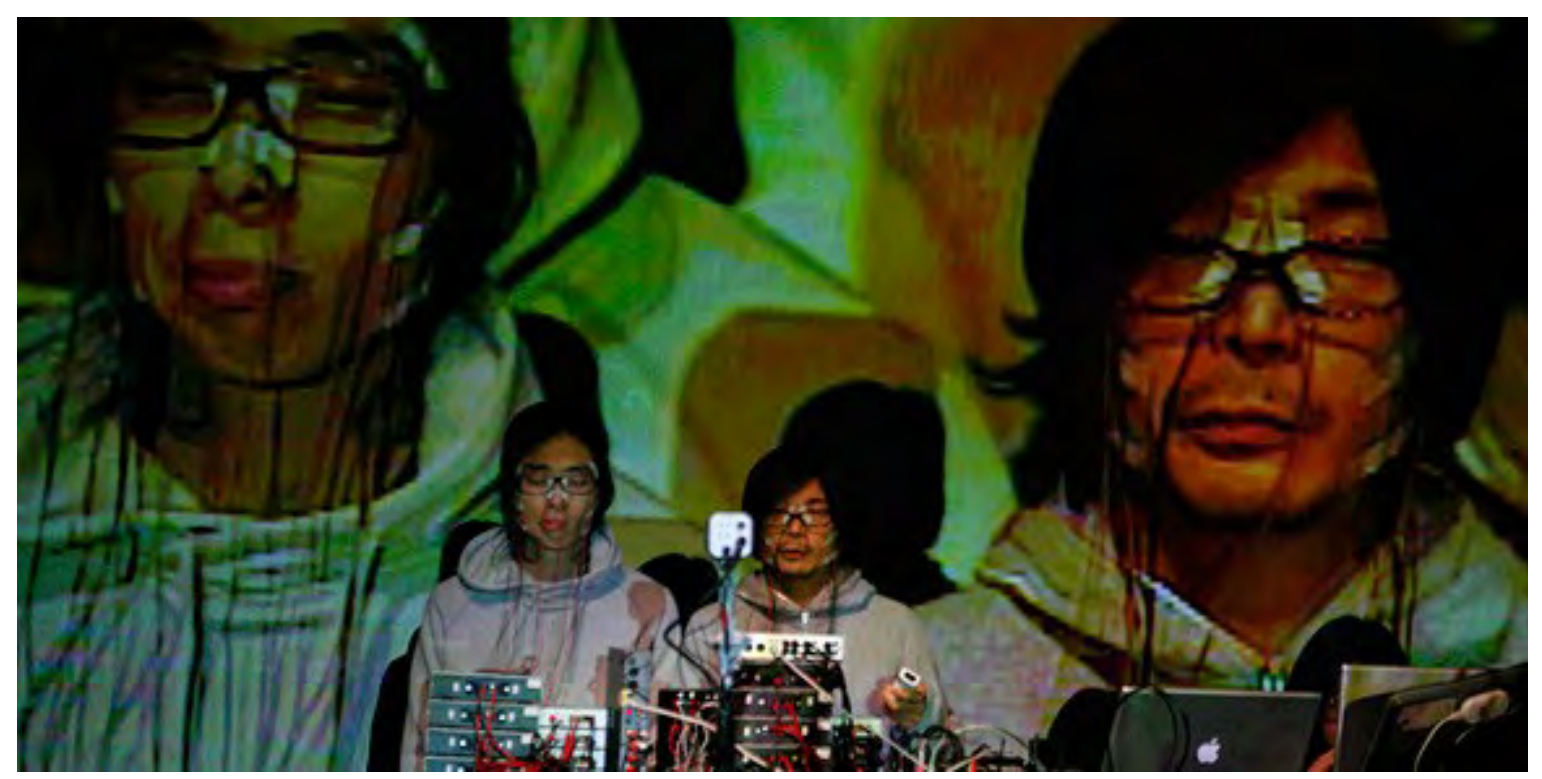

Figura 11: Foto documentando a performance de Face Visualizer/Face Instrument na Harajuko Performance Plus(+) em Tóquio, 2008. Disponível em: $<$ http://www.daito.ws/en/work/smiles.html $>$. Acesso em 20 jun. 2016.

A obra Face Visualizer/Face Instrument (2008) de Daito Manabe (som e programação), em parceria com Taeji Sawai (design sonoro), Masaki Teruoka e Katsuhiko Harada (design e implementação do dispositivo) é composta por dispositivos eletrônicos que estimulam eletricamente os músculos da face dos performers em sincronia com a composição sonora eletrônica, que é tocada de acordo com a programação. Manabe declara que a ideia para a obra surgiu a partir de uma conversa com seu colaborador, Teruoka, que categoricamente afirmou a impossibilidade de criar um sorriso verdadeiro no rosto de indivíduos somente com estímulo elétrico sobre os músculos faciais, sem que exista emoção humana. Outras referências para o trabalho são as pesquisas de G. B. Duchenne, divulgadas em "Mecanismos da fisionomia humana", e o trabalho Ping Body de Stelarc. Na obra, cria-se uma situação na qual ocorre a cópia ou o espelhamento de movimentos faciais de um indivíduo ao outro de 
acordo com o som ${ }^{17}$ por intermédio de sensores mioelétricos e geradores de pulso de baixa frequência. Em contraposição à ideia do corpo como estímulo para o sinal sonoro, propõe-se o estímulo elétrico direto dos músculos correlacionado a dados sonoros, proporcionando uma espécie de sinestesia artificial induzida.

A instalação OP_ERA: Haptic Wall (2004), de Daniela Kutschat e Rejane Cantoni, é composta por uma parede projetada para gerar estímulos táteis a partir de sons captados por microfones. A parede é revestida por uma pele artificial (látex natural) que contém embutida em sua estrutura uma matriz de atuadores, e é ativada de acordo com os registros captados dentro e fora do espaço expositivo. A parede se torna uma interface que induz o contato físico do público, possibilitando uma experiência sensível da relação entre o tátil e o audível.

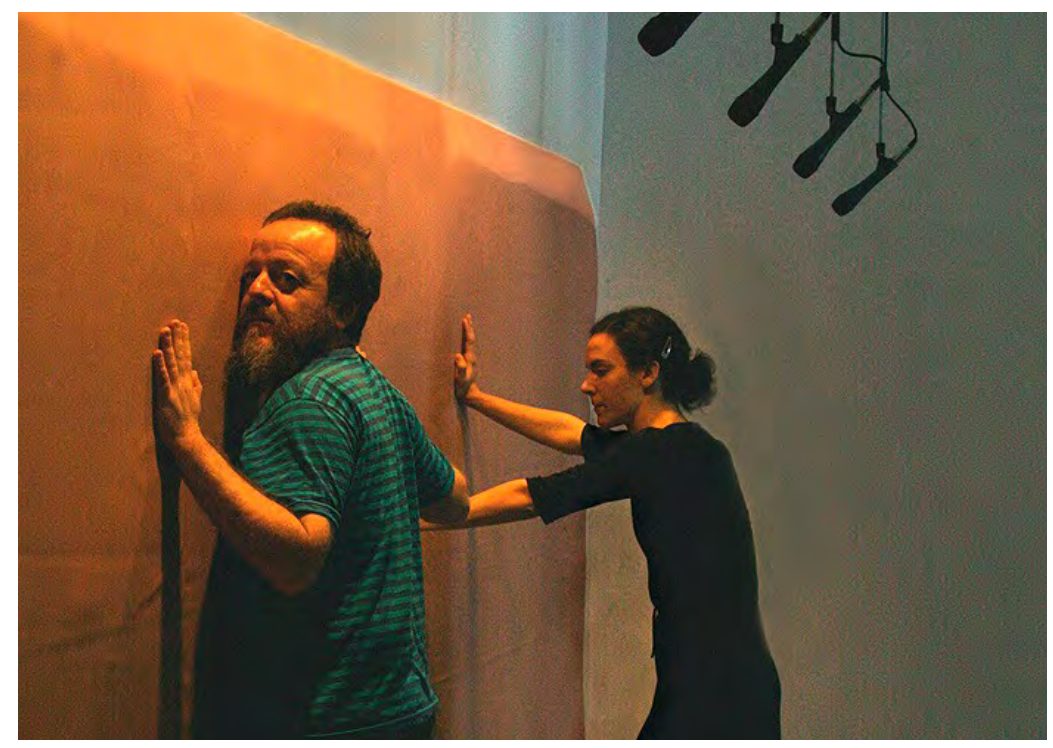

Figura 12: OP_ART : Haptic Wall de Daniela Kutschat e Rejane Cantoni, instalação que transforma sons do ambiente em respostas táteis. Fonte: (GONTIJO, 2013, p.104).

Os três trabalhos descritos apresentam exemplos de diferentes abordagens na utilização do corpo como potencializador de associações multissensoriais em obras artísticas com intermediação tecnológica. As obras apresentam possibilidades sinestésicas latentes que

17 Vídeos documentando testes e o funcionamento desse trabalho estão disponíveis em: $<$ https://www.youtube.com/watch?v=pLAma-lrJRM $>\quad$ e $\quad<$ https://www.youtube.com/watch? $\underline{\mathrm{v}=\text { CvmE4TZfeuo }}>$. Acessos em 27 jun. 2016. 
dependem da presença corporal do público para serem ou não totalizadas. A ação do corpo e sobre o corpo abre portas para construções perceptivas pelo indivíduo, criando a oportunidade de experimentar sensações sinestésicas não por intermédio de sinapses cerebrais, mas de impulsos eletrônicos que relacionam artificialmente dois ou mais sentidos.

\subsection{Do sopro à fala: a voz como mediação}

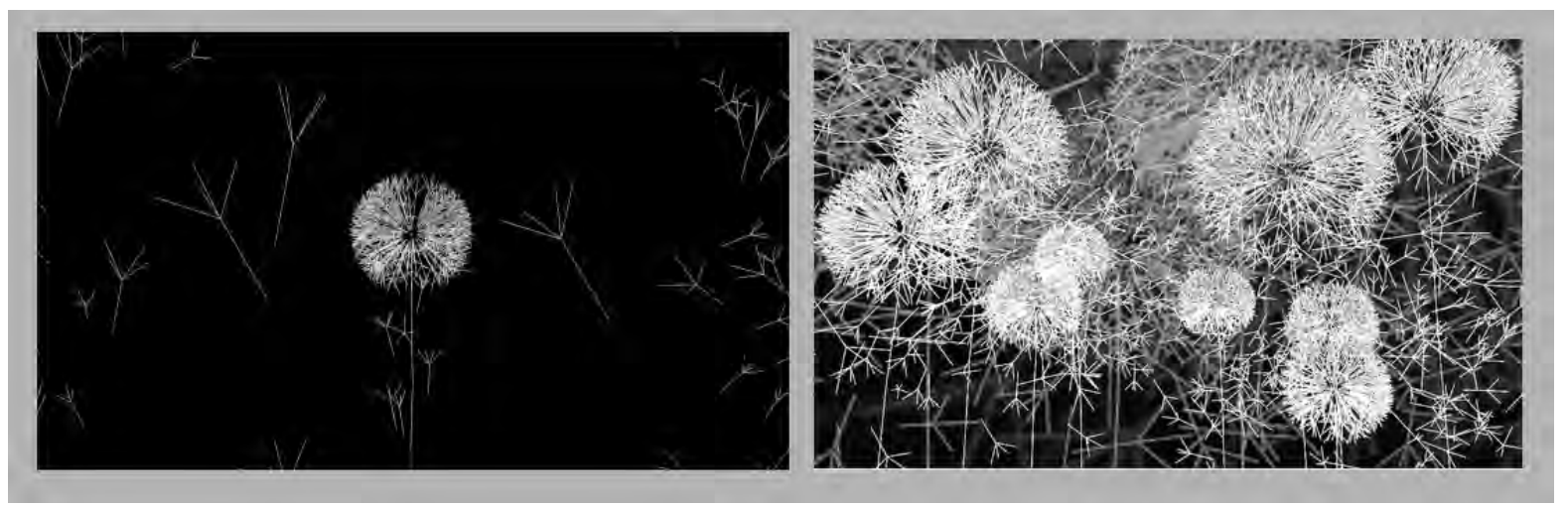

Figura 13: Imagem de La Plume (1988) à esquerda, e a versão múltipla de Les Pissenlits (2005) à direita. Disponíveis em: <http://www.multimedialab.be/doc/images/index.php?album=art-numerique\%2Fbiologicalsystems-models-and-

algorithms\&image=1996_Edmond_Couchot_and_Michel_Bret_Le Pissenlit 1996 03.jpg\&p=*full-image $>$ e $<$ http://www.numeriscausa.com/pages/artistes/couchot/pissenlits.html $>$, respectivamente. Acesso em 25 jun. 2016 .

Les Pissenlits $^{18}$ (2005), de Edmond Couchot e Michel Bret, é uma instalação interativa na qual nove representações artificiais de dentes-de-leão respondem à intensidade do sopro do visitante. Estimula-se o público a assoprar sobre os microfones próximos da projeção, devido à natureza evocativa da flor que, sabidamente, desmancha-se ao vento para dispersar suas sementes em forma de paraquedas. A obra propõe exatamente a simulação da dispersão das flores a partir do sopro do visitante, em tempo real, incluindo o controle da saída de ar como o agente ativo da interação. O trabalho La Plume (1988), dos mesmos artistas e precursor da instalação analisada, apresentou pela primeira vez essa perspectiva de interação.

18 Mais informações disponíveis em: $<$ http://www.arborescence.org/article441.html $>$. Acesso em: 20 jun. 2016. 
O trabalho Sopro/The Blow ${ }^{19}$ (2016) do grupo cAt (ciência/ARTE/tecnologia) também relaciona a ideia de controle da respiração e intensidade do sopro como forma de interação com a obra. A instalação é composta por uma grande estrutura esférica de acrílico preenchida com água, onde boiam pequenas esferas que protegem micromotores vibratórios elétricos. Os pequenos motores oscilam e agitam a água de acordo com a intensidade de sopro aplicada em três estruturas de madeira com hélices acopladas, que transformam energia mecânica (movimento desencadeado nas hélices pelo sopro) em energia elétrica. O mecanismo permite a visualização direta do sopro a partir da agitação da água, que traça um desenho por meio da sombra do líquido.

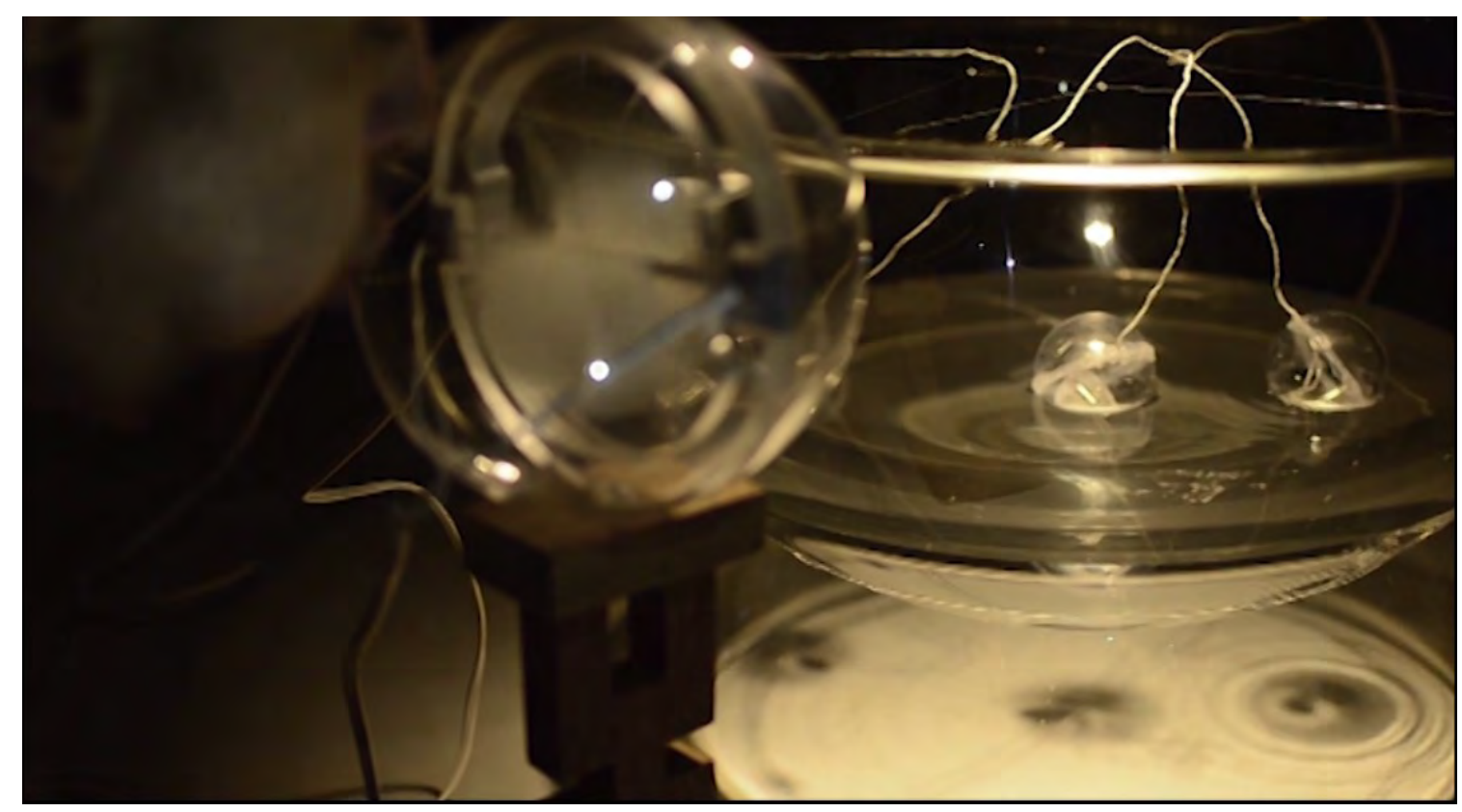

Figura 14: Instalação interativa Sopro/The Blow (2016) do grupo cAt. Frame do vídeo disponível em: $<$ https://vimeo.com/158800251 $>$. Acesso em: 20 jun. 2016.

Breathing (2010) de Guto Nóbrega também incentiva a interação do público por meio da respiração - como sugere explicitamente o título da obra. Contudo, a presença física da planta Jibóia (Epipremnum pinnatum), mesclada com sensores e uma estrutura mecânica aracnídea luminosa, modifica a fruição da obra. Ao misturar sistemas orgânicos e artificiais, Nóbrega cria uma conjuntura de retroalimentação entre os dados eletrofisiológicos monitorados, a 19 Vídeo explicando o funcionamento da obra disponível em: https://vimeo.com/158800251, acesso em 15 jun. 2016. 
interação do público, e a extrapolação das reações do vegetal ao ambiente pelas estruturas de fibra óptica e leds. O contato com a criatura híbrida de uma forma tão natural, a partir da respiração, explicita as relações que conectam processos naturais e artificiais. As mesmas relações ocorrem entre o ser humano e o mundo desde a mais antiga ferramenta inventada. A obra provoca questionamentos acerca das ações humanas e suas consequências no entorno, que cada vez mais apresenta a mistura entre orgânico e artificial.

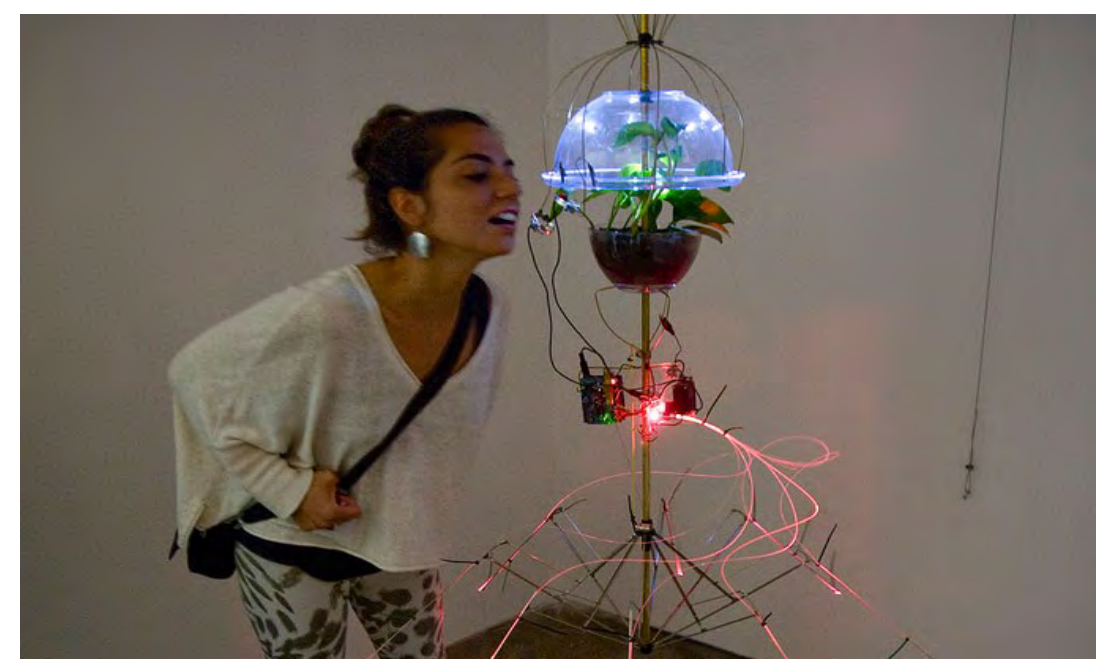

Figura 15: Interação pela respiração na instalação Breathing de Guto Nóbrega, 2010. Disponível em: $<$ http://file.org.br/interactive installation/guto-nobrega/?lang=pt> $>$. Acesso em 20 jun. 2016.

Um dos trabalhos que utiliza o sussurro como potencializador da imersão sensível do público é o vídeo Meus Passos ainda não foram dados ${ }^{20}$ (2012) de Sérgio Basbaum. Nele, o registro de um passeio por Amsterdã é acompanhado por questionamentos filosóficos em primeira pessoa. Este registro vai se desconstruindo continuamente em formas e movimentos borrados, e as perguntas/instruções se tornam cada vez mais pessoais para o ouvinte. A voz, sempre sussurrada, causa um efeito de intimidade, como se ela e o ouvinte compartilhassem um segredo, além de sugerir uma certa universalidade devido à qualidade soprosa da voz. $\mathrm{O}$ contraste entre a trilha sonora que aparece no início (Luciano Berio) e no final (Neil Young) parece conduzir de uma desorganização/procura a uma definição/organização, como se, ao longo da experiência e das perguntas pessoais, o interator pudesse se abrir à possibilidade de descobrir novos aspectos de si mesmo.

20 Vídeo disponível em: <https://vimeo.com/38563003>. Acesso em 20 jun. 2016. 


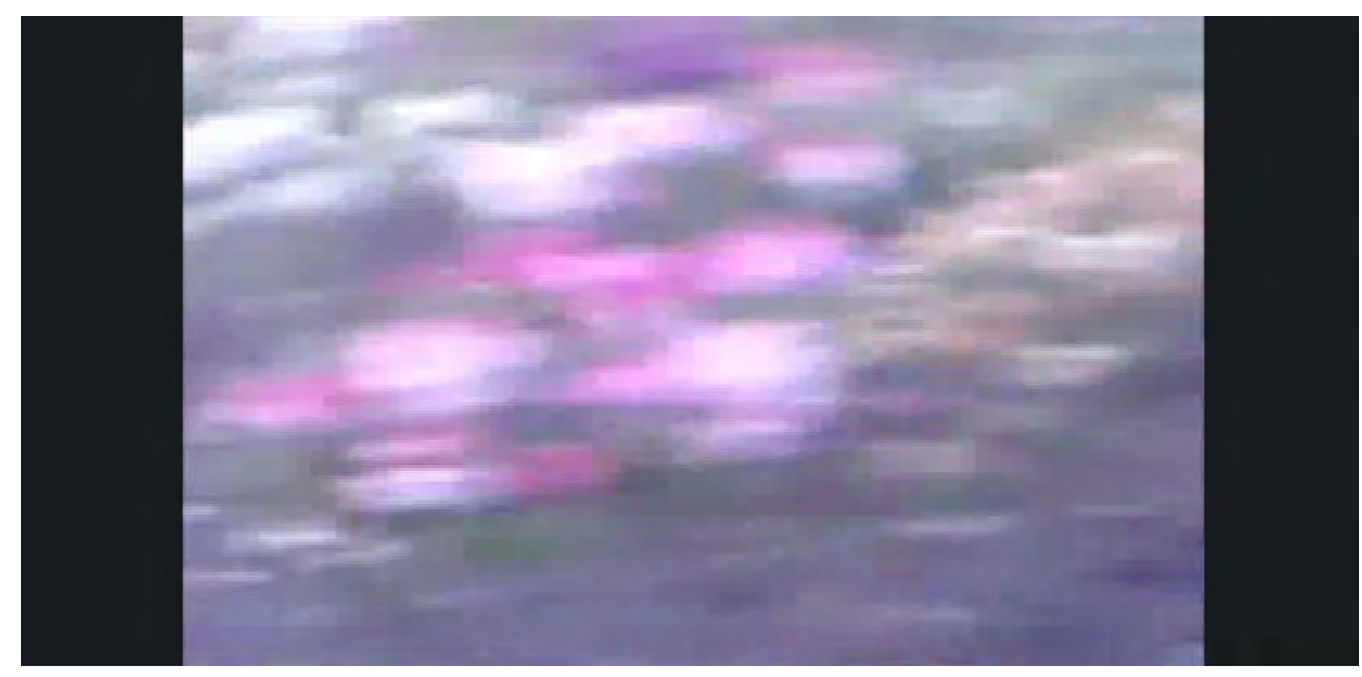

Figura 16: Frame do vídeo Meus passos ainda não foram dados de Sérgio Basbaum. Disponível em: $<$ https://vimeo.com/38563003 $>$. Acesso em 20 jun. 2016.

A voz falada e gravada também é utilizada em Voice Tunnel ${ }^{21}$ (2013), de Rafael LozanoHemmer. Esta instalação interativa de larga escala foi desenvolvida para ocupar o Park Avenue Tunnel durante o Summer Streets, quando o espaço fica disponível somente para pedestres. A celebração, que acontece anualmente em Nova Iorque, dispõe-se a ressignificar espaços da cidade a partir de eventos culturais, atividades esportivas e instalações artísticas. A obra é composta por 300 holofotes dispostos ao longo das paredes do túnel, desenhando abóbodas de luz na arquitetura local. Cada faixa de luz é composta por dois holofotes, que permitem a visualização da velocidade e do ritmo das gravações de voz deixadas pelo público como em um código morse. No meio do túnel posiciona-se o intercomunicador responsável pelas gravações. Os registros vão se locomovendo do centro para as extremidades da galeria, sendo reproduzidos em loop por alto-falantes que acompanham a variação luminosa de cada uma das abóbodas.

Novas participações originam gravações que sucedem e algumas vezes dialogam com as antigas, destacando, dessa forma, questões como memória coletiva, voz popular, redes sociais, redes de informações e bases de dados. A obra proporciona uma estreita relação entre os

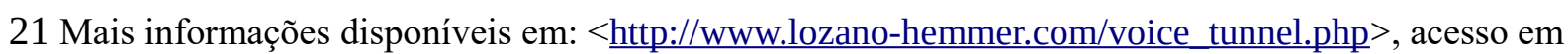
jun. 2016. 
sentidos visual e auditivo no ambiente coletivo, incentivando diálogos livres que transpassam linguagens.

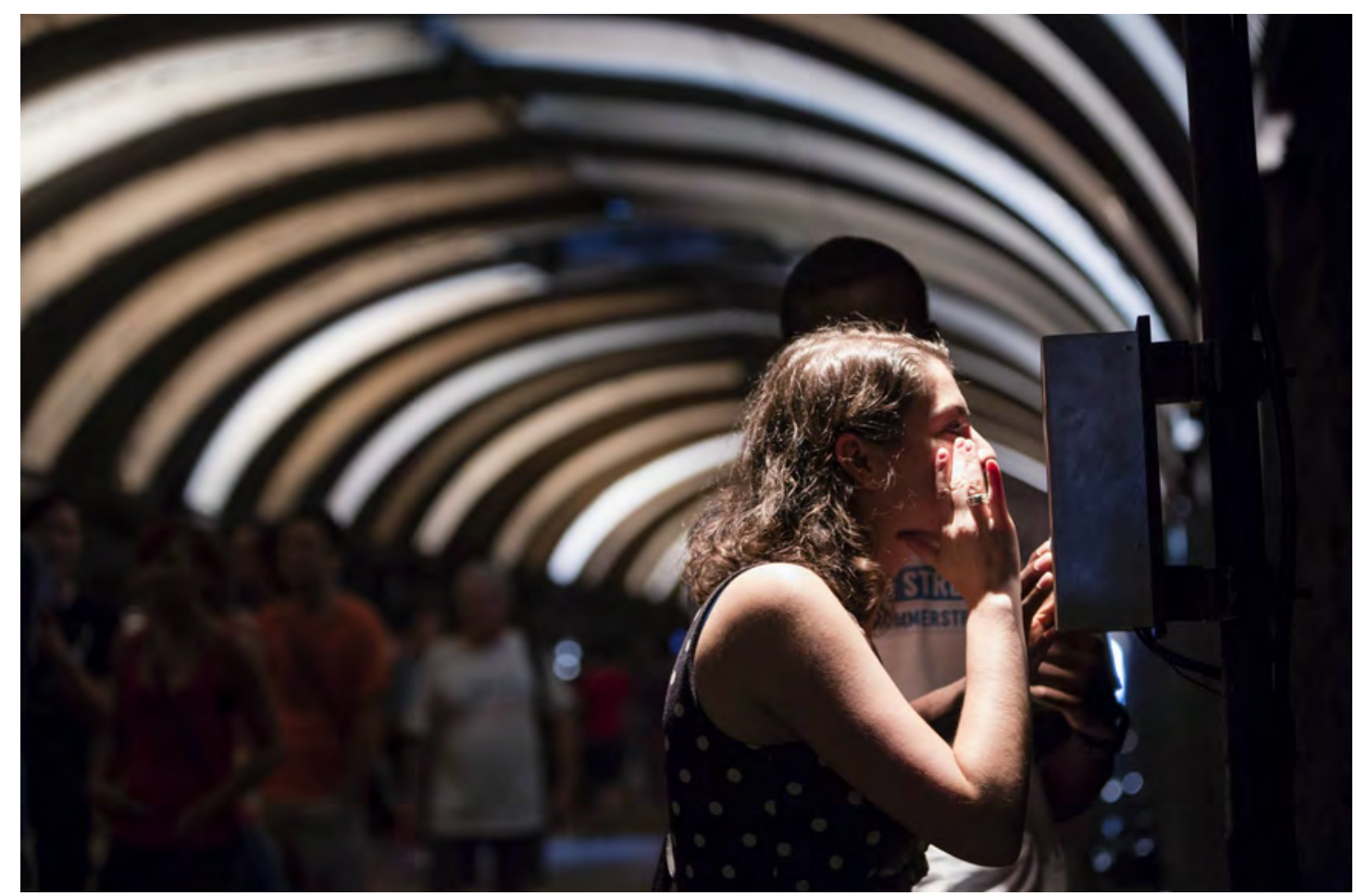

Figura 17: Interação com a instalação Voice Tunnel em Nova York, durante o Summer Streets de 2013. Disponível em: $<$ http://www.lozano-hemmer.com/showimage.php? $\underline{i m g=\text { newyork } 2013 \& \text { proj }=284 \& \text { type }=\text { artwork } \& i d=46>}$. Acesso em 20 jun. 2016.

Outro trabalho que destaca a qualidade espacializada da voz é Murmur ${ }^{22}$ (2014), obra coletiva dos estúdios Chevalvert, 2Roqs, Polygraphik e Splank. Na instalação é disponibilizada uma prótese arquitetônica que permite a comunicação entre voz (intensidade sonora captada) e o mural, a qual está ligada por uma estrutura que remonta a ideia de cordão umbilical. $\mathrm{O}$ estímulo sonoro, captado pela "câmara de eco" (interface em forma de caixa construída para captar o som dos transeuntes) ativa lâmpadas de led enfileiradas em um tubo que se conecta à parede. A luminosidade se expande e se espalha em abstrações luminosas que simulam o movimento de ondas sonoras na superfície da parede. Criam-se visualizações das vozes no espaço expositivo, intermediadas pela captação e simulação tecnológicas.

22 Disponível em: $<$ http://file.org.br/interactive installation/chevalvert-2roqs-polygraphik-splank/?lang=pt $>$. Acesso em 16 jun. 2016. 
Uma das obras pioneiras na utilização da voz captada por microfone para gerar diretamente formas visuais é a Participatory TV (1969), de Nam June Paik. Nesta instalação, formas coloridas abstratas apresentadas por uma televisão de tubo são modificadas de acordo com o som captado por dois microfones. As linhas desenhadas no aparelho variam de acordo com as nuances vocais de frequência e intensidade dos dois participantes, permitindo a interação simultânea entre o duo de vozes e as linhas coloridas das imagens. A montagem de 1969 é uma versão mais elaborada do trabalho de $1963^{23}$, que possuía menos cores e só dispunha de um microfone. Pela primeira vez, apresentou-se uma proposta de relação imediata entre voz, linhas abstratas e cor, abrindo a possibilidade sinestésica de visualização artificial da voz.

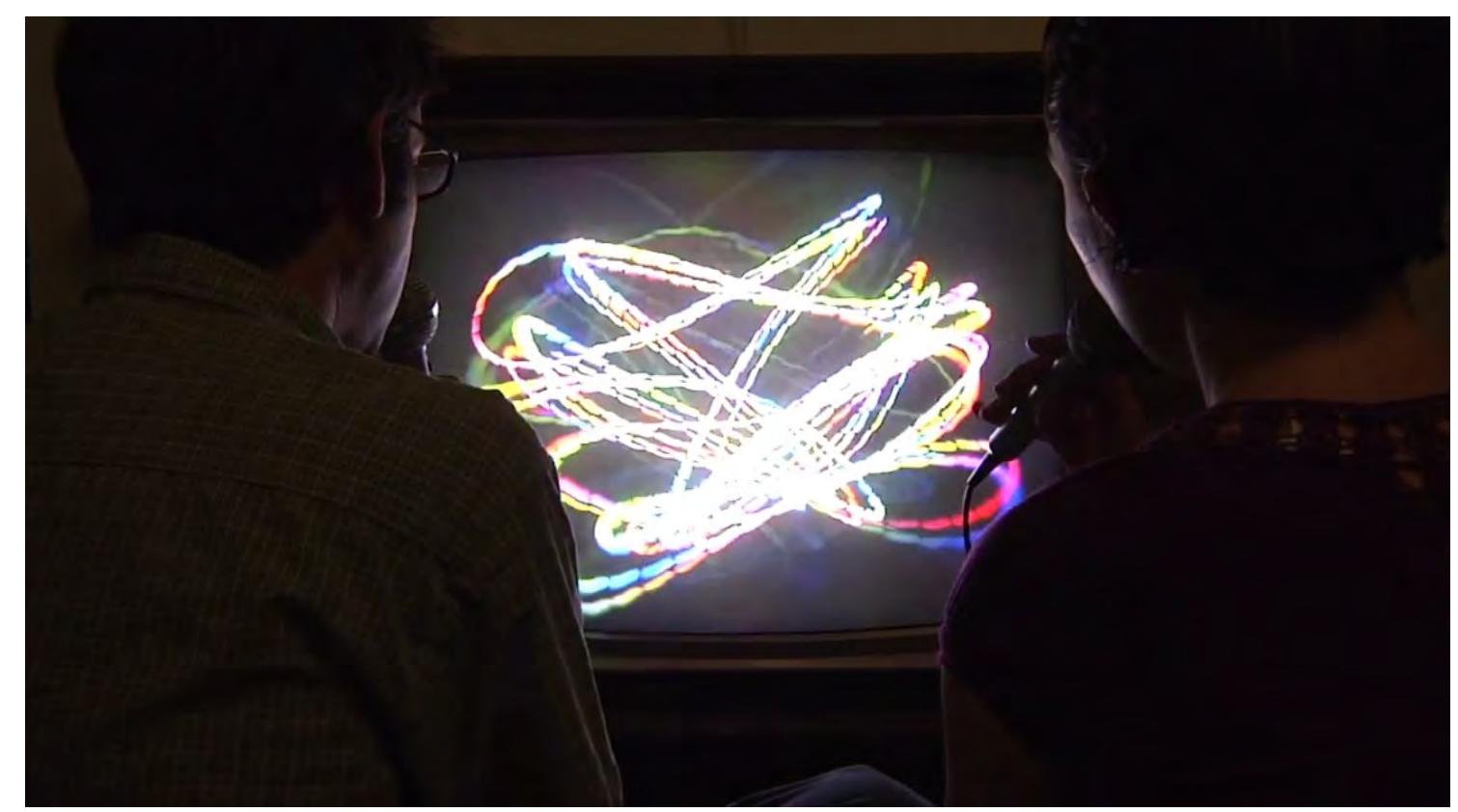

Figura 18: Documentação contemporânea da instalação Participatory TV de Nam June Paik (1969). Frame do

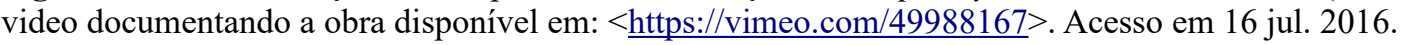

Messa Di Voce (2003), de Golan Levin e Zach Lieberman dão continuidade à ideia de visualização vocal a partir da criação e controle diretos de conteúdos visuais por estímulos vocais. O nome do trabalho faz referência ao termo em italiano utilizado no estudo do canto erudito Messa Di Voce (Colocação Vocal, em português). Este termo denomina o ponto de ressonância da voz nos ossos da face que o cantor deve encontrar para melhor projetar sua voz

23 Mais detalhes disponíveis em: $<\underline{\text { http://www.medienkunstnetz.de/works/participation-tv/images/2/>. }}$ Acesso em 15 jul. 2016. 
para a audiência sem auxílio de microfones. A obra permite que o interator encontre estímulos visuais diversos, associados a diferentes colocações de voz.

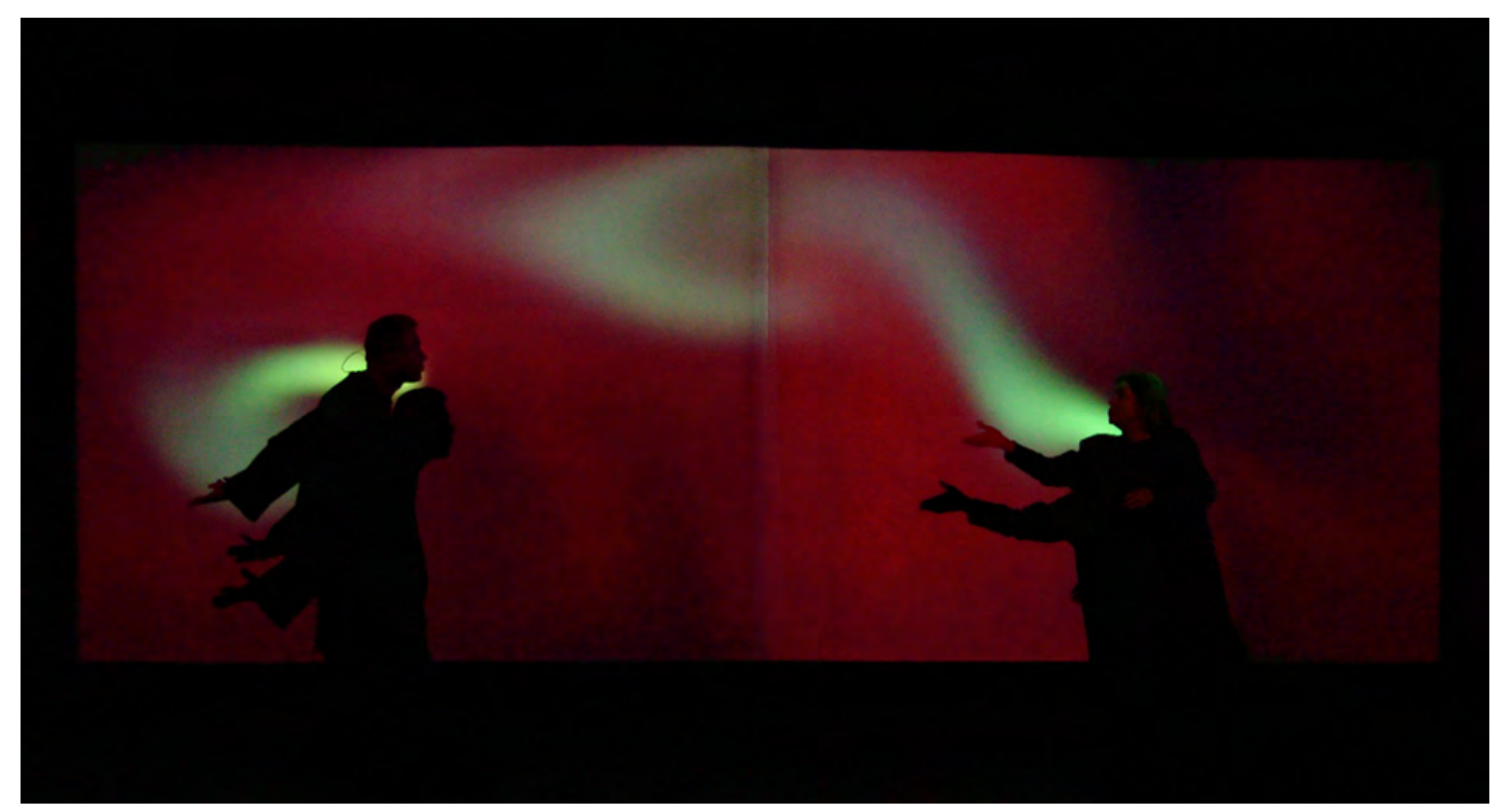

Figura 19: Performance realizada com o modo fluids de Messa di Voce, performers: Jaap Blonk e Joanna La Barbara, 2003. Imagem disponível em: $<$ http://www.tmema.org/messa/img/messa_fluid ica 1698.jpg $>$. Acesso 20 jun. de 2016.

A obra foi apresentada em vários módulos, onde cada módulo oferece uma tradução visual diferente para o estímulo vocal: linhas que desenham, círculos que ricocheteiam, cores e texturas que fluem, etc. Os módulos utilizam tecnologias variadas, tanto de captação sonora e análise da fala, quanto de rastreamento de movimento. Uma série de apresentações do trabalho foi realizada pelos performers Jaap Blonk e Joan La Barbara em 2003, que demonstraram as diversas possibilidades de relação entre voz e imagem proposta pela instalação.

A pequena seleção de trabalhos apresentados nesta seção teve como objetivo demonstrar algumas possibilidades de abordagem entre a voz, compreendida de forma ampla como o resultado do equilíbrio entre a força do ar que saí dos pulmões e a força muscular da laringe (VALENTE,1999, p.128), e correspondência visuais. A potência sinestésica de relação direta 
entre vocalidade e visualidade é mais evidente em algumas obras do que em outras, principalmente quando a proposta do artista é direcionada mais para a correlação entre as propriedades da voz e elementos visuais, como em Participatory TV, Mesa Di Voce, Murmur, Sopro/The Blow e Les Pissenlits, do que quando são abordadas também outras questões a partir do estímulo vocal, como em Voice Tunnel, Breathing e Meus Passos ainda não foram dados. No segundo caso, os artistas usam as características materiais da voz e toda carga emocional e simbólica que ela carrega como matéria poética. 


\section{TRABALHOS EXPERIMENTAIS}

Foram realizados três trabalhos experimentais que abordam a ideia de sinestesia durante o mestrado. Os dois primeiros foram realizados coletivamente, enquanto o último de forma individual. A descrição e documentação de cada um dos trabalhos serão abordados nas próximas seções.

\subsection{Projeto Híbrida: $\mathrm{Syn}^{2}$ - Simulador de Sinestesia}

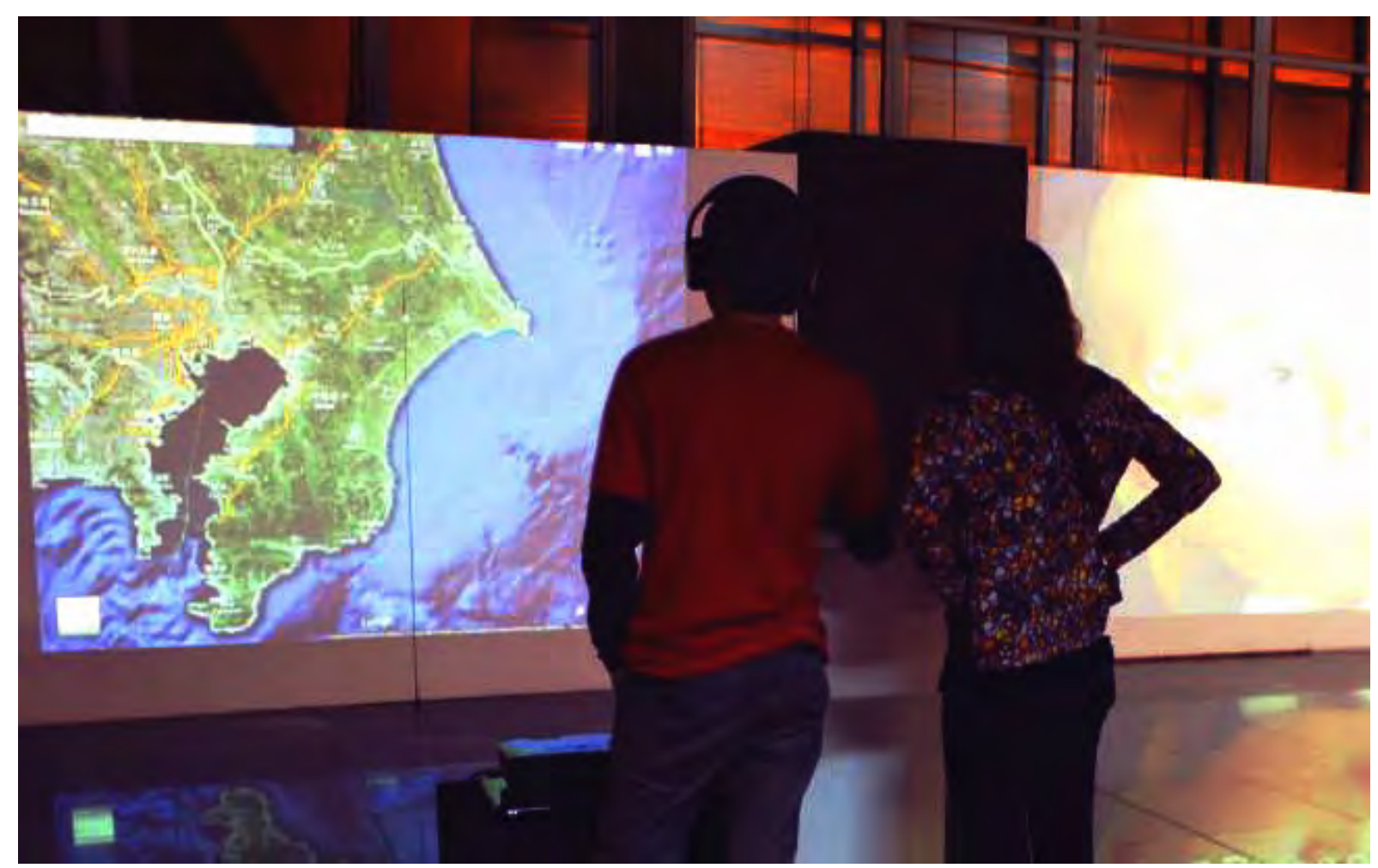

Figura 20: Documentação da primeira montagem de Syn²-Simulador de Sinestesia em 2014. Autoria própria.

O Simulador de Sinestesia: a.k.a Syn ${ }^{2}$ propõe a interação entre visão e audição, espaço e tempo, virtual e atual através da tradução de imagens do Google Maps em sínteses sonoras. A simulação de conexões sinestésicas estabelecidas entre cor e som proporciona a criação de novas relações de identidades entre sujeito, espaço real e virtual. O sistema de funcionamento da instalação baseia-se na análise da cor, saturação e brilho das imagens por códigos computacionais da linguagem de programação Processing. 
Os dados analisados são armazenados temporariamente e convertidos em tempo real em sons midi sintetizados. Cada cor (especificamente, cinza, violeta, azul, verde, amarelo, laranja e vermelho) recebe a sonoridade de um timbre distinto, enquanto a relação entre o brilho e a saturação determinam, respectivamente, a altura (grave ou aguda) e intensidade (forte ou fraca) do som gerado.

A interação com a obra pressupõe um tempo de aprendizagem para que o público possa reconhecer o timbre de cada cor e a relação sinestésica se estabeleça de fato. A escolha da localidade e do ponto de vista do que se pretende "ouvir" permite uma grande combinação de sonoridades e até, em alguns casos, o controle composicional da sequência sonora pelo usuário. O sistema criado baseia-se na interdependência entre: a) escolha individual; b) reconhecimento das relações sinestésicas; c) disponibilidade virtual do espaço (controlado pelas relações políticas e econômicas da empresa Google com o resto do mundo) e d) a velocidade da rede de internet disponível, que pode limitar ou expandir o ritmo da navegação. O trabalho foi desenvolvido por: Rafael V. Ribeiro, Loren Bergantini, Vinicius Franulovic, Gloria Fernandes e Alex Tso a partir do projeto "Simulador de Sinestesia ${ }^{24 ",}$, concebido e enviado por Rafael V. Ribeiro e selecionado como um dos trabalhos práticos a serem realizados dentro do projeto Híbrida.

O projeto Híbrida - prototipagem experimental de ampliadores de percepção ${ }^{25}$ foi idealizado e organizado por Paloma Oliveira e Jaime Lobato, com apoio da Universidade de São Paulo (USP) e a Universidad Nacional Autónoma de México (UNAM). Este projeto propôs uma abordagem teórico-prática sobre a ampliação das percepções humanas, a partir da exploração e reflexão artísticas sobre técnicas e dispositivos que oferecessem conexões entre corpo e tecnologia. O debate teórico sobre o tema ocorreu a partir de uma série de conferências de palestrantes convidados que ocorreram semanalmente entre 21 de março a 12 de abril em São Paulo, e entre 23 de maio e 27 de junho na Cidade do México. Já a abordagem prática foi 24 O projeto inicial de Simulador de Sinestesia pode ser encontrado em anexo. Mais informações sobre o projeto disponíveis em: $<$ https://garoa.net.br/wiki/Hibrida/Simulador_de_Sinestesia $>$. Acesso em: 15 jul. 2016.

25 Mais informações sobre o Projeto Híbrida estão disponíveis em:

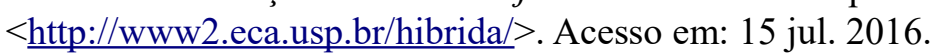


iniciada com uma chamada pública de projetos, seguida por uma segunda chamada de colaboradores que se inscreviam para contribuir com a realização de cada projeto, tanto no Brasil quanto no México. Os laboratórios de prototipagem que cederam espaço para a realização dos projetos selecionados se localizavam no InovaLab da POLI/USP em São Paulo e no Laboratório de Pós graduação de Desenho Industrial da UNAM, na Cidade do México.

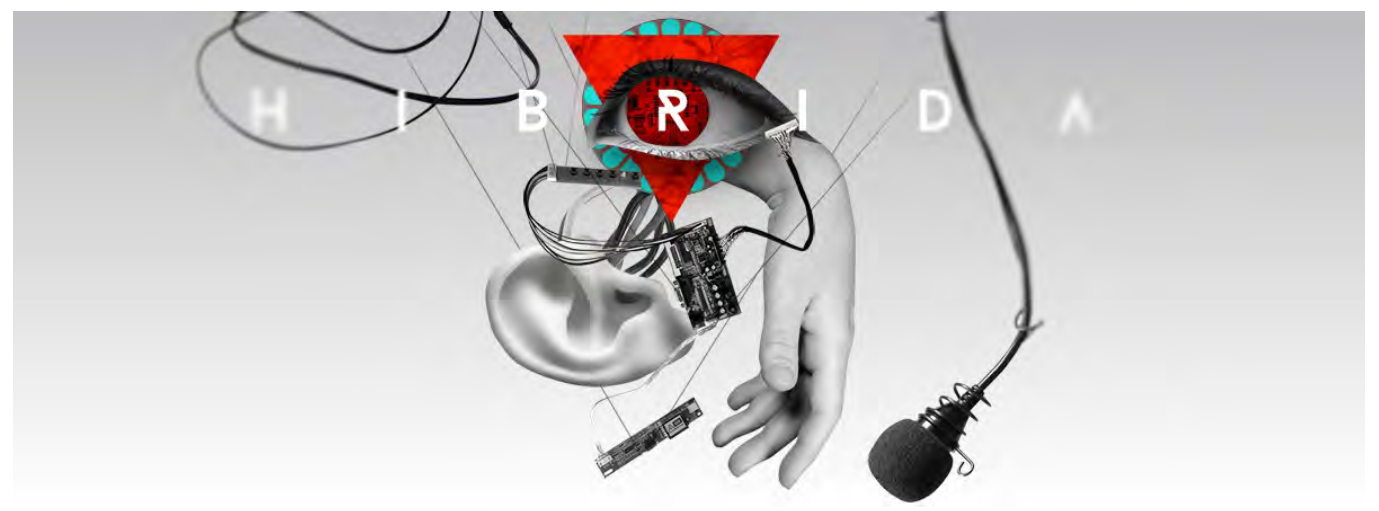

Figura 21: Imagem de divulgação do Projeto Híbrida, que ocorreu entre 17 de março a 28 de julho de 2014 em parceria com a Universidade de São Paulo (USP-Brasil) e Universidad Nacional Autónoma de México (UNAMMéxico). Imagem disponível em:<http://www2.eca.usp.br/hibrida/> . Acesso em: 20 jul. 2016.

A proposta inicial do Simulador de Sinestesia, selecionada para o Hibrida, tinha como objetivo desenvolver um dispositivo portátil para ser usado sobre a cabeça, possivelmente em formato de óculos, que obtivesse as informações referentes ao movimento da pupila do usuário e comparasse o foco de atenção do interator às imagens do campo de visão também captados por uma câmera de vídeo. Com base nestes dados, seriam gerados feedbacks sonoros, simulando relações sinestésicas entre as imagens visualizadas e sonoridades prégravadas enquanto a pessoa caminhasse.

O grupo do $S y n^{2}$ realizou dois encontros por semana entre os dias 17 de março e 2 de maio de 2014 (total de doze encontros) no laboratório Inovalab da Escola Politécnica da USP. Neste trabalho, o grupo também contou com o apoio de Paloma Oliveira, Jaime Alonso e Pedro Pessoa. As primeiras reuniões focaram na pesquisa teórica sobre o tema, na discussão do projeto, nas possibilidades de linguagem de programação, e nas necessidades de hardware para implementação prática. 
Devido às dificuldades técnicas e limite de tempo, o grupo decidiu simplificar o projeto e apresentar um protótipo que fosse o mais coeso possível. Focamos inicialmente na pesquisa sobre visão computacional, identificando quais dados de imagens capturadas por webcams no Processing e quais parâmetros seriam relacionados aos sons, com o objetivo de criar a base de programação que representava a ideia principal do projeto: a sinestesia.

Encontramos algumas dificuldades com o desenvolvimento da programação, pois poucas pessoas no grupo tinham uma base sólida na atividade. Tentamos trabalhar com o Super Collider para desenvolver o som a partir de ondas senoides simples sobrepostas. No entanto, acabamos convergindo para a solução de utilizar sons midi, que poderiam fornecer um banco de dados de timbres mais variado e de forma mais rápida.
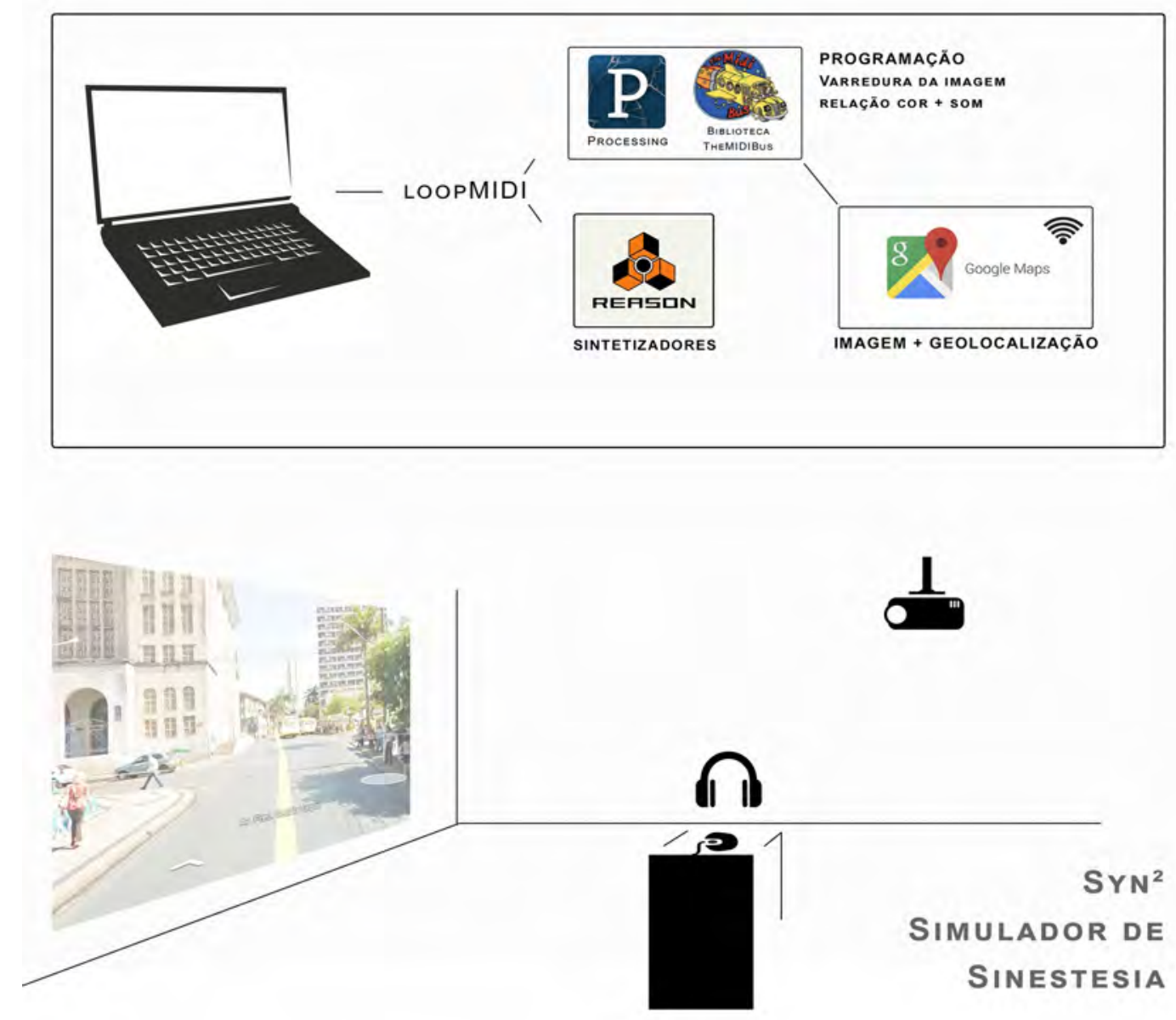

Figura 22: Esquema de montagem do protótipo do Simulador de Sinestesia a.k.a Syn². Autoria própria. 
Conseguimos resolver a compatibilidade e manejamento dos sons midis a partir dos softwares loopMIDI (reconhecimento dos sons midi do Reason pelo Windows e Processing), do Propellerhead Reason (armazenamento e manipulação dos sons sintetizados) e da biblioteca para Processing: The Midi Bus (intermediação entre a programação do Processing e o Reason). Inicialmente, pesquisamos a implementação do eyetracking no projeto. No entanto, devido a limitações técnicas e de tempo, adaptamos a ideia de escolha geográfica e passeio (que existia com a ideia de portabilidade do projeto inicial) com a utilização do Google Maps, onde utilizamos dados do Google Streetview e a varredura da própria tela para obter informações de cor sobre os locais escolhidos. Um desenho esquemático da montagem do protótipo de Simulador de sinestesia pode ser observada na Figura 22.

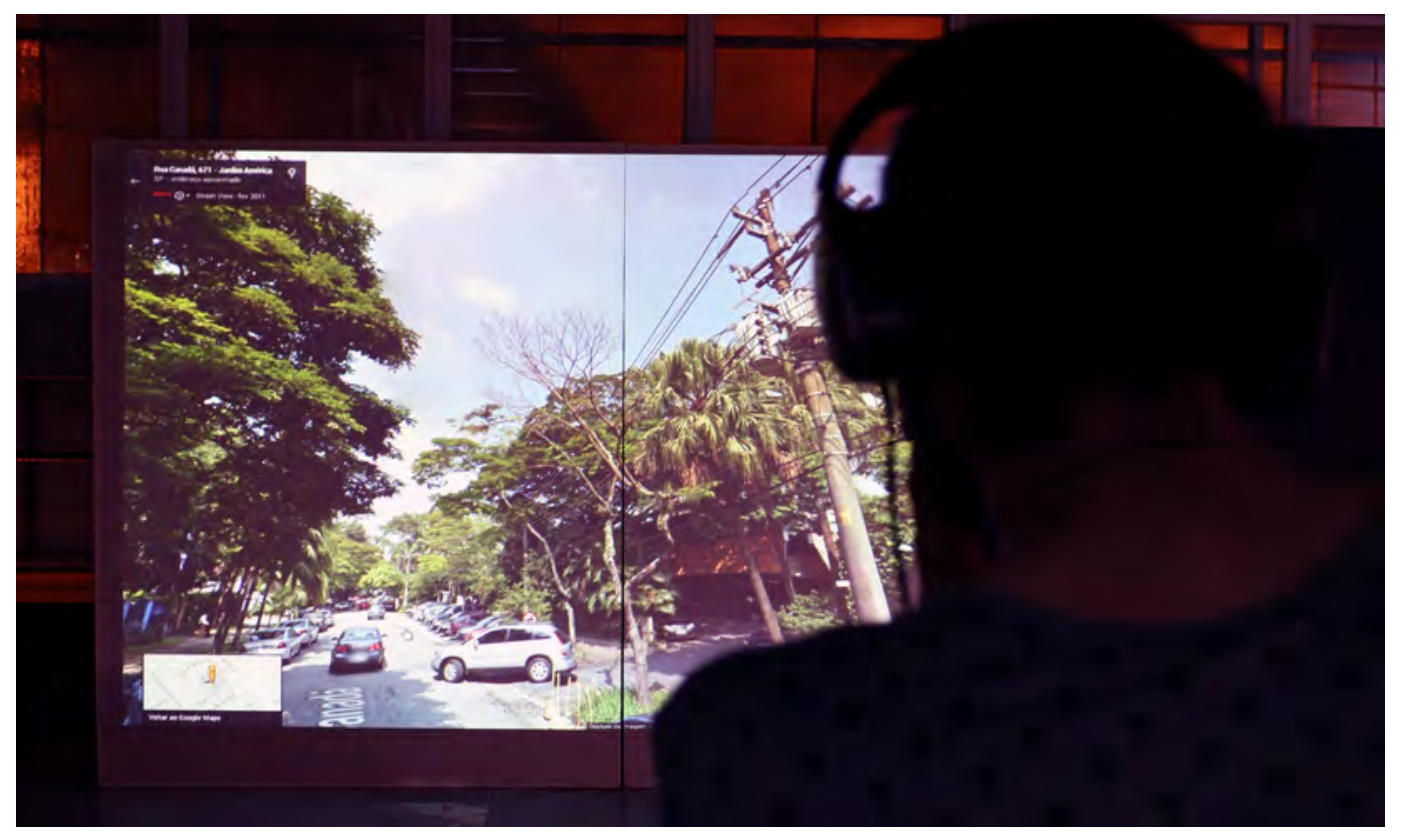

Figura 23: Interação com o protótipo de Simulador de Sinestesia na montagem da Exposição "Hibrida: Exposição e Performances" (2014). Autoria própria.

Discutimos bastante sobre quais parâmetros musicais seriam relacionados a quais parâmetros das imagens. Dada a utilização dos midis e sua extensa biblioteca, optamos por estabelecer um timbre para cada cor. Mais especificamente, determinamos visualmente os valores RGB que representariam as cores: cinza, violeta, azul, verde, amarelo, laranja e vermelho. A seguir, incluímos os valores de luminosidade e saturação do pixel para se relacionar à frequência e à intensidade, respectivamente, do sintetizador acionado. Como decidimos por utilizar o Google Streetview para uma melhor fruição da obra, adaptamos a leitura dos pixels para a tela 
em full screen. A versão final do protótipo ${ }^{26}$ foi montada na exposição coletiva dos trabalhos do Híbrida, realizada no dia 30 de abril de 2014 na Galeria do Instituto de Artes da Universidade Estadual de São Paulo, sob o título: Hibrida: exposição e performance.

A inclusão do Google Streetview conseguiu resolver satisfatoriamente a ideia de utilizar espaços geograficamente localizados para a discussão da obra, e trouxe o questionamento de até que ponto essas imagens realmente apresentam os espaços reais, e quais as influências políticas da empresa que permitem ou não o mapeamento dos espaços do globo. Como não tivemos tempo para implementar o eyetracking, não pudemos identificar o foco de visão do interator. Por isso, algumas vezes os sons pareciam um pouco dissociados da imagem, a não ser que se escolhessem locais com cores bem marcantes e houvesse tempo hábil para reconhecer quais timbres estavam associados com cada cor, para que realmente fosse simulada uma experiência sinestésica.

\subsection{Grupo Realidades: Enigma 3.1 - Ф: Um enigma para Gibson}

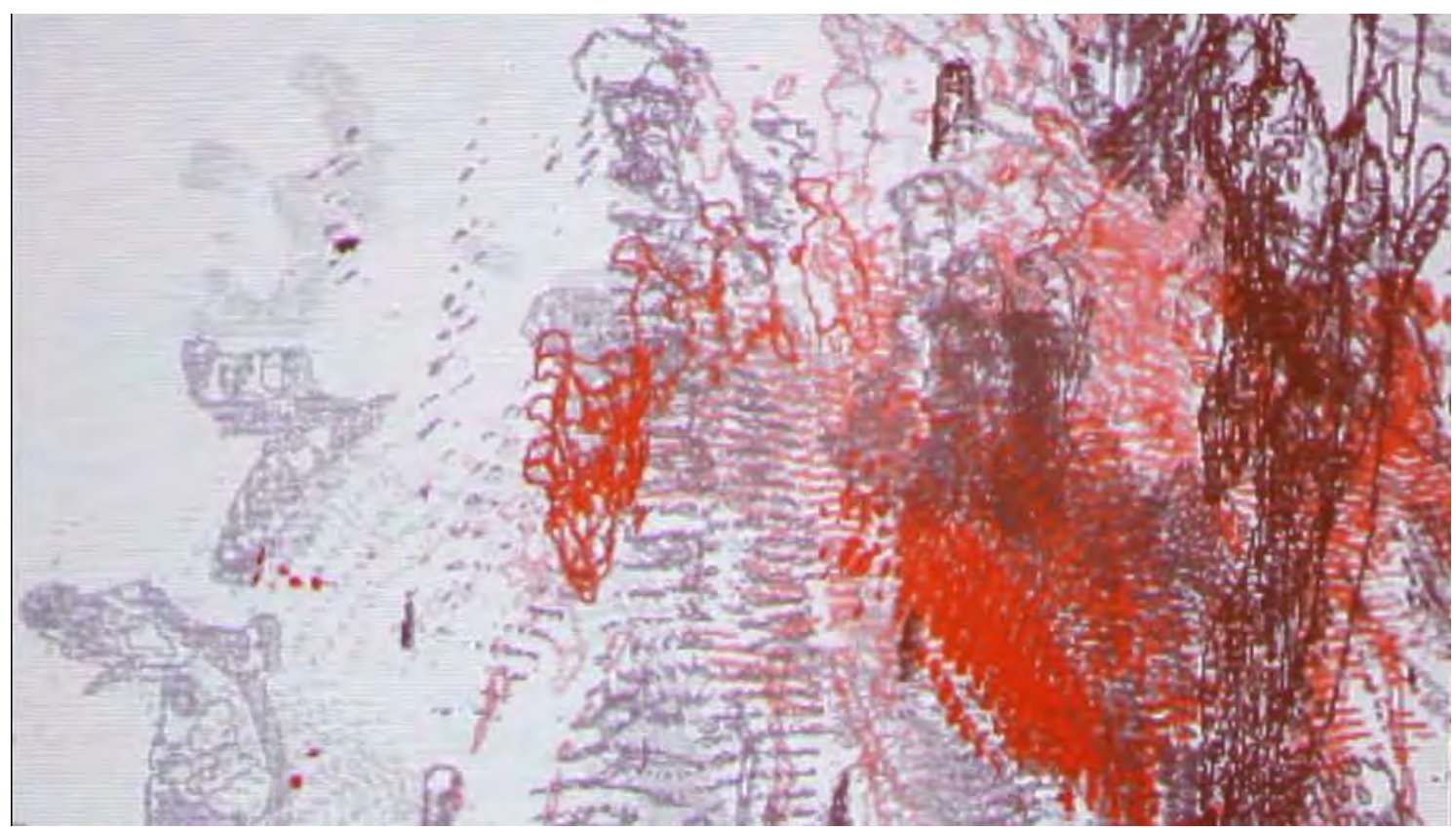

Figura 24: Imagem obtida durante a interação com o Enigma 3.1 - : Um enigma para Gibson (2015). Autoria própria.

$26 S_{y n^{2}}$ a.k.a Simulador de Sinestesia (2014). Autoria: Rafael V. Ribeiro, Loren Bergantini, Vinicius Franulovic, Gloria Fernandes e Alex Tso. 
$\Phi$ - Um enigma para Gibson 3.1 é uma instalação interativa que realiza a leitura em tempo real da variância e invariância da luz do espaço expositivo a partir de duas webcams. As informações captadas por cada uma das câmeras são processadas por um filtro e traduzidas em linhas monocromáticas e em sons sintetizados a partir da linguagem de programação Processing. As linhas sobrepostas representam os caminhos e rastros de luz da imagem captada, atualizadas constantemente em um monitor. O sistema de amplificação sonora reproduz sons sintetizados que variam em frequência e amplitude de acordo com as informações referentes a quantidade e complexidade de elementos luminosos captados por cada uma das câmeras, gerando duas vozes. A luz desenha, e a linha canta. O fluxo luminoso $(\Phi)$, medido em lúmens $(\mathrm{lm})$ e captado pelas câmeras, é o responsável pelas variações das imagens e dos sons, modificando diretamente a percepção. Segundo formulou James J. Gibson, são as variâncias e invariâncias do espaço circundante que permitem a constituição da percepção e localização espacial racionalizada, ou seja, aquela que se abstrai em linhas, remetendo imediatamente ao desenho, desígnio. O trabalho foi concebido e realizado pelo grupo de pesquisa Realidades, formado na ocasião por: Anita Cavaleiro, Cassia Aranha, Giovanna Lucci, Jose Dario Vargas, Lali Krotoszynski, Leandro Roman, Loren Bergantini, Silvia Laurentiz e Viviane Sá.

$\Phi$ Um enigma para Gibson, em suas versões 3 e 3.1, fazem parte de uma série de trabalhos artísticos realizadas pelo Grupo de Pesquisa Realidades - das realidades tangíveis, às realidades antológicas e seus correlatos, sediado no Departamento de Artes Visuais da ECA/USP e coordenado pela Prof $^{a}$ Dr $^{a}$ Silvia Laurentiz. O grupo Realidades tem como objetivo discutir e refletir sobre as diferentes possibilidades de representação e significação do termo realidade a partir de âmbitos diversos. O campo de pesquisa inclui questões como: realidade virtual, mista e aumentada; arte móvel; computação ubíqua; e todas as possíveis variantes de representação, simulação e emulação da realidade que estão presentes nos mais diversos contextos - como em games, sites, arte interativa, instalações, etc.

A série de trabalhos denominada Enigmas $^{27}$, realizada pelo grupo entre 2012 e 2016, propôs a 27 Documentação de todas as obras artísticas realizadas pelo grupo Realidades está disponível em: 
reflexão poética de conceitos teóricos dos pensadores:

a) Vilém Flusser - Enigma 1-(-1) x (-1) = 1: Um enigma para Flusser, realizado em 2012, que discute a representação do real e irreal a partir da imagem técnica de Flusser e seu caráter conceitual;

b) Henri Bergson - Enigma 2 - $f(\Delta t)$ : Um Enigma para Bergson, realizado em 2013, que aborda o conflito entre espaço e tempo a partir a partir do conceito de duração de Bergson, e a relação da de estabilidade e instabilidade de eventos em relação à dependência sistêmica; e

c) James J. Gibson (Enigmas 3 e 3.1 - $\varphi$ : Um enigma para Gibson, realizados, respectivamente, em 2014 e 2015, que debatem a leitura perceptiva do mundo a partir da variância e invariância dos elementos que compõem o espaço circundante.

No início de 2014, o grupo debateu sobre os interesses temáticos comuns para a realização do terceiro trabalho prático, que finalizaria a série de enigmas. Convergiu-se para o tema do espaço e foi proposta a leitura inicial da Poética do Espaço (1993) de Gaston Bachelard. Os escritos inspiraram a utilização de sensores e do dispositivo kinectic para captar informações espaciais. No entanto, acabamos por optar pelo uso de câmeras webcams, devido a sua maior acessibilidade. Finalmente, decidimos utilizar duas câmeras simultaneamente, de modo a simular a percepção do espaço pelos olhos humanos. Como o debate sobre o espaço acabou convergindo para a questão perceptiva, incluímos em nossas discussões as teorias de percepção visual de James J. Gibson, com a leitura do artigo The ecological approach to the visual perception of picures (1978).

Inspirados pelas reflexões das teorias de Gibson, buscamos por uma solução que rastreasse, de alguma forma, a variação que ocorria no ambiente de acordo com as informações captadas pelas webcams. Encontramos essa solução na biblioteca blobscanner ${ }^{28}$ da linguagem de programação Processing, que permite delimitar e rastrear as áreas de maior luminosidade das imagens captadas. Desta forma, as variações luminosas mapeadas em nosso código foram utilizadas para traçar linhas de rastreamento da luz sobre a imagem gerada. A uma câmera foram associadas linhas negras, enquanto à outra, linhas vermelhas. Contudo, os traços se $<$ http://www2.eca.usp.br/realidades/pt/obras/>. Acesso 26 jul. 2016.

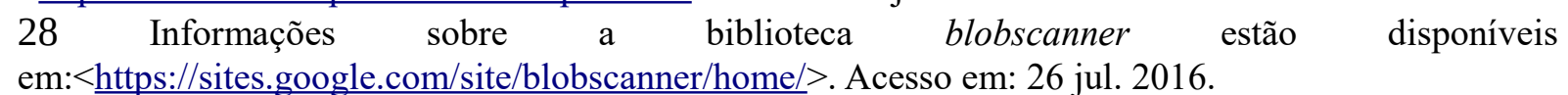


sobrepunham infinitamente, tornando permanentes informações desatualizadas que, ao invés de informar a percepção, confundiam-na. Conseguimos resolver o infortúnio ao tomar partido da repetição constante que o Processing realiza dentro da função "draw" utilizando a imagem de uma tela branca semitransparente. Cada vez que o programa atualizava a imagem das webcams, as informações mais antigas suavemente desapareciam com a sobreposição da camada branca. $\mathrm{O}$ efeito obtido pode ser observado na Figura 25.

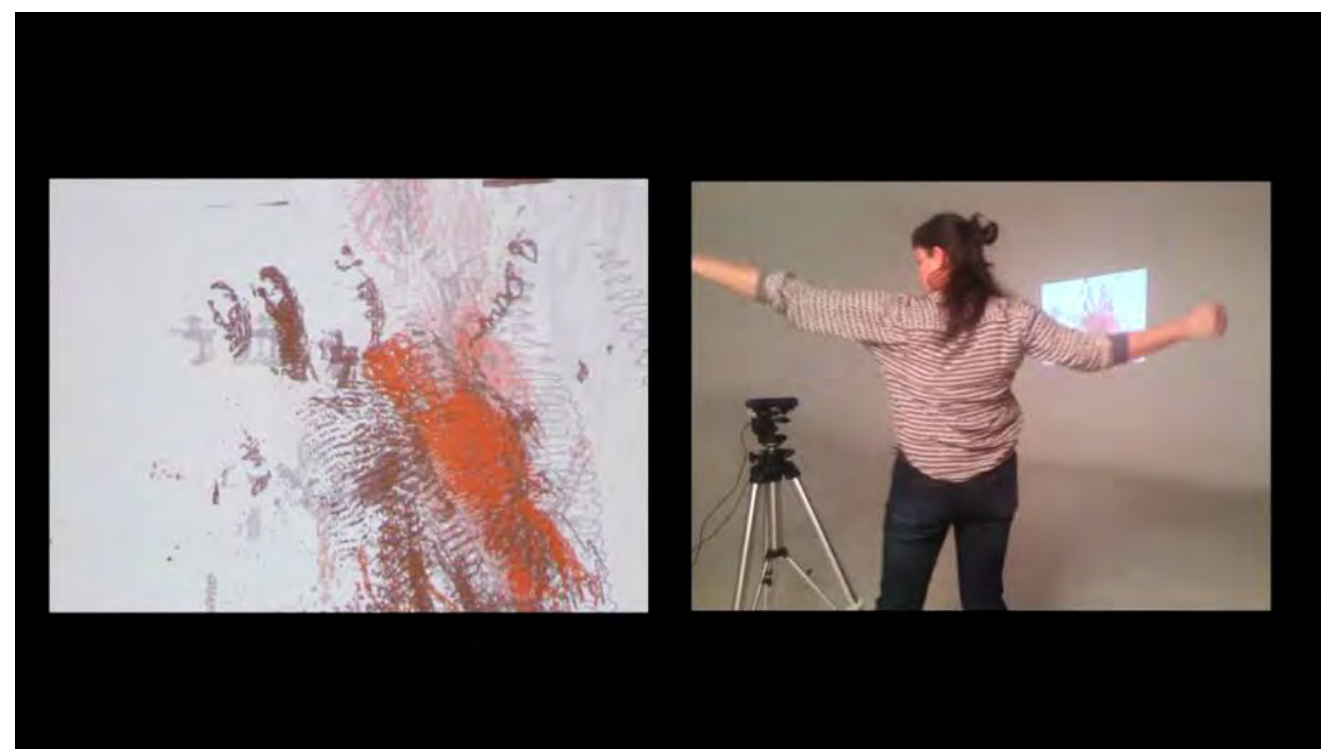

Figura 25: Comparação entre a interação com as webcams no terceiro enigma e a variação das áreas luminosas delimitadas pelas linhas vermelha e preta. Repare na estampa da camiseta reconhecida pelas câmeras e sua movimentação em relação à interação do corpo. Autoria própria.

O Enigma 3.1 (2015) foi uma ampliação do Enigma 3, com a inclusão de efeitos sonoros à programação desenvolvida em 2014. Utilizou-se a biblioteca minim para a configuração sonora produzida de acordo com cada conjunto de linhas desenhadas, a partir da utilização de ondas senoides (sons de frequência pura, gerados por computador). Desta forma, a característica de cada voz foi modelada a partir da sobreposição de frequências simples, inspirada na ideia de série harmônica.

A série harmônica é uma sequência infinita que apresenta todas as frequências múltiplas de uma nota fundamental, geradas pela vibração de corpos. Essa série é caracterizada por apresentar uma proporcionalidade específica e imutável de origem física, e pode ser encontrada em vários instrumentos musicais. O primeiro som da série harmônica, sobreposto 
à fundamental, sempre soará uma oitava acima (ou o dobro da frequência); o segundo uma quinta justa acima do primeiro (2/3 acima da frequência anterior); o terceiro duas oitavas acima da fundamental; o quarto uma terça maior acima da frequência anterior (5/4 acima do som antecedente); e assim, sucessivamente, são definidas todas as frequências múltiplas da nota fundamental. Essas frequências que se sobrepõem ao som gerador compõem os sobretons (ou harmônicos). Combinados a outras características de emissão e decaimento sonoros, eles permitem a identificação do timbre de fontes sonoras distintas. É a diferença de timbre que permite que se identifique uma mesma nota como sendo tocada por um piano, por um violino ou por um cantor, por exemplo.

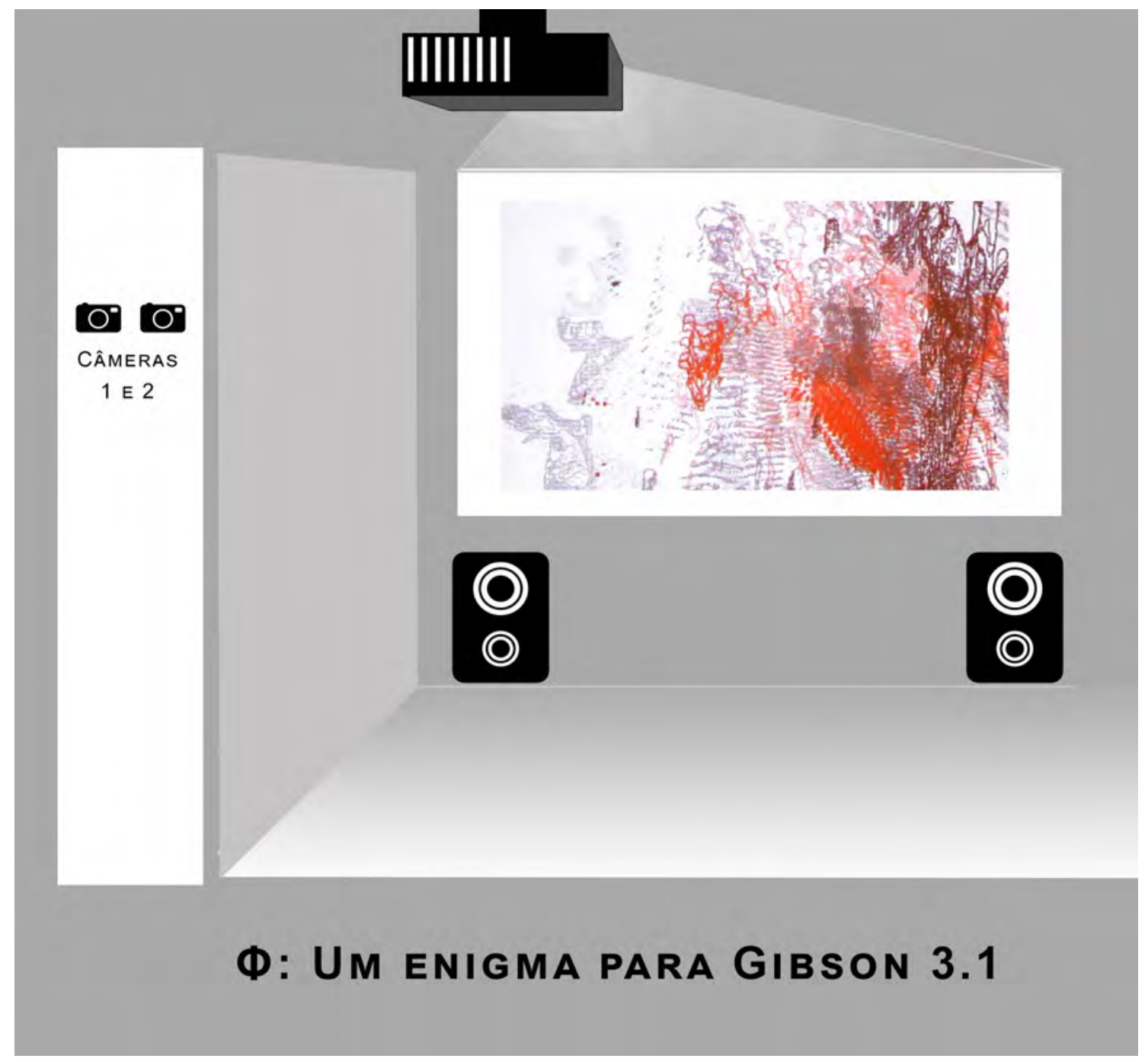

Figura 26: Figura esquemática representando a montagem da instalação interativa $\Phi$ : um enigma para Gibson 3.1 (2015). Autoria própria. 
Em Enigma 3.1, a frequência fundamental de cada uma das vozes é configurada para ser proporcional ao número de objetos luminosos (ou blobs) detectados pelas câmeras: quanto maior o número de elementos encontrados, mais agudo soará o conjunto de linhas de cada cor, e quanto menor o número, mais grave. Portanto, cria-se uma relação direta entre as abstrações desenhadas e os sons gerados. Em uma analogia musical, seria como se as linhas estivessem cantando, em um dueto, cada uma sua melodia. Pode-se observar na Figura 26 o esquema da montagem da instalação.

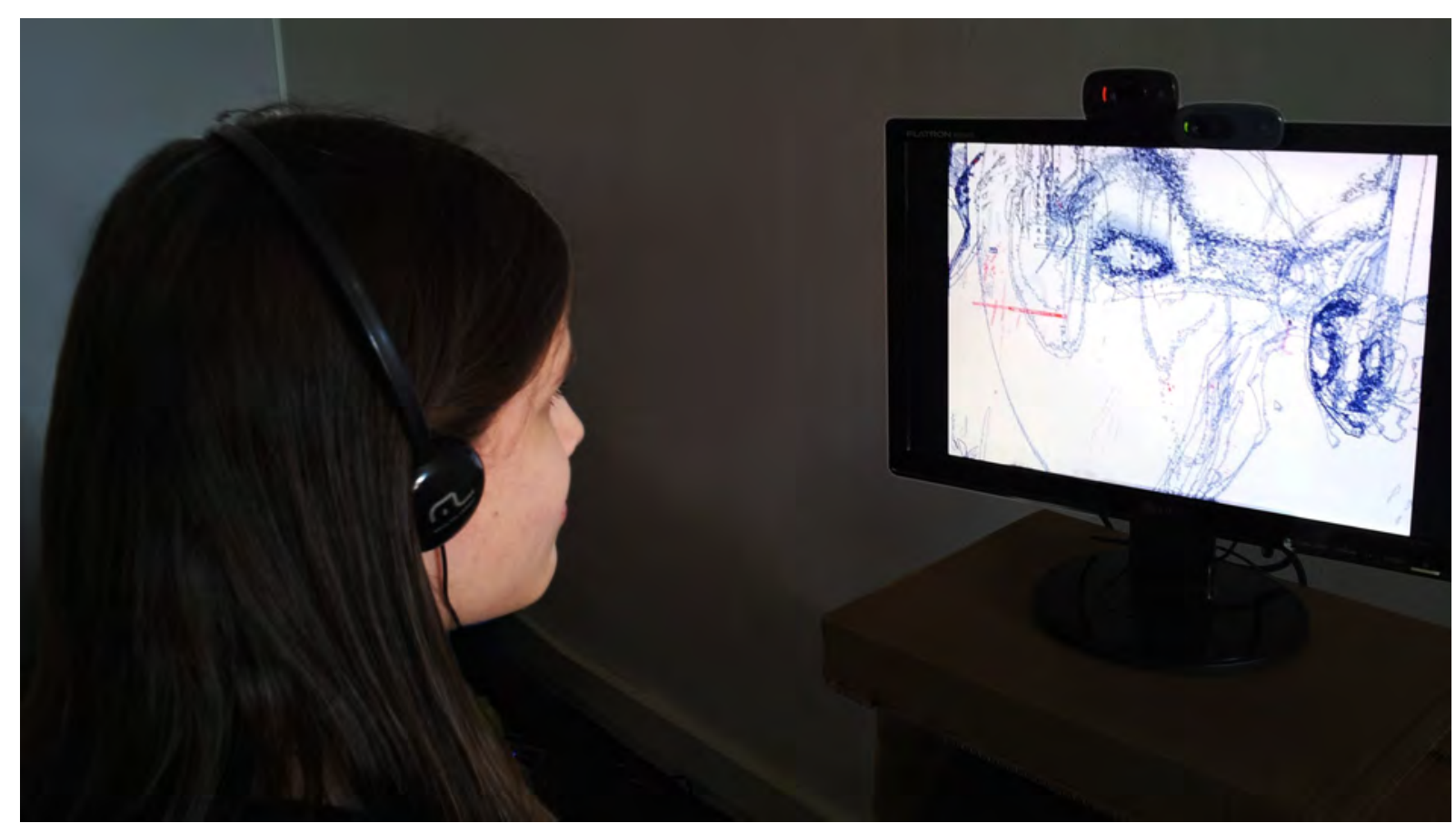

Figura 27: Foto da montagem de $\Phi$ : Um enigma para Gibson 3.1 na exposição internacional Visual Music: Interações Música-Imagem (arte computacional), Centro Cultural Banco do Brasil de Brasília (2015). Autoria própria.

A instalação interativa $\Phi$ : Um enigma para Gibson $3.1^{29}$ foi montada nas exposições: Visual Music: Interações Música-Imagem (arte computacional), que ocorreu entre os dias 10 e 29 de junho de 2015 no Centro Cultural Banco do Brasil de Brasília (foto da montagem na Figura 27); e Lugares da Experiência, que ocorreu entre os dias 29 de junho a 1 de julho de 2016 na Galeria da Universidade Estadual de São Paulo (foto da montagem na Figura 28).

29 Ф : Um Enigma para Gibson 3.1 (2015) Autoria: grupo Realidades: Silvia Laurentiz (cordenação) e Loren Bergantini, Silvia Laurentiz, Cássia Aranha, Anita Cavaleiro, Giovanna Lucci, José Dario Vargas, Lali Krotoszynski, Leandro Roman e Viviane Sá (criação). 


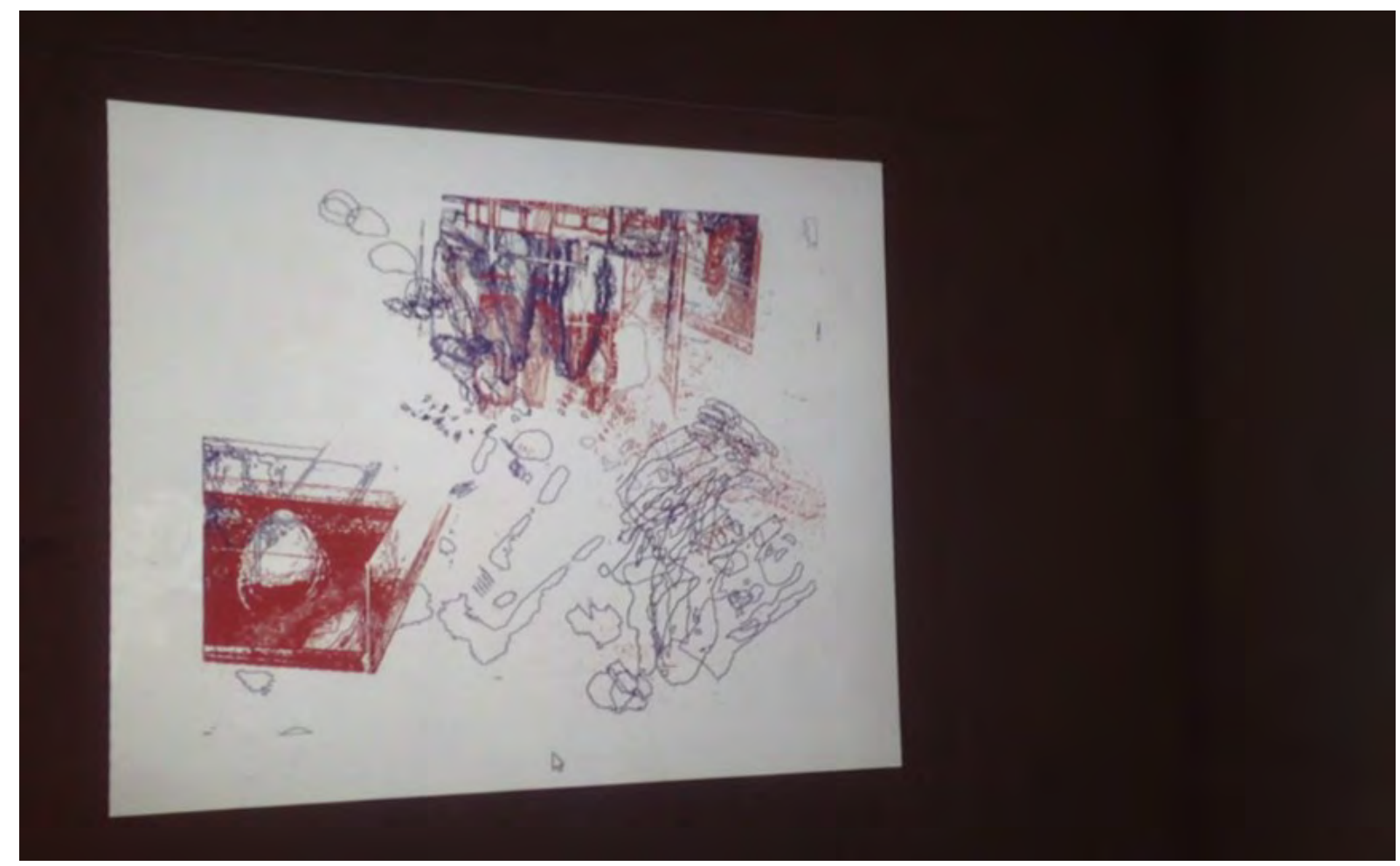

Figura 28: Foto da montagem de $\Phi$ : Um enigma para Gibson 3.1 na exposição Lugares da Experiência, na Galeria da Universidade Estadual de São Paulo (2016). Autoria própria.

\subsection{Projeto Vendo Vozes: vozes policromáticas}

O Projeto Vendo Vozes da série de trabalhos experimentais realizados durante o período de mestrado. Seu objetivo foi experimentar as possibilidades de interações entre voz e imagem intermediadas pela tecnologia. Todo o conhecimento adquirido nos trabalhos práticos anteriores, no curso de introdução à programação (realizada durante os cursos de verão de 2015 do Instituto de Matemática e Estatística (IME-USP), nas pesquisas teóricas e nas disciplinas cursadas durante o mestrado, além dos conhecimentos musicais adquiridos durante os estudos de canto lírico na Escola Municipal de Musica da Fundação Theatro Municipal de São Paulo (EMMSP), foram de fundamental importância para o desenvolvimento das possibilidades teóricas e estéticas deste projeto.

O primeiro passo para o desenvolvimento do projeto consistiu na escolha da linguagem de 
programação, bibliotecas e técnicas para realizar o processamento sonoro. A plataforma de pesquisa escolhida foi o Processing, por ser uma linguagem de programação aberta, direcionada a designers e artistas visuais, com boa documentação on-line. Outra razão levada em consideração para tal escolha foi a experiência prévia com esta linguagem obtida durante os trabalhos anteriores.

A pesquisa sobre a análise computacional do som, levou-nos ao conceito de Transformada de Fourier. Essa operação matemática decompõe uma função de tempo (sinal) nas diversas frequências que a formam, permitindo a identificação das notas que constituem um determinado sinal sonoro. A biblioteca Minim $^{30}$, que permite a utilização de recursos sonoros no Processing, realiza a Transformada de Fourier Rápida (Fast Fourier Transform - FFT) como um dos métodos para análise do som. A FFT, utilizada no projeto, não apresenta todas as frequências do som analisado, mas sim bandas de frequência centradas em notas particulares.

Geralmente a frequência central de cada banda é representada como uma fração do tamanho do arquivo de som analisado, ignorando-se as frequências inaudíveis para humanos (abaixo de $20 \mathrm{~Hz}$ e acima de $20000 \mathrm{~Hz}$ ). Contudo, como o objetivo proposto no trabalho é conseguir identificar qual nota a pessoa está vocalizando em tempo real, configurou-se para que cada oitava fosse subdividida em 12 bandas (em acordo com a subdivisão semitonal da escala cromática da música ocidental) facilitando, dessa forma, o reconhecimento da nota cantada. Tomou-se como referência para a definição da afinação ${ }^{31}$ da escala e como extensão para análise a nota Lá-0 $(\mathrm{A}-0=55 \mathrm{~Hz})$, sendo a nota mais grave considerada, e a Lá-6 (A-6 = 3520 $\mathrm{Hz}$ ), a frequência mais aguda avaliada na análise. Nossa análise considerou seis intervalos de oitavas, para que pudesse englobar com folga a extensão vocal desde vozes graves masculinas (graves extremos em torno de $65 \mathrm{~Hz}$ ) a vozes femininas agudas (agudos extremos em torno de

\footnotetext{
30 Documentação da biblioteca pode ser encontrada disponível em: $<$ http://code.compartmental.net/minim/index analysis.html $>$. Acesso em: 23 jul. 2016.

31 Tabela relacionando as frequências de cada nota de acordo com a afinação ocidental com referência no La-3 $440 \mathrm{~Hz}$ disponível em: $<$ http://www2.eca.usp.br/prof/iazzetta/tutor/acustica/introducao/tabela1.html $>$. Acesso em: $23 \mathrm{Jul}$. 2016.
} 
$2000 \mathrm{~Hz})^{32}$, além de algumas frequências um pouco mais agudas para identificar possíveis harmônicos da voz. O próximo estágio foi adicionar o reconhecimento da entrada do som (microfone) pelo Processing e a identificação das notas cantadas que apresentavam maior amplitude (força) dentro de cada oitava.

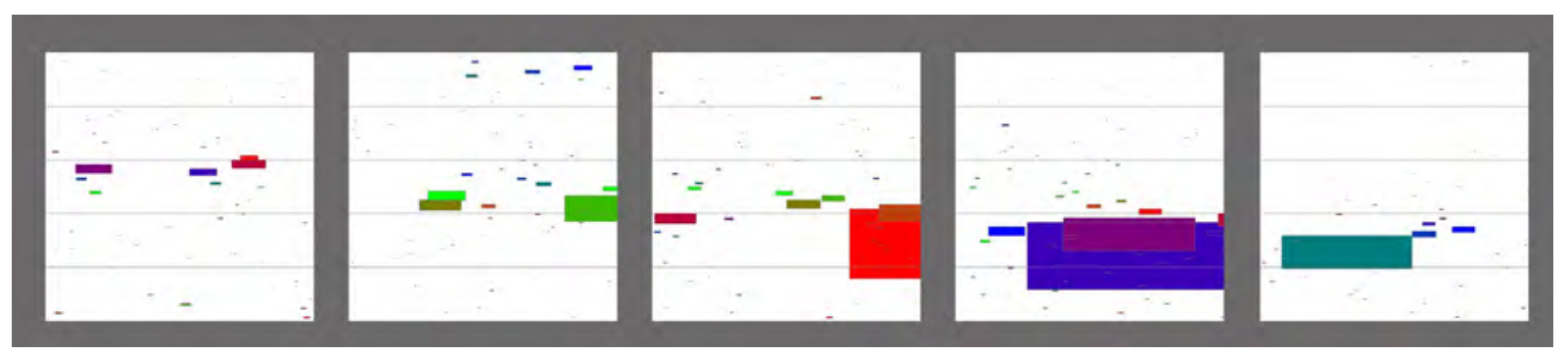

Figura 29: Uma das primeiras tentativas de relacionar voz e imagem, associando-se sons agudos a espaços altos da tela e sons graves a espaços baixos. Autoria própria.

Resolvida a pesquisa sobre a análise, identificação e definição dos sons captados pelo microfone do computador, iniciou-se a pesquisa sobre as possibilidades estéticas de interação com as informações sonoras obtidas pelo computador. Os primeiros testes buscaram estabelecer a escolha clássica de relacionar o espaço superior da tela aos sons agudos, e espaço inferior da tela às frequências graves. Foram utilizadas formas simples, como elipses e retângulos, para a realização dos primeiros testes. A figura acima mostra uma das primeiras tentativas, com o estabelecimento da relação entre alto-agudo, baixo-grave e as primeiras associações entre notas musicais e cores.

A escala de cores foi desenvolvida com o objetivo de relacionar matizes diferentes para cada uma das notas da escala cromática, começando pelo Lá (A) como vermelho, de forma que a relação entre os valores de matiz pudessem ser sequenciais e se repetissem a cada oitava. Nos primeiros testes foram utilizados valores RGB aproximados, que foram retificados nas últimas versões do código, de acordo os valores apresentados na Figura 30.

32 Mais informações sobre extensão vocal estão disponíveis em: $<$ http://www.voz.fob.usp.br/do/Conteudo_View/106/frequencia_das_vibracoes_sonoras/1 $>$. Acesso em: 15 jul. 2016. 


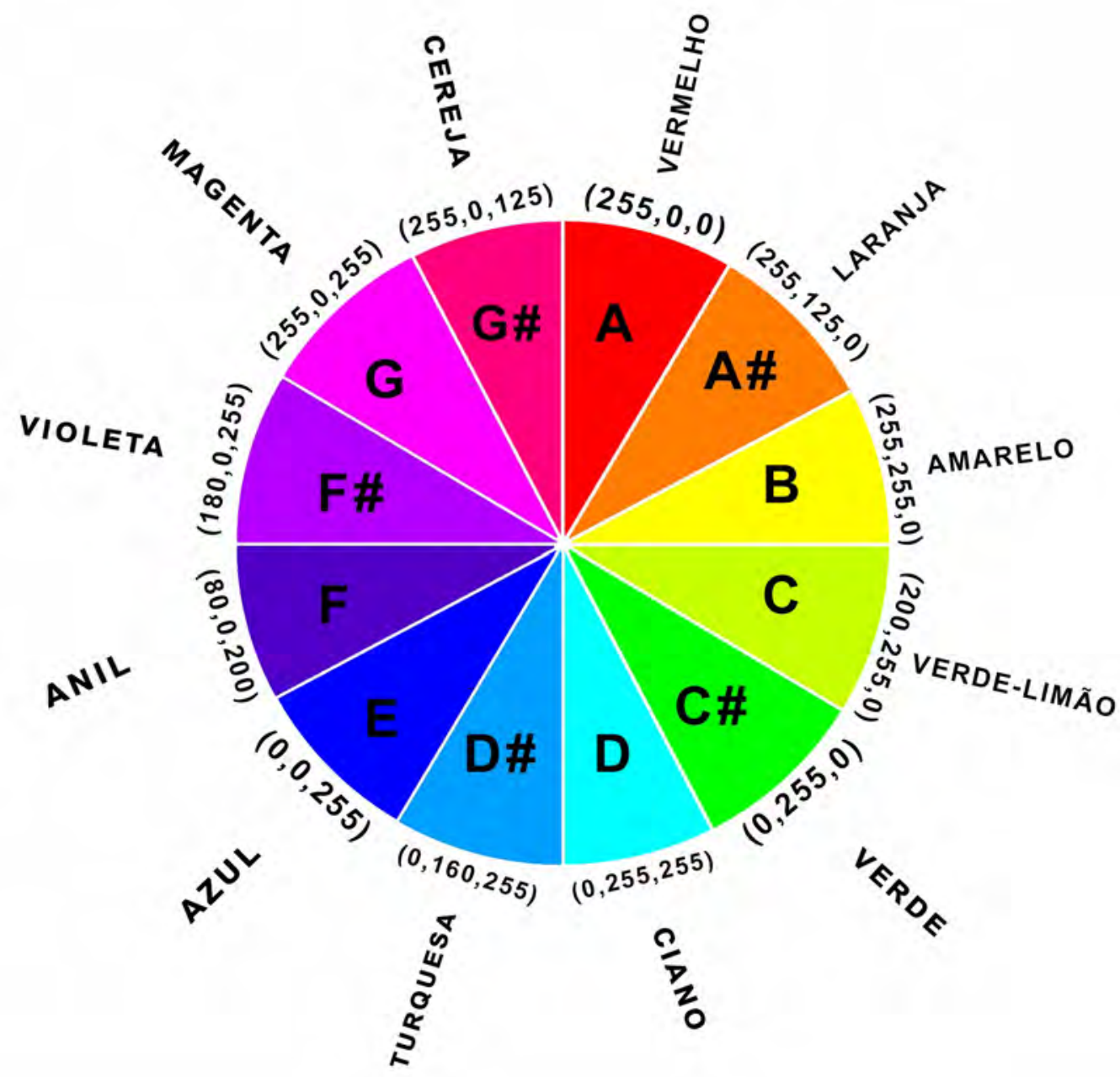

Figura 30: Imagem representando a escala de cores final utilizada, com seus nomes e valores RGB, em relação às notas da escala cromática identificadas (nomenclatura inglesa: la-A, si-B, do-C, re-D, mi-E, fa-F, sol-G). Autoria própria.

No início da pesquisa estética, buscou-se o formato de linhas simples que respondessem à voz, apresentando maior deformação na região de maior amplitude (força) e mantendo a relação já estabelecida entre espaços e frequências agudas e graves. Como a solução da linha branca no centro da tela se apresentou demasiadamente monótona, iniciou-se a repetição sucessiva das linhas e a adição posterior das relações entre nota e cor, como se pode observar na Figura 31. 
A inclusão das cores no preenchimento dos espaços entre as linhas repetidas geraram combinações de cores psicodélicas e de efeitos interativos não evidentes (era difícil identificar qual som estava relacionado a qual cor), além de exigir um processamento intensivo, tornando a execução do programa lenta para a interação em tempo real.

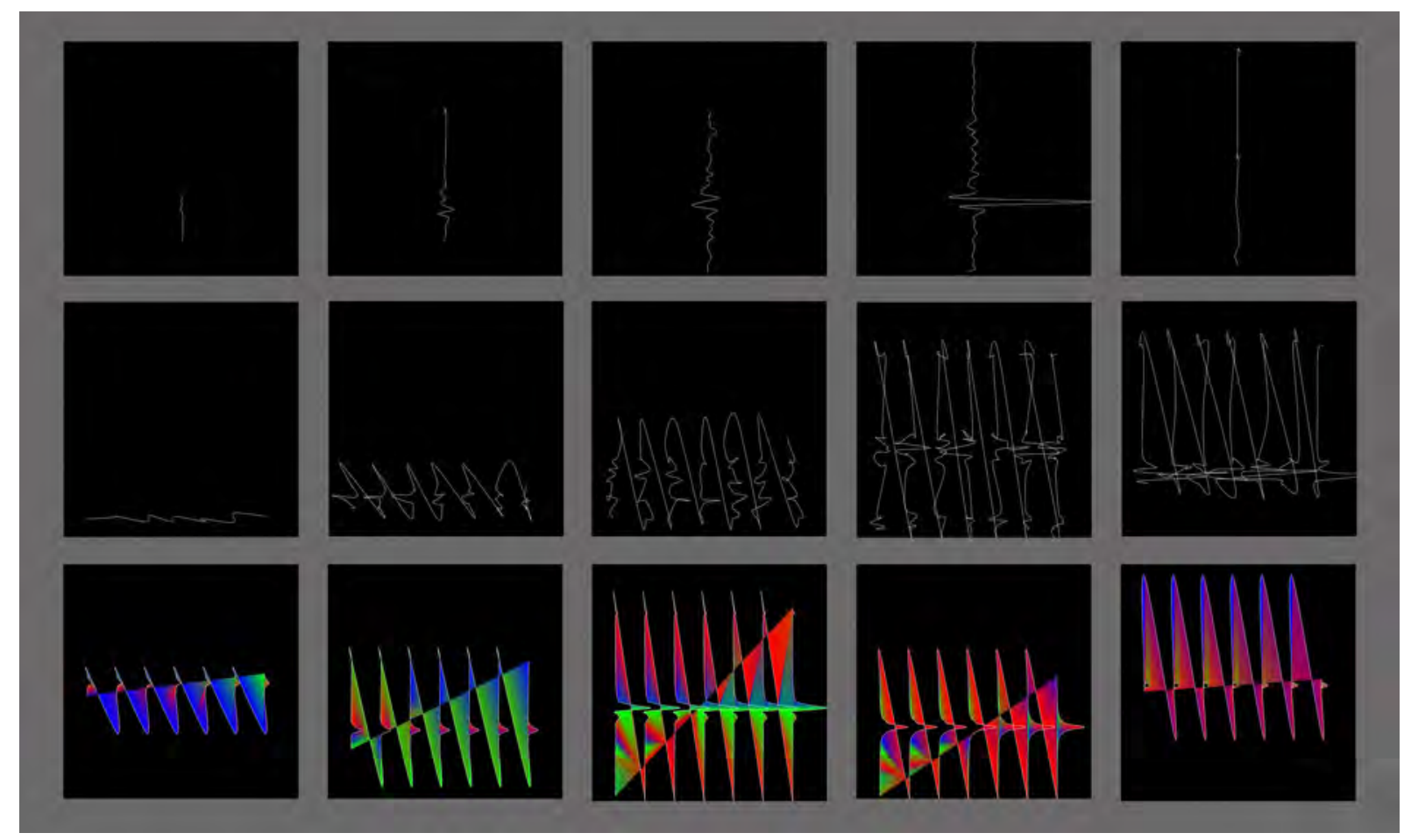

Figura 31: Sequência que representa a interação com os testes relacionando linha e voz no Processing. A primeira linha apresentando a interação com a linha branca única, a segunda linha, a repetição das linhas e a terceira, a repetição com adição de cor. Autoria própria.

Contudo, a ideia de repetição de padrões aliada à primeira concepção de som relacionado ao espaço incitou a continuidade das investigações para testes com texturização. Desta forma, foi proposta a repetição de formas que pudessem tornar o espaço da tela como uma colcha texturizada, que responderia, com mudanças de movimento e cor, à intensidade e frequência das notas cantadas. As duas formas escolhidas para testar a ideia de texturização foram os arcos (segmentos de circunferência - dois primeiros exemplos da Figura 32) e os próprios círculos (dois últimos exemplos da mesma imagem). As primeiras tentativas levaram em consideração os contornos das formas para criar a ideia de teia ou trama, com a adição de cor 
nas linhas ou no preenchimento das formas (segunda e terceira linha da figura). O último teste dessa série (apresentado na última linha da figura abaixo) excluiu os contornos das circunferências, utilizando somente o preenchimento dos círculos e diminuindo seu tamanho para construir texturas através de uma espécie de pontilhismo.

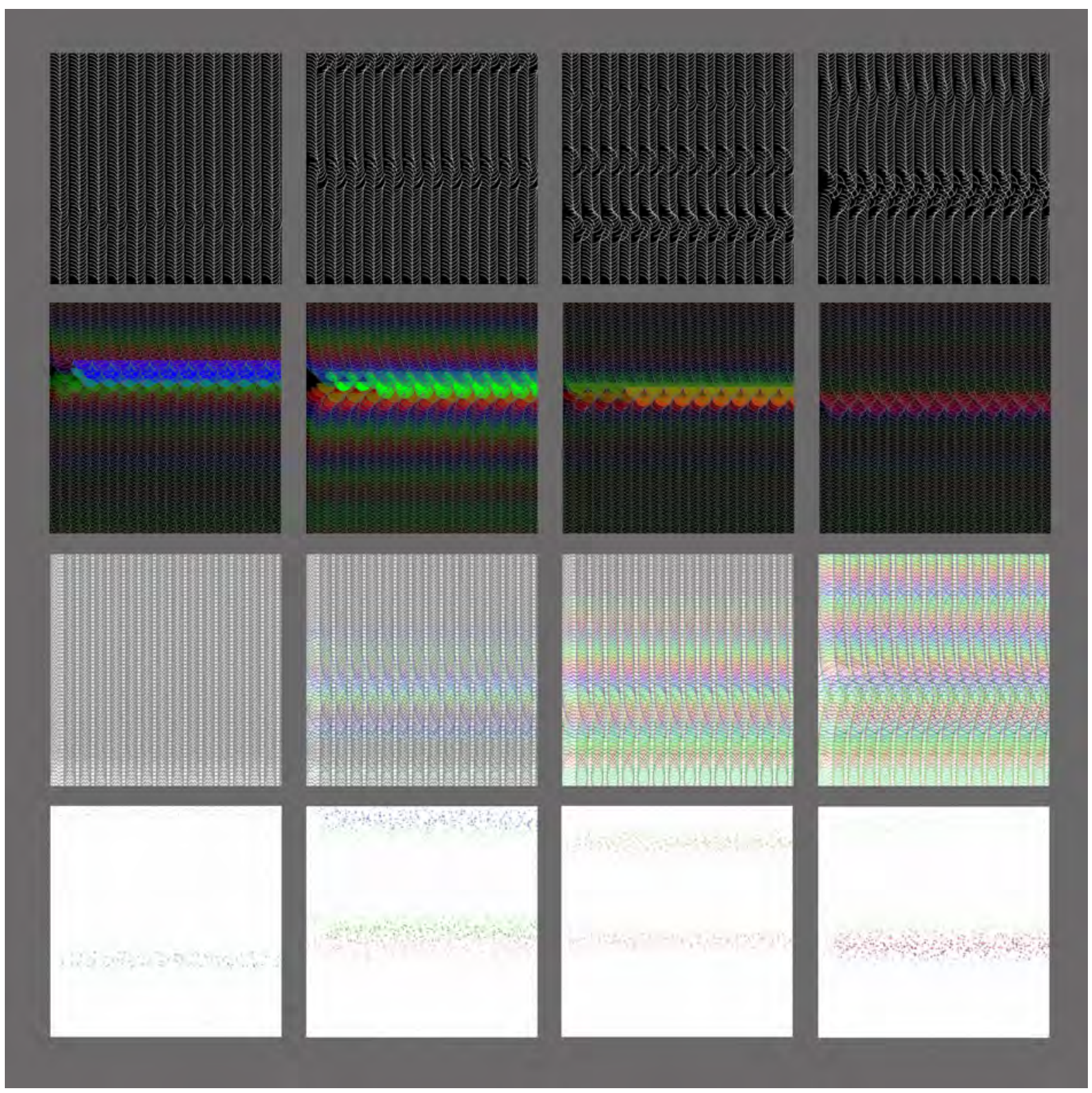

Figura 32: Imagem que apresenta, em cada uma das linhas, sequências de interação dos testes realizados no Processing com o objetivo de criar texturas sinestésicas.

Durante o desenvolvimento da pesquisa visual sobre possibilidades de texturas, deparou-se 
com a inflexibilidade das informações de cor no espaço. A visualização da mesma nota com maior ou menor intensidade não era satisfatória (apenas a variação de transparência era modificada pela intensidade). Por isso, decidiu-se buscar novos caminhos estéticos fora do conceito inicial.

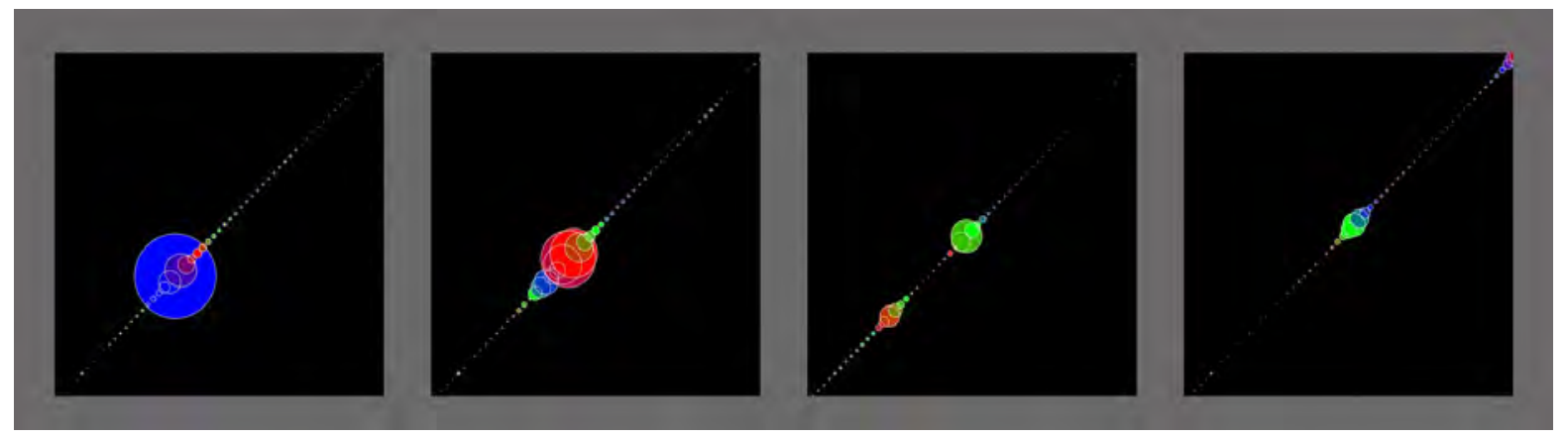

Figura 33: Teste para a visualização mais efetiva da voz em relação a tamanho de circunferências e o espaço da tela.

Uma das soluções para a melhor visualização da intensidade, nota e relação entre graves e agudos vocalizados é exibida na Figura 33. Na interação, círculos deslizam da parte inferior esquerda (graves) até a parte superior direita (agudos), além de responder com variações de tamanho e cor de acordo com a intensidade e frequência sonoras.

Buscou-se também novas possibilidades estéticas no Open Processing ${ }^{33}$, um site colaborativo criado para compartilhar sketches (códigos do Processing) e facilitar colaborações entre programadores. Neste site, foi encontrado o interessante exemplo da obra Noise Circle ${ }^{34}$ de Peter Hoffmann, no qual informações obtidas pelo mouse (localização do cursor, e interações com o botão esquerdo) modificavam o contorno de um círculo centralizado na tela a partir da função noise (baseada no método Perlin Noise, algoritmo desenvolvido por Ken Perlin em 1983 para adicionar variações inesperadas e texturas mais realistas a gráficos computacionais). Na Figura 34, pode-se observar a representação do funcionamento do código de Hofmann. A localização nos eixos x e y do cursor na tela eram responsáveis,

33 Disponível em: <www.openprocessing.org/sk> $>$. Acesso em 26 jul. 2016.

34 Códigos e mais informações sobre Peter Hoffmann estão disponíveis em:

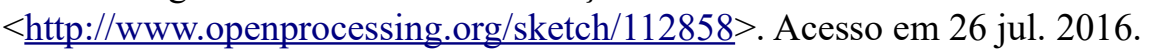


respectivamente, pela variação do ruído no contorno do círculo e seu tamanho, enquanto a interação com o botão do mouse preenchia ou não a forma criada.

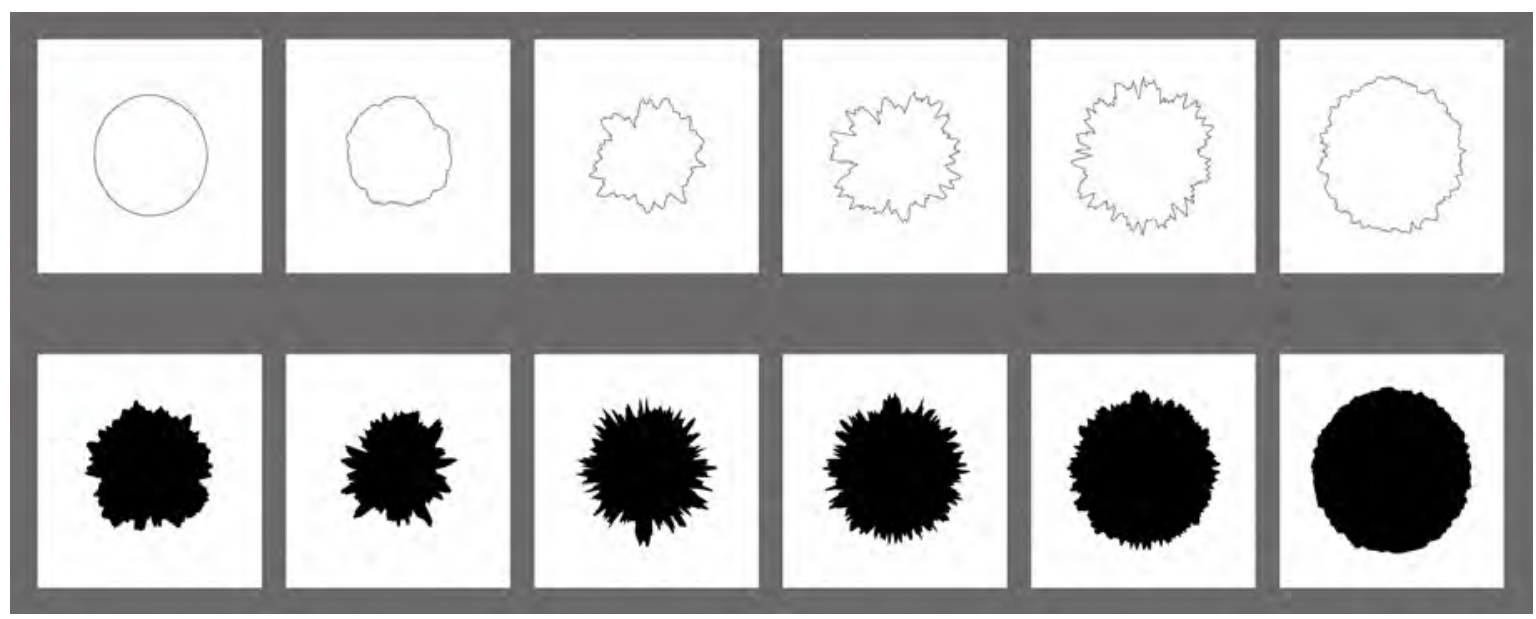

Figura 34: Representação do funcionamento da programação de Noise Circle de Peter Hoffman. Imagens retiradas do sketch disponível em: $<$ http://www.openprocessing.org/sketch/112858 $>$. Acesso em: 16 jul. 2016.

A ideia de relacionar turbulências mais ou menos pontudas a partir da interação apresentou uma perspectiva interessante de comparação com a metáfora comum no canto: considerar o timbre de vozes agudas como mais pontudas (estridentes) e vozes graves como mais arredondadas (aveludadas). Além do mais, como no sketch representado pela Figura 33 seria possível definir o tamanho do raio da circunferência desenhada como sendo proporcional à intensidade vocal identificada em cada uma das frequências. Iniciou-se então uma pesquisa sobre a aplicação desse conceito de turbulência na superfície de círculos, e sua associação às informações vocais registradas pelo computador. Estabeleceu-se que quanto mais aguda a frequência identificada, maior seria o grau de turbulência da superfície desenhada (e mais pontuda a representação), e quanto mais forte a intensidade vocal, maior seria o tamanho da forma. Seguindo esses padrões, vozes com a tessitura (região de maior conforto e volume vocais) mais grave produziriam contornos mais arredondados, mesmo em círculos maiores, e timbres agudos o contrário.

Como todos os instrumentos musicais, incluindo a voz, possuem harmônicos (mais agudos e de menor volume), os desenhos formados acabaram se caracterizando por possuir um miolo com circunferências coloridas menores sobrepostas umas as outras. A notas mais fortes e suas 
cores acabaram formando uma espécie de coroa em torno das frequências menores. A Figura 35 mostra o resultado estético obtido somente com os contornos coloridos (na parte superior), e com o preenchimento das circunferências com saturação total das cores identificadas (parte inferior).

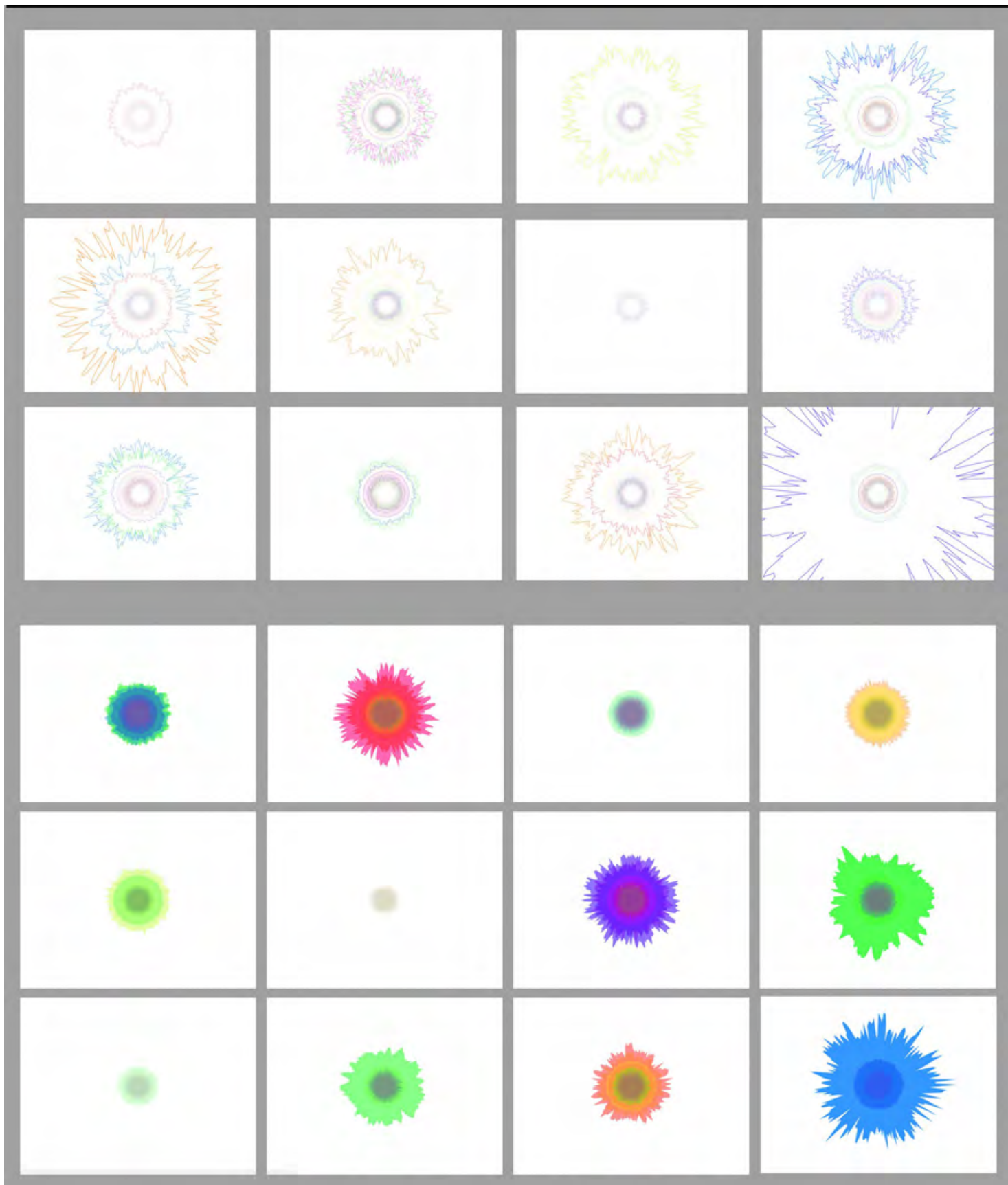

Figura 35: Representação dos resultados estéticos obtidos com a interação vocal e sua associação a cores e formas circulares nodosas. A parte superior apresenta o funcionamento somente com o contorno e a parte superior, com o preenchimento das cores identificadas. Autoria própria. 
No teste realizado somente com os contornos coloridos as matizes se apresentaram muito apagadas. Já no teste com o preenchimento colorido, as cores ficaram muito extravagantes e com formatos muito próximos da representação de flores. Por estas razões, buscou-se um resultado estético intermediário, acrescentando transparência às cores identificadas. Esta escolha foi tal que as formas destacassem a cor predominante da nota cantada, ao mesmo tempo que ressaltasse a qualidade gráfica dos contornos dos círculos concêntricos. A Figura 34 apresenta algumas possibilidades de interação nesta última versão, nomeada de Vozes Policromáticas por apresentar várias matizes quando em interação com a voz.

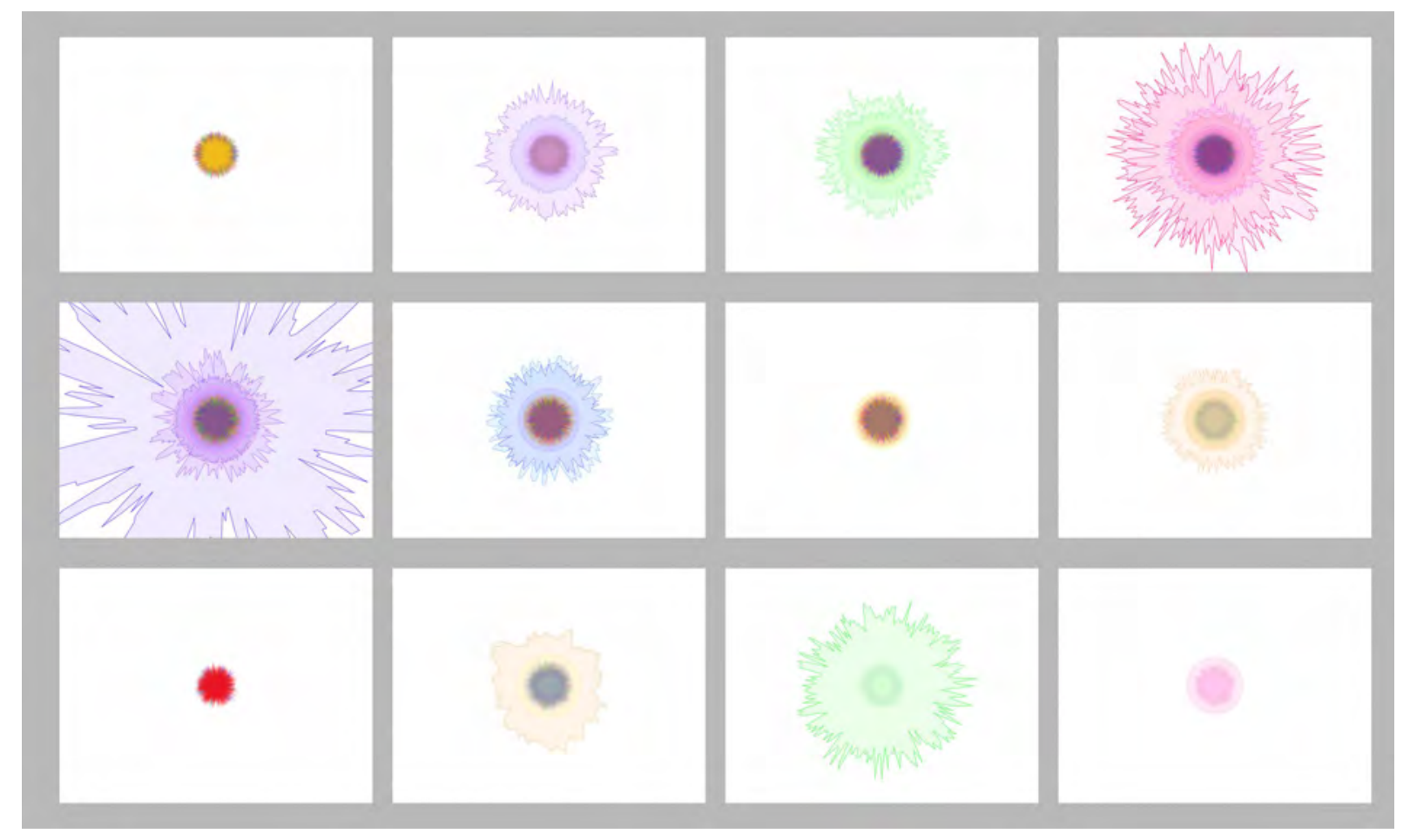

Figura 36: Interação com a versão apresentando um visual intermediário entre os dois testes anteriores, com contornos coloridos e preenchimento das cores com transparência. Autoria própria.

Um ponto que ainda pode ser verificado em Vozes Policromáticas, numa possível continuidade do trabalho, seria a tentativa de desestruturar a concentricidade dos círculos representados, com o intuito de adicionar também algum tipo de associação espacial na tela. Outra possibilidade seria abordar a espacialidade da voz a partir de novas propostas de montagem no espaço expositivo. A continuidade e aprofundamento tanto prático quanto 
teórico do Projeto Vendo Vozes pode ser eventualmente realizada durante as atividades de doutorado. A montagem proposta para o atual estágio da obra está descrita na Figura 35.

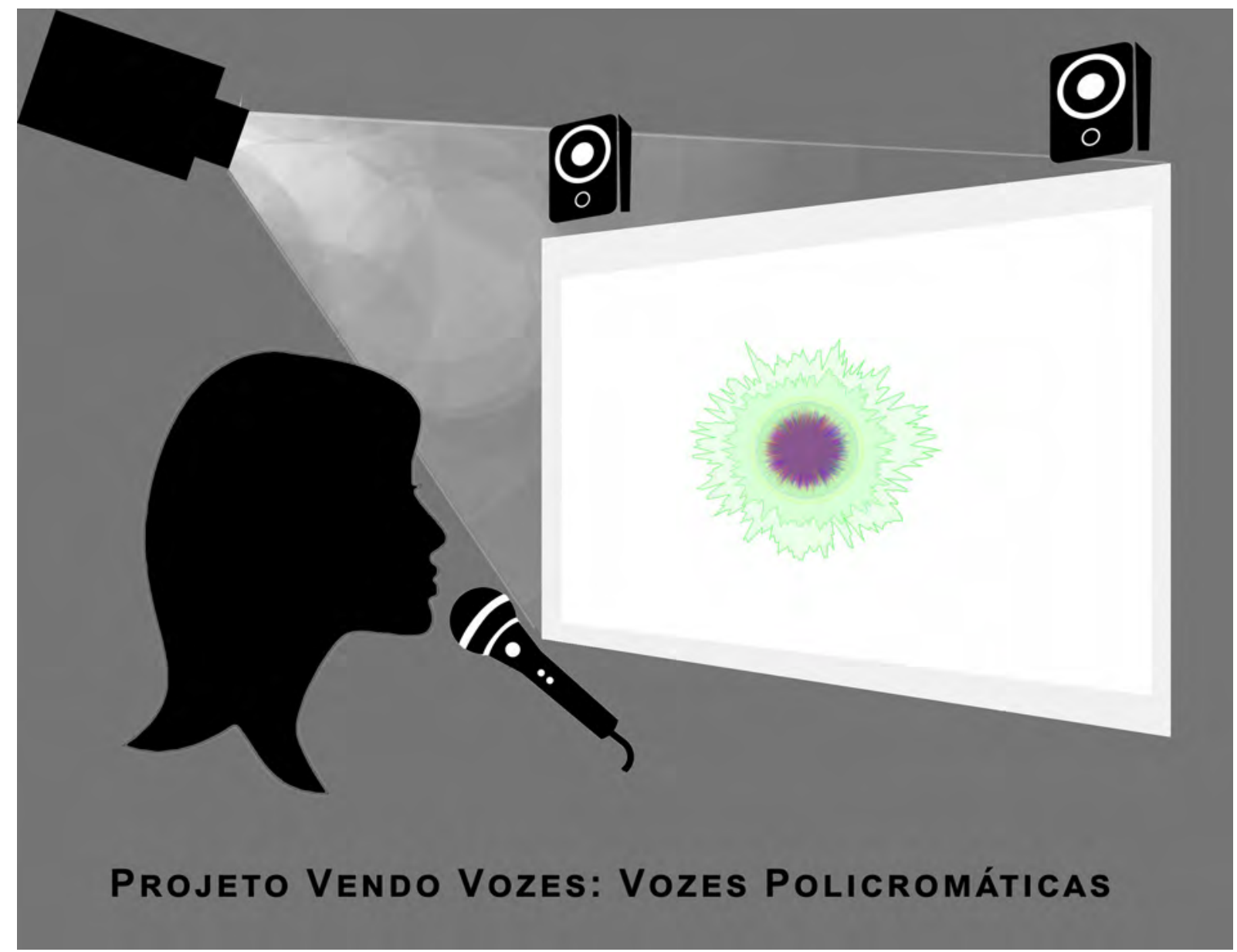

Figura 37: Proposta de montagem para o estágio atual de Vozes Policromáticas dentro do Projeto Vendo Vozes (2014-2016). Autoria própria. 


\section{CONSIDERAÇÕES FINAIS}

Esta dissertação sobre a relação entre voz e imagem em obras artísticas interativas relacionada aos estudos da sinestesia, à vocalidade e a trabalhos artísticos contemporâneos apresentou vários desafios investigativos, sendo o primeiro e o maior deles a sinestesia. $\mathrm{O}$ estudo da sinestesia esbarra em muitas dificuldades relacionadas ao caráter onipresente da relação entre os sentidos, tanto no aspecto cultural quanto no perceptivo, além do problema da utilização generalizada do termo para caracterizar obras artísticas. Foi necessária uma compreensão mais aprofundada dos estudos científicos sobre o tema para conseguir identificar o que exatamente significa o termo sinestesia e o que ele descreve. Por isso, entre os resultados apresentados, estão o reconhecimento da trajetória histórica dos estudos científicos sobre sinestesia (p.20-22) e a atualização dos conhecimentos sobre as características do fenômeno sinestésico junto com as terminologias mais usadas na área (p.22-25).

Durante as pesquisas dentro das áreas da neurociência e psicologia, confirmou-se a existência de indivíduos diferenciados que possuem a capacidade de experimentar respostas perceptivas desencadeadas por modalidades distintas dos estímulos recebidos. Portanto, a primeira diferença entre a percepção regular e a sinestesia é que essa adiciona percepções de algo ausente aos estímulos dados, enquanto aquela reúne todos os sentidos para empreender uma percepção de acordo com os estímulos factuais recebidos. Contudo, existem alguns fenômenos (como metáforas, figuras de linguagem e aspectos ficcionais) que são capazes de adicionar informações ausentes ao mundo, associando sensações, em princípio, independentes. A apresentação desses fenômenos (p.26) e a discussão de sua relação com a sinestesia é o principal ponto de desacordo entre os cientistas e o maior ponto de interesse para os artistas. Isso ocorre porque, de um lado, a expansão não criteriosa dos estudos sobre o fenômeno sinestésico para outros campos poderia enfraquecer o status científico adquirido pelo assunto nos últimos anos; e de outro, abriria a oportunidade de relacionar obras artísticas a estudos científicos sobre a percepção.

A relação entre sinestesia e arte pode ocorrer de três formas, como já mencionado no Capítulo 2 (p.32). A primeira, com os artistas sinestetas, é a mais reconhecida e estimula investigações 
científicas sobre a possível correlação entre sinestesia e criatividade (p.30-31). A segunda é caracterizada pela recepção de obras de arte por sinestetas não-artistas, que percebem obras de arte sob a individualidade de suas próprias sinestesias e é a menos estudada. Tanto a primeira quanto a segunda forma de relacionar sinestesia à arte abordam indivíduos que se enquadram nos conhecimentos já convencionados sobre o fenômeno sinestésico. Este não é o caso da terceira forma, das obras artísticas sinestésicas, que é a mais abordada no contexto artístico e também a mais controversa.

A controvérsia existe porque essas obras procuram induzir, a princípio, associações sinestésicas (associações essas nomeadas das mais diversas formas, como observado na página 37), que fazem parte dos fenômenos relacionados à sinestesia, mas que não são considerados consensualmente como sinestésicos pela ciência (ver discussão sobre nos textos das páginas 27 a 29). Além do mais, parece existir uma grande diferença de tratamento do termo por diferentes teóricos da arte (p.37-41), os quais algumas vezes se apropriam da palavra sinestesia pelo significado etimológico da palavra, sem considerar o contexto em que ela foi cunhada (por Flournoy, no século XIX). Um breve encadeamento histórico de obras artísticas que propuseram a ligação entre dois ou mais sentidos, destacadamente entre visual e sonoro, foi incluído no final do Capítulo 2 (p.41-45).

Outra questão sobre esse tipo de obra é que a originalidade desses trabalhos não está, absolutamente, em apresentar dois sentidos simultaneamente. Tal originalidade reside em como o artista estrutura poeticamente esses sentidos, com o objetivo de potencializar similitudes perceptivas. A seleção de trabalhos apresentada no quarto capítulo descreve algumas das diversas formas de abordar a questão da sinestesia em obras artísticas mediadas tecnologicamente (p.52-65). Desta forma, este capítulo apresenta a contextualização das pesquisas estéticas na área, e considera também exemplos que utilizam a voz como a intermediária entre corpo e tecnologia.

O primeiro aspecto da voz apresentado foi baseado em informações fisiológicas, de forma a esclarecer o papel central das estruturas físicas do corpo humano para a formação, caracterização e amplificação vocal (p.46-48). Esta ênfase foi empregada para se contrapor à 
tendência de compreensão da voz como uma entidade separada do corpo, ideia originária das tendências filosóficas de fatiamento corporal do ocidente (p. 50). A segregação factual entre corpo e voz pôde se tornar realidade com os novos meios tecnológicos de gravação e armazenamento de registros sonoros (p.49), reiterando esta perspectiva. Propôs-se a compreensão da voz como expressão absoluta do corpo, relacionando todos os sentidos e o espaço circundante. Compreender uma parte da complexidade vocal nesses termos permite a ênfase dos aspectos sinestésicos da voz, e as potencialidades que a vocalidade pode trazer para obras artísticas.

Os trabalhos experimentais expostos relacionam-se diretamente às pesquisas teóricas sobre a sinestesia, buscando apresentar possibilidades poéticas na abordagem do tema. A trajetória do projeto individual, Vendo Vozes (p.77-87), demonstra algumas das dificuldades técnicas e poéticas na concretização de ideias artísticas por meios tecnológicos. Apesar de a obra Vozes Policromáticas apresentar um resultado interessante de associação entre voz e imagem, ela ainda não conseguiu abranger os aspectos espaciais e corporais almejados da vocalidade. Trabalhos experimentais futuros poderão dar continuidade no desenvolvimento destes aspectos.

Em suma, as investigações abordaram diversos aspectos sobre o tema da sinestesia e da voz relacionada a obras artísticas interativas. Investigações futuras sobre o assunto deverão buscar: a) a atualização constante dos conhecimentos sobre sinestesia nas investigações científicas dos próximos anos, b) a atenção para possíveis mudanças nos paradigmas de utilização do termo sinestesia pelos neurocientistas, c) a investigação mais detalhada das utilizações do termo sinestesia na arte, brevemente apontados nesta pesquisa, e d) a incorporação e aprofundamento das questões espaciais e corporais da voz em trabalhos experimentais futuros que abordem o assunto. 


\section{BIBLIOGRAFIA}

BACHELARD, G. A poética do espaço. Trad. Antônio da Costa Leal e Lídia do Valle Santos Leal. São Paulo: Martins Fontes, 1993.

BASBAUM, Sérgio Roclaw. Sinestesia, arte e tecnologia: fundamentos da cromossonia. São Paulo: Annablume/FAPESP, 2002.

.Sinestesia e percepção digital. Trabalho apresentado no Subtle Technologies Festival, em maio de 2003.

BARON-COHEN, S.; WYKE, M. A.; BINNIE, C. Hearing words and seeing colors - an experimental investigation of a case of synesthesia.In Perception, 16, p. 761-767, 1987.

BOSLEY, Hannah G.; EAGLEMEN, David M. Synesthesia in twins: Incomplete concordance in monozygotes suggests extragenic factors. In Behavioural brain Research, no. 286, p. 93-96, 2015.

BRET,Michel; COUCHOT, Edmond. Les Pissenlits (2005). Documentação de trabalho artístico. Disponível em: $<$ http://www.archives-video.univ-paris8.fr/video.php?recordID $=232$ >. Acesso em: 20 jun. 2016.

CAETANO, Alexandra C. Moreira. SYNESTHESIAS: Instalações Sinestésicas Interativas In 12.ART\# Anais do Encontro Internacional de Arte e Tecnologia, no 12, 2013. Disponível em: https://art.medialab.ufg.br/up/779/o/alexandracaetano.pdf, acesso em julho de 2016.

SYNESTHESIAS : Interfaces da sensorialidade. 2015,

$218 \mathrm{f}$. Tese (doutorado em artes visuais), Universidade de Brasília, UNB, Livro digital.

CAMPEN, Cretien van. The hiden sense: synesthesia in art and science. The MIT Press, Cambridge, Massachusetts, 2007.

. The Hidden Sense: On Becoming Aware of Synesthesia. In

Teccogs - Revista digital de tecnologias cognitivas, PUC, edição 1, 2009. 
CAZNOK, Yara Borges. Música. Entre o audível e o visível. 2.ed., São Paulo: Editora UNESP, Rio de Janeiro: Funarte, 2008, (publicação da pesquisa de doutorado defendida em 2001).

CHIOU, Rocco; RICH, Anina N. The role of conceptual knowledge in understanding synesthesia: evaluating contemporary findings from a 'hub-and-spokes' perspective. In Frontiers in Psychology, 1-18p, 2014.

CHEVALVERT, 2ROQS, POLYGRAPHIK \& SPLANK. Murmur (2014). Descrição de trabalho artístico. Disponível em: $<$ http://file.org.br/interactive installation/chevalvert-2roqspolygraphik-splank/?lang=pt $>$. Acesso em: 20 jun. 2016.

CRARY, Jonathan. Las técnicas del observador: Visión y modernidad en el siglo xix. Trad. Fernando López García, Cendeac, Murcia, 2008.

CYTOWIC, Richard E. Escuchar colores y probar formas: el cambio de paradigma em el Cerebro. In Revista Artecittá Synesthesia Journal, no 1, año 1, p.11-16, 2014.

Synesthesia: A union of the Senses. $2^{\mathrm{a}}$. ed.,Cambridge, MA: MIT

Press, 2002.

DAITO, Manabe. Face Visualizer, Face Instrument (Performance, 2008). Documentação de trabalho artístico. Disponível em: $<$ http://www.daito.ws/en/work/smiles.html $>$. Acesso em: 20 jun. 2016.

DAMÁSIO, Antônio R. O erro de descartes: emoção, razão e o cérebro humano. Trad. Dora Vicente e Georgina Segurado, Companhia das Letras, São Paulo, 1996.

DAY, Sean. Demographic aspects of synesthesia. Site do pesquisador Sean Day com

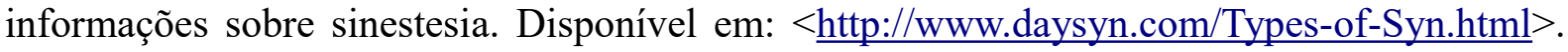
Acesso em: 20 jun. 2016.

A brief history of synaesthesia and music, 2002. Disponível em: $\overline{<\mathrm{http}: / / w w w}$.thereminvox.com/article/articleview/33/1/5/>. Acesso em: 16 mai. 2015.

DEROY, Ophelia; SPENCE, Charles. Why we are not all synesthetes (not even weakly so). in Psychon Bull Rev, v.20, p 643-664, 2013. 
DIXON, Mike J.; SMILEK, Daniel; MERIKLE, Philip M. Not all synaesthetes are created equal:Projector versus associator synaesthetes. In Cognitive, Affective, \& Behavioral Neuroscience, 4 (3), p. 335-343, 2004.

ECO, Umberto. Obra aberta. Trad. Giovanni Cutolo, 3a reimp.(1a ed. 1962, em língua italiana), Da 9a edição de 2003, São Paulo: Editora Perspectiva, 2010.

FOB-USP, Fonoaudiologia. Frequências e vibrações sonoras da voz. Descrição das características vocais do ponto de vista da fonoaudiologia. Disponível em:

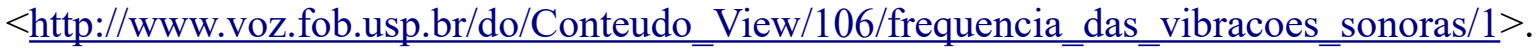
Acesso:15 jul. 2016.

FREITAS, Alexandre Siqueira de. O sonoro e o visual: questões históricas, fenomenológicas e uma abertura à estética comparada. In Per Musi - questões históricas, fenomenológicas. Belo Horizonte, n.19, p. 91-96, 2009.

\section{RESSONÂNCIAS, REFLEXOS}

$\mathbf{E}$

CONFLUÊNCIAS: Três maneiras de conceber as semelhanças entre o sonoro e o visual em obras do século XX. 2012, 341 f. Tese (doutorado em música) Escola de Comunicações e Artes da Universidade de São Paulo, USP. Livro digital.

GABRIEL, Marta C. C. Interfaces de voz em ambientes hipermidiáticos. 2006, 120 f. Dissertação (mestrado em artes plásticas), Escola de Comunicações e Artes, USP. Livro impresso e CD-multimídia.

GALEYEV, B. M.; VANECHKINA, I. L. Was Scriabin a Synesthete? In Leonardo, MIT Press, Vol. 34, No. 4, p. 357-361, 2001.

GAROA, Wiki. Híbrida/Simulador de Sinestesia. Documentação de trabalho artístico. Disponível em: $<$ https://garoa.net.br/wiki/Hibrida/Simulador_de Sinestesia $>$.Acesso em: 6 ago. 2016.

GIBSON. James J. The ecological approach to the visual perception of pictures. In Leonardo, Vol. 11, p.227-235, Pergamon Press Ltd, Great Britain, 1978. 
GOGH, Vincent van. Letter from Vincent van Gogh to Theo van Gogh:The Hague, 31 and 2 Dec-Jan 1882. Cartas ao Théo de 31 de dezembro a 2 de janeiro. Disponível em:<http://www.webexhibits.org/vangogh/letter/11/256.htm>. Acesso em: 20 jun. 2016.

GREINER, Christine O Corpo - pistas para estudos indisciplinares. Editora Annablume, São Paulo, 2005.

Grupo cAt (ciência/ARTE/tecnologia). Sopro (The Blow) (2016). Video documentando

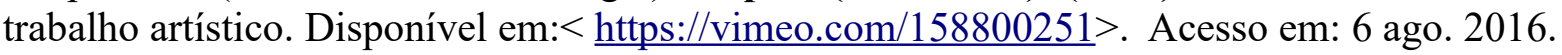

HARBISSON, Neil. Portifólio on-line. Disponível em: < http://www.harbisson.com/ $>$. Acesso em: 15 jul. 2016.

I hear colours TEDTalk disponível em: $<$ https://www.ted.com/talks/neil harbisson_i listen to color?language=pt-br $>$.AAcesso em: 20 jun. 2016.

HEYRMAN, Dr. Hugo. Art and Synesthesia: in search of the synesthetic experience. Lecture presented at the First International Conference on Art and Synesthesia Primer Congreso Internacional sobre Arte y Sinestesia 25th - 28th July, 2005 - Universidad de Almería, Spain. Disponível em: <http://www.doctorhugo.org/synaesthesia/art/>. Acesso em: 25 jul. 2016.

HOCKNEY, David. Stravinsky Oedipus: triple. Site do artista David Hockney documentando seu trabalho para o Oedipus de Stravinsky. Disponível em: $<$ http://www.hockneypictures.com/stravinsky triple/stravinsky_oedipus title.php $>$.

Acesso em: 20 jun. 2016.

HOFFMAN, Peter. Noisy Circle. Sketch do Processing. Disponível em:< http://www.openprocessing.org/sketch/112858>. Acesso em: 6 ago. 2016.

HUBBARD, Edward M. ; RAMACHANDRAN, V.S. Neurocognitive Mechanisms of Synesthesia. In Neuron, vol. 48, p. 509-520, November, 3, 2005.

IAZZETA,Fernando. Tabela de Frequências, Períodos e Comprimentos de Onda. Disponível em:

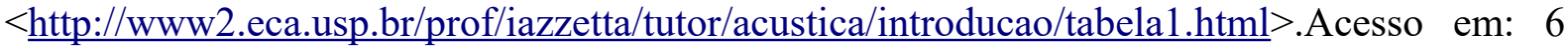


ago. 2016.

IHDE, Don. Listening and Voice. Phenomenologies of Sound. Second Edition.State University of New York Press, Albany, 2007.

IONE, Amy; TYLER,Christopher. NEUROHISTORY AND THE ARTS: Was Kandinsky a Synesthete? In Journal of the History of the Neurosciences, Vol. 12, No. 2,pp. 223-226, 2003.

JEWANSKI, Jörg; DAY, Sean; WARD, Jamie. A Colorful Albino: The First Documented Case of Synaesthesia, by Georg Tobias Ludwig Sachs in 1812. In Journal of the History of the Neurosciences, 18:3, p. 293-303, 2009.

JEWANSKY, Jörg; SIMNER, Julia; DAY, Sean A; WARD, Jamie. The Development of a Scientific Understanding of Synesthesia from Early Case Studies (1849-1873), In Journal of the History of the Neurosciences: Basic and Clinical Perspectives, 20:4, p. 284-305, 2011.

JEWANSKY, Jörg; SIMNER, Julia; DAY, Sean A; WARD, Jamie. Édouard Cornaz (18251911) and his importance as founder of synesthesia research. In Musik-, Tanz- und Kunsttherapie, 23 (2), 78 - 86 \# Hogrefe Verlag, Go“ttingen, p.78-84, 2012.

KADOSH, Roi Cohen; HENIK, Avishai; WALSH,Vincent. Synesthesia: learned or lost?, In Developmental Science, 12:3, p.484-491, 2009.

KOJIMA, Kenji. Fukushima 2011. Documentação de trabalho artístico. Disponível em:

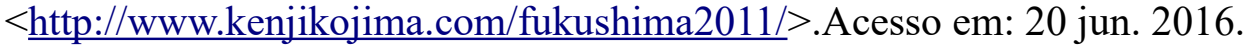

LEOTE, Rosangella. Multisensorialidade e sinestesia: poéticas possíveis? In $A R S$, ano 12, No 24, p. 42-61, 2014.

LEVIN,Golan; LIEBERMAN, Zach; BLONK,Jaap; LA BARBARA, Joan. Messa di Voce (2003). Documentação de trabalho artístico. Disponível em: $<$ http://www.tmema.org/messa/messa.html $>$ Acesso em: 20 jun. 2016. 
LOZANO-HEMMER, Rafael. Voice Tunnel (2013). Documentação de trabalho artístico. Disponível em: $<$ http://www.lozano-hemmer.com/voice tunnel.php $>$. Acesso em: 20 jun. 2016.

MARKS, Lawrence E. Synesthesia, Then and Now. Intellectica, no. 55, Saint Denis, p. 4780, 2011.

MARKS,Lawrence E. ; MULVENNA, Catherina. Synesthesia, at and near its borders. In Frontiers in Psychology, Cognitive Science, Volume 4, Article 651, p. 1-4, 2013.

MARTINO,Gail; MARKS, Lawrence E. Synesthesia:Strong and Weak. Current directions in psychology science in American Psychology Society, p.61-65, 2001.

McLUHAN, Marshall. The Playboy Interview: Marshall McLuhan. Playboy Magazine, Março de 1969, editado por ROGAWAY, Phillip para uso na UC Davies, p. 1-23, 1994.

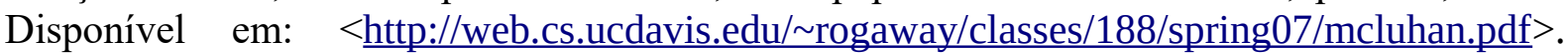
Acesso em: 13 jul. 2016.

NABOKOV, Vladimir. Speak, Memory: An Autobiography Revisited. Vintage International Books, New York, 1989.

NUNES, Sandra Meyer. O Corpo do ator em ação. In GREINER, Christine; AMORIM, Claudia (Orgs.), Leituras do corpo, Annablume, São paulo, p. 105-121, 2010.

OLIVEIRA, Paloma; LOBATO, Jaime. Projeto Híbrida. Site com informações sobre o projeto híbrida. Disponível em: $<$ http://www2.eca.usp.br/hibrida/ $>$.Acesso em: 6 ago. 2016.

PACKER, Randall e JORDAN, Ken (edited by). Multimedia - From Wagner to Virtual Reality. W.W.Norton\&Company, New York/London, 2001.

PAIK, Nam June. Participation TV (1963). Documentação de trabalho artístico. Disponível em: $<$ http://www.medienkunstnetz.de/works/participation-tv/images/2/>. Acesso em: 6 ago. 2016.

PLAZA, Julio. Tradução intersemiótica. 2.edição, (1a ed. 1987). São Paulo: Perspectiva, 2010. 
. Arte e interatividade: autor-obra-recepção. ARS (São Paulo), vol.1, no.2, São Paulo, p.8-29, 2003. Disponível em: <http://www.scielo.br/scielo.php?pid=S1678-

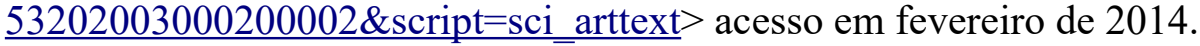

PROCESSING FOUNDATION. Processing. Site oficial da linguagem de programação processing.Disponível em:<www.processing.org/>.Acesso em: 6 ago. 2016.

RAMACHANDRAN, V. S; HUBBARD, E.M. Synaesthesia: A Window Into Perception, Thought and Language. In Journal of Consciousness Studies, 8, No. 12, pp. 3-34, 2001.

REALIDADE, Grupo de Pesquisa. Obras. Documentação das obras artísticas do grupo

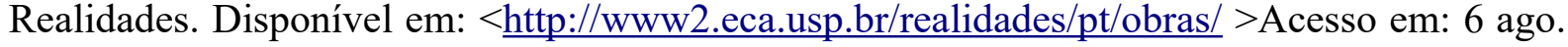
2016.

ROKEBY, David. Works : Very Nervous System (1986-1990). Documentação de trabalho artístico. Disponível em:<http://www.davidrokeby.com/vns.html $>$. Acesso em: 20 jun. 2016.

SACKS, Oliver. Alucinações Musicais - Relatos sobre a música e o cérebro. Trad. Laura Teixeira Motta, 2a reimpressão, Companhia das Letras, São Paulo, 2007.

Vendo Vozes: uma viagem ao mundo dos surdos. Trad. Laura Teixeira Motta, $4^{\mathrm{a}}$ reimpressão, Companhia das Letras, São Paulo, 2010.

SCHAFER, R. Murray. A afinação do mundo - Uma exploração pioneira pela história passada e pelo atual estado do mais negligenciado aspecto do nosso ambiente: a paisagem sonora. Trad. Marisa Trench Fonterrada, editora UNESP, São Paulo, 2001.

SIBILIA, Paula. O Homem Pós-Orgânico: Corpo, subjetividade e tecnologias digitais. Reluma Dumará, Rio de Janeiro, 2002.

SIMNER, Julia. Defining Synaesthesia. In British Journal of Psychology ,103, p. 1-15, 2012.

SOMMERER, Christina; MIGNONNEAU, Laurent; KING, Dorothée (eds). Interface Cultures - Artistic Aspects of Interaction. Bielefeld:[transcript]Cultural and Media Studies, 
2008.

SPECTOR, Ferrinne; MAURER, Daphne.Synesthesia: A New Approach to Understanding the Development of Perception. In American Psychological Association, Vol. 45, No. 1, 175-189, 2009.

STOROLLI, Wania Mara Agostini. Movimento, Respiração e Canto: a performance do corpo na criação musical. 2009. Tese (Doutorado em Processos de Criação Musical) - Escola de Comunicações e Artes, Universidade de São Paulo, USP. Livro digital Disponível em: $<$ http://www.teses.usp.br/teses/disponiveis/27/27158/tde-13052009-104317/>. Acesso em: 2016-06-20.

SUNDBERG, Johan. CIÊNCIA DA VOZ. Fatos sobre a Voz na Fala e no Canto. Tradução e revisão: Gláucia Laís Salomão.Editora da Universidade de São Paulo, EDUSP, São Paulo, 2015.

VALENTE, Heloísa de Araújo Duarte. Os cantos da voz: entre o ruído e o silêncio. ed. AnnaBlume, São Paulo, 1999.

WARD, Jamie; TOMPSON-LAKE, Dasy; ELY, Roxanne; KAMINSKI, Flora. Synaesthesia, creativity and art: What is the link? In British Journal of Psychology, 99, 127-141, 2008.

ZUMTHOR, Paul. Performance, Recepção e Leitura. Trad. Jerusa Pires Ferreira e Suely Fenarich. Cosac Naify Portátil, São Paulo, 2014. 
APÊNDICE 


\section{APENDICE A - Códigos : Syn² a.k.a Simulador de Sinestesia}

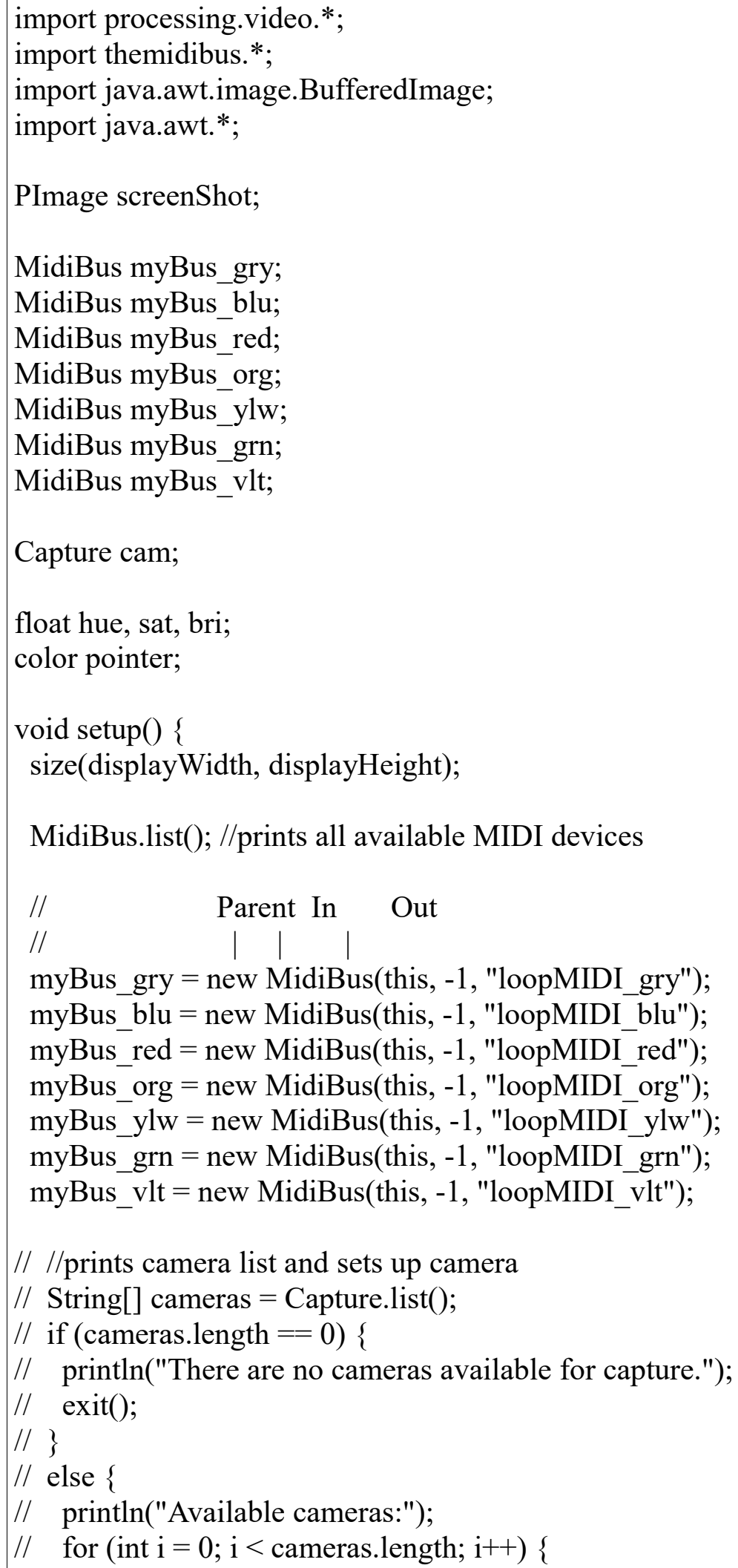




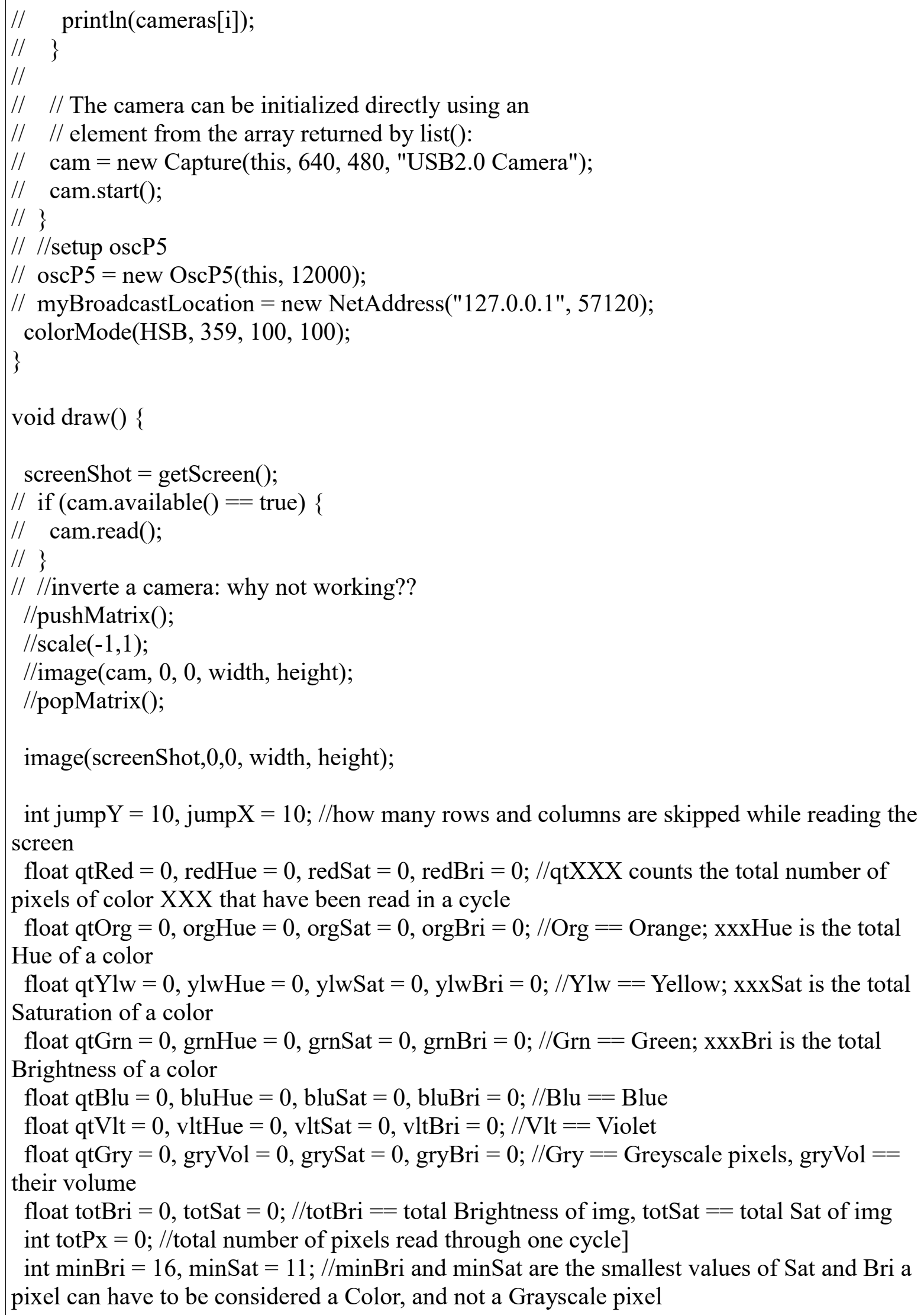


float rhythm;

int pitch_red $=0$, pitch_org $=0$, pitch_gry $=0$, pitch_blu $=0$, pitch_grn $=0$, pitch_ylw $=0$, pitch_vlt $=0$;

//these loops read through the image

for (int readY $=0$; readY $<$ height; readY $+=$ jumpY) \{

for (int readX $=0$; readX $<$ width; $\operatorname{readX}+=$ jumpX) \{

pointer $=\operatorname{get}(\operatorname{readX}$, readY);

hue $=$ hue(pointer);

sat $=$ saturation $($ pointer $)$;

bri $=$ brightness(pointer);

totBri $+=$ bri; //the total brightness and saturation control the overall rhythm of the instruments

totSat $+=$ sat;

if (sat $<=$ minSat $-1 \|$ bri $<=\operatorname{minBri}-1)\{$ //if it's a grayscale pixel

qtGry++;

if ( sat $<=10$ ) played

grySat $+=\operatorname{map}($ sat, 0 , minSat $-1,0,11)$; /grySat act as color's Hues: it sets the notes

else

grySat $+=\operatorname{map}($ sat $, 0,100,0,11)$

if (bri $<=\operatorname{minBri}-1)$

gryBri += map(bri, 0 , minBri - 1, 0, 9);

else

\}

gryBri += map(bri, 0, 100, 0, 9);

else $\{$ //if it's not gray, it's a color!

if (hue $>=23 \& \&$ hue $<=49$ ) $\{$ //if it is orange

qtOrg++; //add a unit to the total number of orange pixels read

orgHue $+=\operatorname{map}($ hue $, 23,49,0,11)$; //the avg hue of a color sets the MIDI note it will

play, from $\mathrm{C}(+0)$ to $\mathrm{B}(+11)$

orgSat $+=$ sat; //the avg saturation of a color sets the octave that'll be played

orgBri $+=$ bri; //their avg brightness sets their volume

\}

else if (hue $>=50 \& \&$ hue $<=75)\{/ /$ if it's yellow

qtYlw++;

ylwHue $+=\operatorname{map}($ hue, $50,75,0,11)$;

ylwSat $+=$ sat;

ylwBri += bri;

\}

else if (hue $>=76 \& \&$ hue $<=169)\{/ /$ if it's green

qtGrn++;

grnHue $+=\operatorname{map}($ hue $, 76,169,0,11)$; 


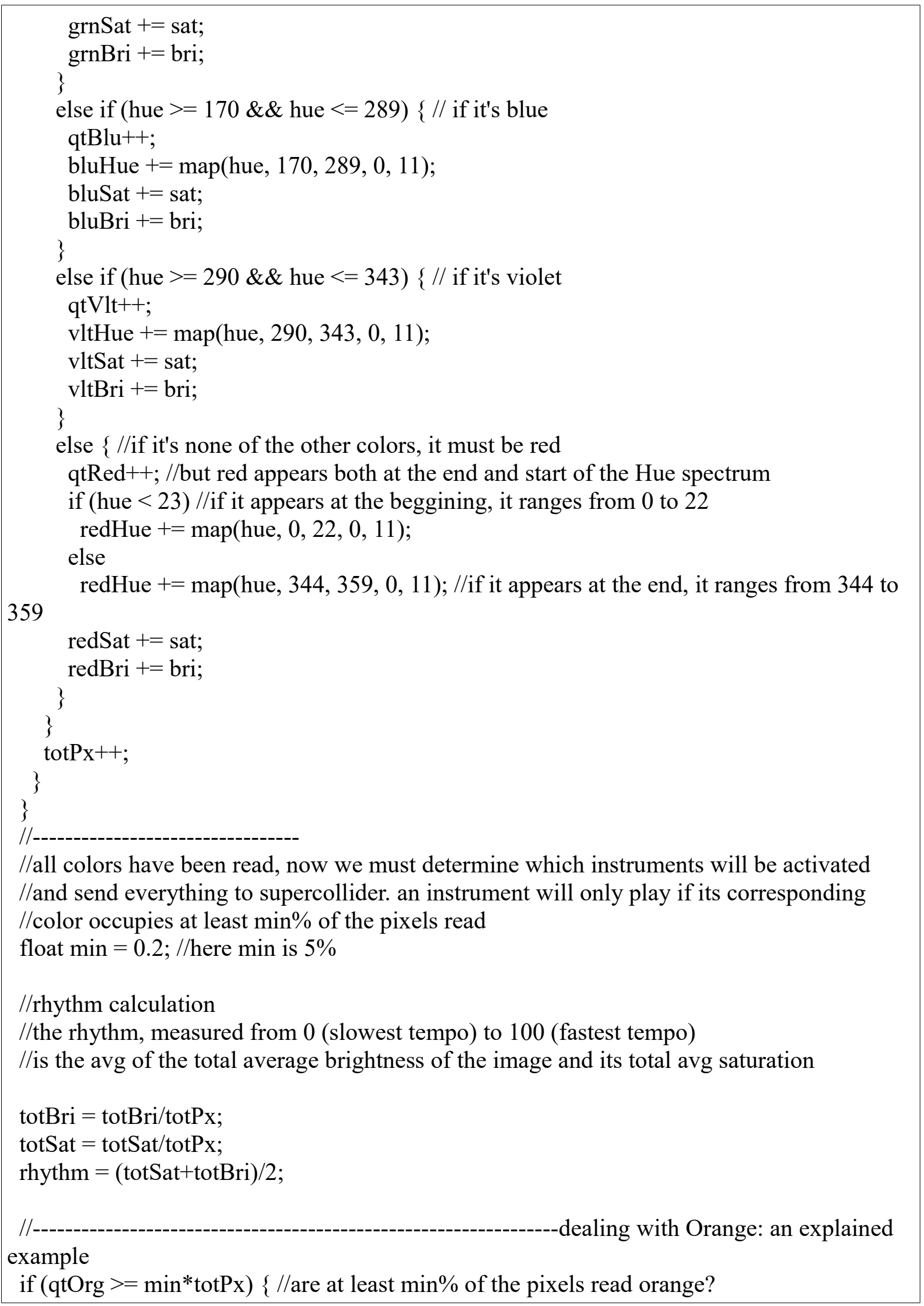


orgBri $=\operatorname{map}(($ orgBri/qtOrg $), \operatorname{minBri}, 100,0.25,1) ; / /$ this actually sets the volume of instr. Orange

orgSat $=12 *$ round $(\operatorname{map}($ orgSat/qtOrg, minSat, 100, 0, 9));

//the above line sets the MIDI octave: I've chosen a range of 10 possible octaves (0-9) //that may be played. This averages the saturation of the color, maps it from its original //range of 21 to 100 (corresponding to a pixel not belonging to the grayscale) to a range //from 0 to 9 . Then it takes the round value of this operation, which will give an integer //from 0 to 9 . This value is then multiplied by 12 , setting the base value of the MIDI octave orgHue $=$ round $($ orgHue $/$ qtOrg $)+$ orgSat;

//println("Orange note: " + orgHue);

pitch_org $=$ round(map $($ orgHue, $0,119,21,108))$;

println("Orange pitch: " + pitch_org + ", note number: " + orgHue);

myBus_org.sendNoteOn(0,int(pitch_org), 127); // Send a Midi noteOn delay $(40 /(2 *$ round $($ rhythm $)))$;

myBus_org.sendNoteOff( 0 , int(pitch_org), 127); // Send a Midi noteOff \}

else \{

orgBri $=0$;

myBus_org.sendNoteOff(0,int(pitch_org), 127);

\}

//-------------------------------------------------------------------dealing with Yellow

if (qtYlw $>=\min *$ totPx $)\{$

ylwBri $=\operatorname{map}((\mathrm{ylwBri} / \mathrm{qtYlw}), \operatorname{minBri}, 100,0.25,1)$;

ylwSat $=12 *$ round $(\operatorname{map}($ ylwSat/qtYlw, minSat, 100, 0, 9) $)$;

ylwHue $=$ round $(y l w H u e / q t Y l w)+y l w S a t ;$

// println("Yellow note: " + ylwHue);

pitch $\_$ylw $=\operatorname{round}(\operatorname{map}($ ylwHue, $0,119,21,108))$;

println("Yellow pitch: " + pitch_ylw + ", note number: " + ylwHue);

myBus_ylw.sendNoteOn(0,int(pitch_ylw), 127); // Send a Midi noteOn

$\operatorname{delay}(40 /(2 *$ round(rhythm $)))$;

myBus_ylw.sendNoteOff( 0 , int(pitch_ylw), 127); // Send a Midi noteOff

\}

else \{

ylwBri $=0$;

myBus_ylw.sendNoteOff( 0 , int(pitch_ylw $), 127)$;

\}

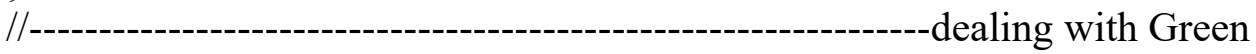

if (qtGrn $>=\min *$ totPx $)\{$

grnBri $=\operatorname{map}(($ grnBri/qtGrn $), \operatorname{minBri}, 100,0.25,1)$;

grnSat $=12 *$ round $(\operatorname{map}($ grnSat/qtGrn, minSat, 100, 0, 9) $)$;

grnHue $=$ round $($ grnHue/qtGrn $)+$ grnSat;

$/ /$ println("Green note: " + grnHue); 


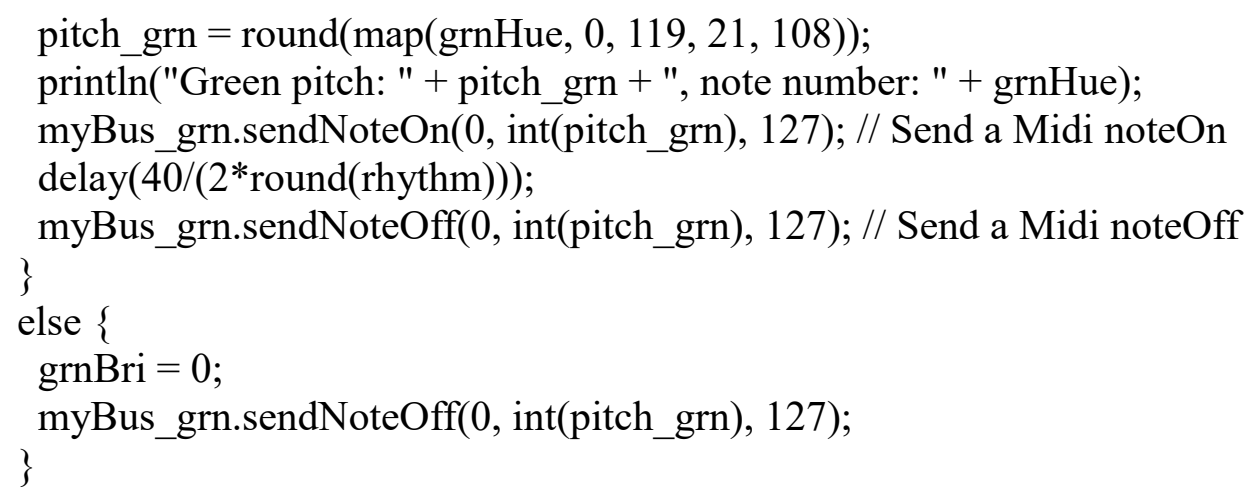




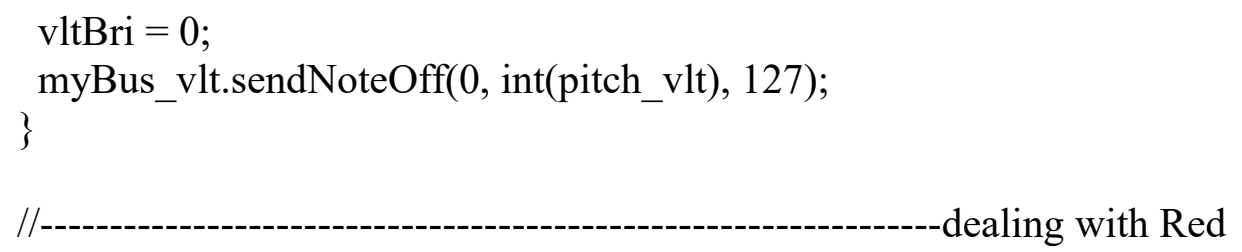

//dealing with grayscale pixels: always on as long as qtGry $>0$

//in the case of the Grayscale pixels, they have a constant volume, since they're the base instrument

//thus their Bri and Sat values are used to map the note and octave that'll be played if (qtGry $>0)\{$

gry Vol $=0.3$; / this is the volume of the Gray instr: a constant, as long as there is one gray pixel in the image

gryBri $=12 *$ round(gryBri/qtGry); //this sets the octave of the base Gray instr. grySat $=$ round $($ grySat/qtGry $)+$ gryBri; //this numbers the note of the base Gray instr.

pitch_gry $=$ round $(\operatorname{map}($ grySat, $0,119,21,108))$;

println("Gray pitch: " + pitch_gry + ", note number: " + grySat);

myBus_gry.sendNoteOn(0, int(pitch_gry), round(random(1000))); // Send a Midi noteOn delay(round(random(1000)));

$/ / \operatorname{delay}(1 /(2 *$ round(rhythm $)))$;

myBus_gry.sendNoteOff(0, int(pitch_gry), 127); // Send a Midi noteOff

//sends out Gray's note, already mapped from 0 to 119

// OscMessage grySatMSG = new OscMessage("/grySat");

// grySatMSG.add(grySat);

// oscP5.send(grySatMSG, myBroadcastLocation);

\}

else 
gry Vol $=0$; //if there is NO gray (highly unlikely), the base instrument disappears

//sends out Greyscale's volume, remember it is a constant (you may change it above)

// OscMessage gryVolMSG = new OscMessage("/gryVol");

// gryVolMSG.add(gryVol);

// oscP5.send(gryVolMSG, myBroadcastLocation);

\}

PImage getScreen() \{

GraphicsEnvironment ge = GraphicsEnvironment.getLocalGraphicsEnvironment();

GraphicsDevice[] gs = ge.getScreenDevices();

DisplayMode mode = gs[0].getDisplayMode();

Rectangle bounds $=$ new Rectangle $(0,0$, mode.getWidth( $)$, mode.getHeight ()$)$;

BufferedImage desktop $=$ new BufferedImage (mode.getWidth(), mode.getHeight $($ ),

BufferedImage.TYPE_INT_RGB);

try \{

desktop $=$ new Robot(gs[0]).createScreenCapture(bounds);

\}

catch(AWTException e) \{

System.err.println("Screen capture failed.");

\}

return (new PImage(desktop));

\} 


\section{APÊNDICE B - Códigos : $\Phi$ - Um enigma para Gibson 3.1}

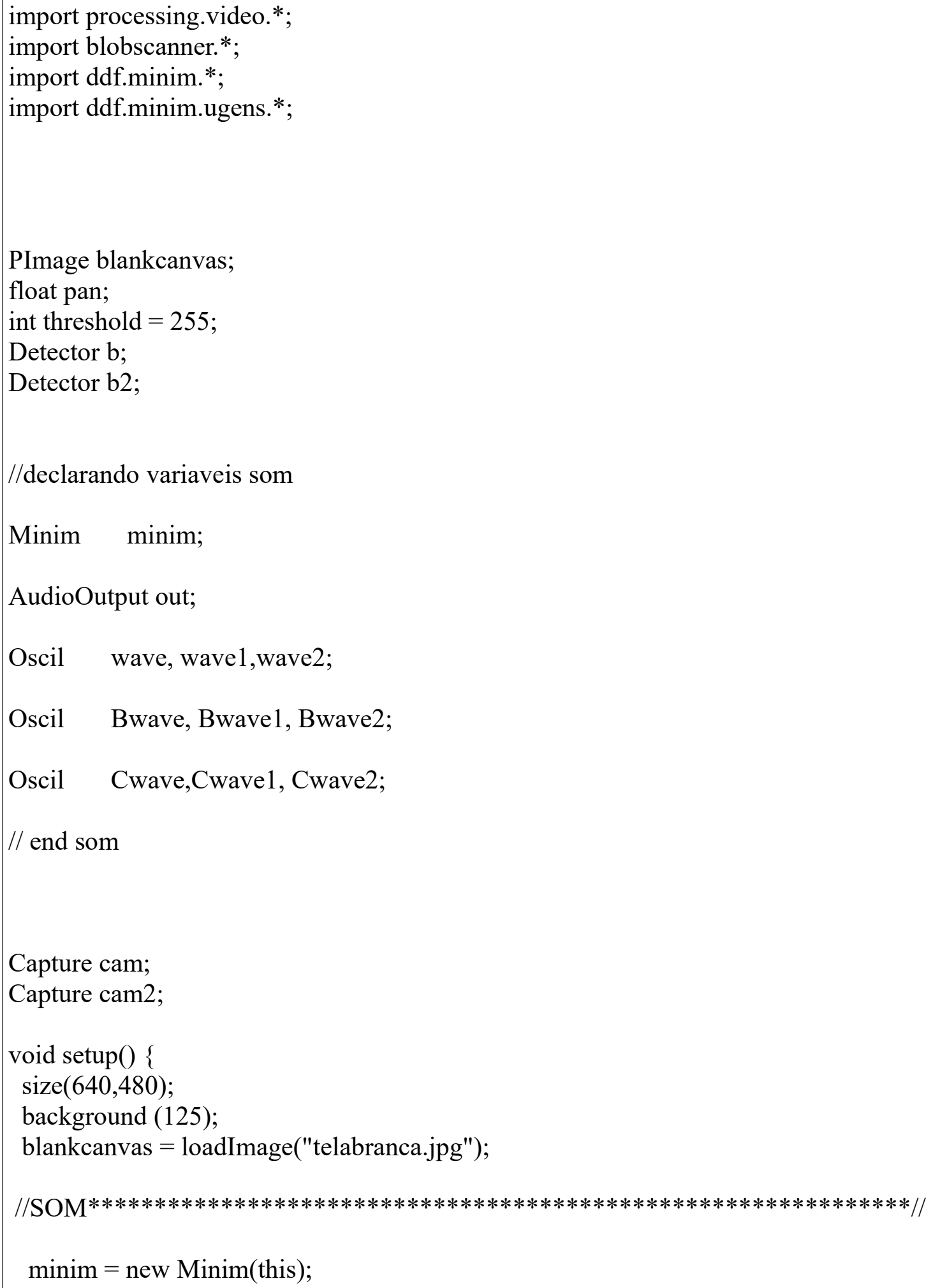


// use the getLineOut method of the Minim object to get an AudioOutput object out $=$ minim.getLineOut () ;

//wave - inicialização (freq,amp,tipo de onda)

wave $=$ new Oscil ( 60, 0.5f, Waves.SINE );

wave1 = new Oscil( 60, 0.5f, Waves.SINE );

wave2 $=$ new Oscil( 60, 0.5f, Waves.SINE );

//Bwave

Bwave $=$ new Oscil $(60,0.5 f$, Waves.SINE $) ;$

Bwave1 = new Oscil( 60, 0.5f, Waves.SINE );

Bwave2 = new Oscil( 60, 0.5f, Waves.SINE );

//Cwave

Cwave $=$ new Oscil $(60,0.5 f$, Waves.SINE $)$;

Cwave1 = new Oscil( 60, 0.5f, Waves.SINE );

Cwave2 = new Oscil( 60, 0.5f, Waves.SINE );

// patch the Oscil to the output

//wave

wave.patch( out );

wave1.patch(out);

wave2.patch(out);

//Bwave

Bwave.patch( out );

Bwave1.patch(out);

Bwave2.patch(out); 
//Cwave

Cwave.patch( out );

Cwave1.patch(out);

Cwave2.patch(out);

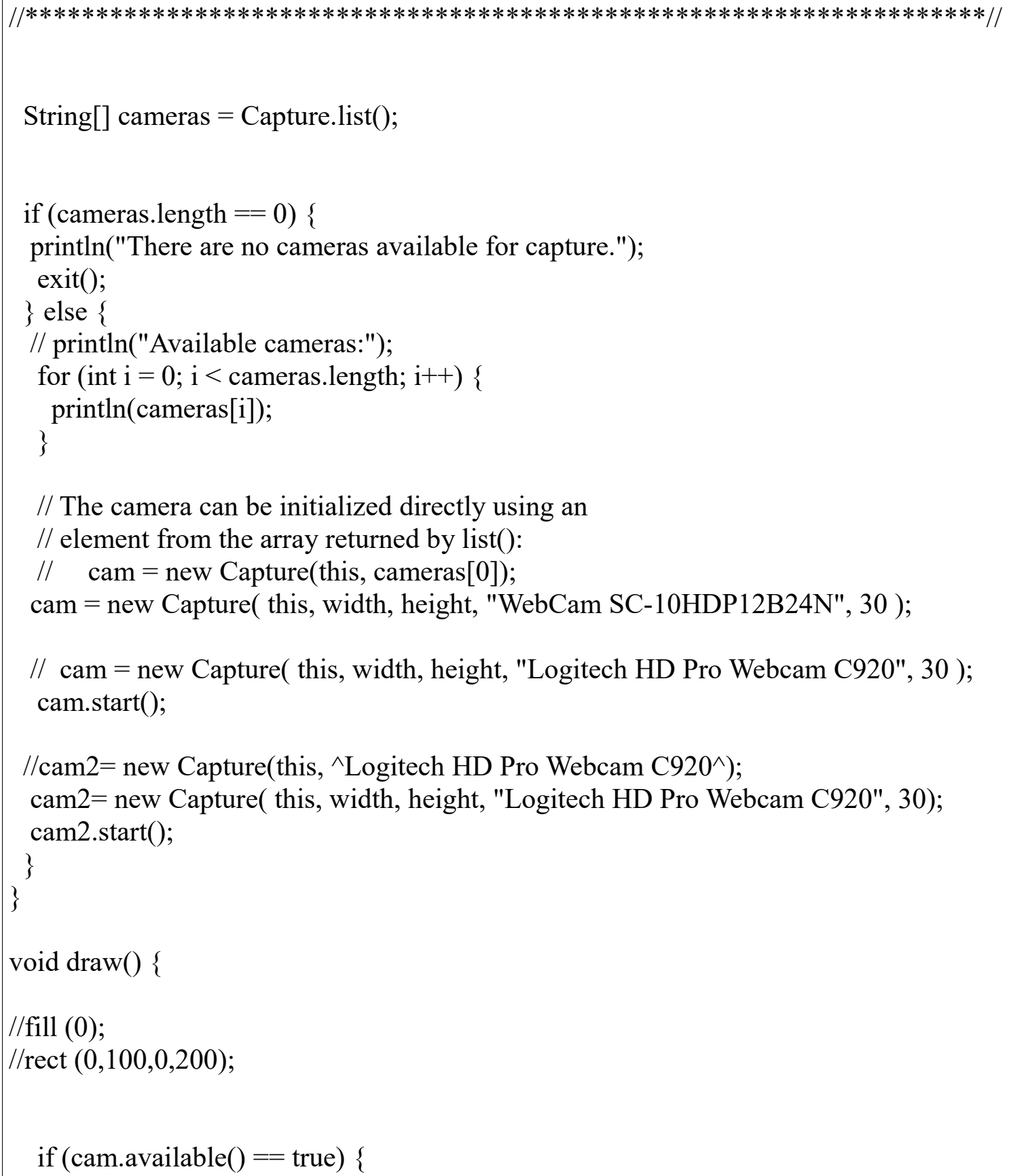




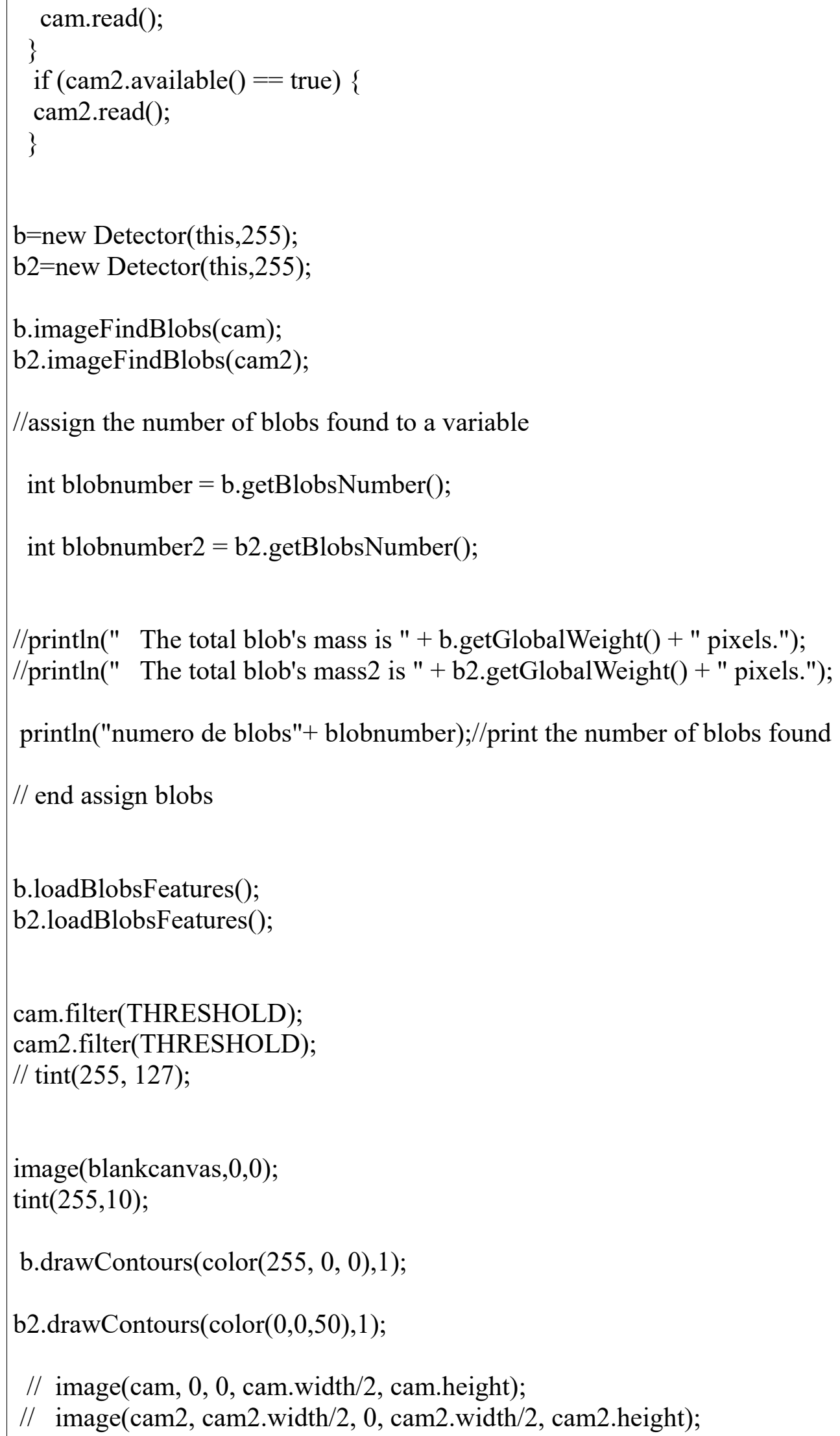


/////////////////////////////////////SOM*

$* * * * * * * * * * * * * * * * * * * * * * * * / /$

//AMPLITUDE - FORTE(1) vs Fraco(0)

//MAP=REGRA DE 3

$/ /$ float amp $=\operatorname{map}($ mouseY, 0 , height, 1,0$)$;

float amp $=0.1$;

wave.setAmplitude( amp );

wave1.setAmplitude(amp/2);

wave2.setAmplitude(amp/4);

Bwave.setAmplitude( amp );

Bwave1.setAmplitude( amp/2 );

Bwave2.setAmplitude( amp/3 );

Cwave.setAmplitude( amp );

Cwave1.setAmplitude( amp/2 );

Cwave2.setAmplitude( amp/3 );

//FREQUENCIA - Altura - nota mais

//frequencia base freq

$/ *$ freq $* 2=$ subir $18 \mathrm{~J}$

freq $/ 2=\operatorname{descer} 18 \mathrm{~J}$

freq $* 5 / 4=3 \mathrm{M}$

freq $* / 3=4 J$ 


$$
\text { freq } * 2 / 3=5 J
$$

$* /$

float freq0 $=\operatorname{map}($ blobnumber, $0,100,200,400)$;

float freq $=\operatorname{map}($ blobnumber $2,0,100,100,200)$;

wave.setFrequency ( freq0);

float pan $=\operatorname{map}($ blobnumber, $0,150,-1,1)$;

// wave.setPan(pan);

$/ /$ freq $* 2=8 \mathrm{~J}$

wave1.setFrequency $($ freq*0.2);

wave2.setFrequency (freq*0.3);

$/ / 3 \mathrm{M} 5 * \mathrm{FREQ} / 4$

Bwave.setFrequency( 5/4*freq/2 );

Bwave1.setFrequency $((5 / 4 *$ freq $) * 2 / 2)$;

Bwave2.setFrequency $((5 / 4 *$ freq $) * 3 / 2)$;

$/ /$ freq $* 2 / 3=5 \mathrm{~J}$ (abaixo)

Cwave.setFrequency( $2 / 3 *$ freq/3);

Cwave1.setFrequency $((2 / 3 *$ freq $) * 2 / 3)$;

Cwave2.setFrequency $((2 / 3 *$ freq $) * 3 / 3)$;

$* * * * * * * * * * * * * * * * * * * * * * * * * * * * / /$ 


\section{APÊNDICE C - Códigos : Vozes Policromáticas (Projeto Vendo Vozes)}

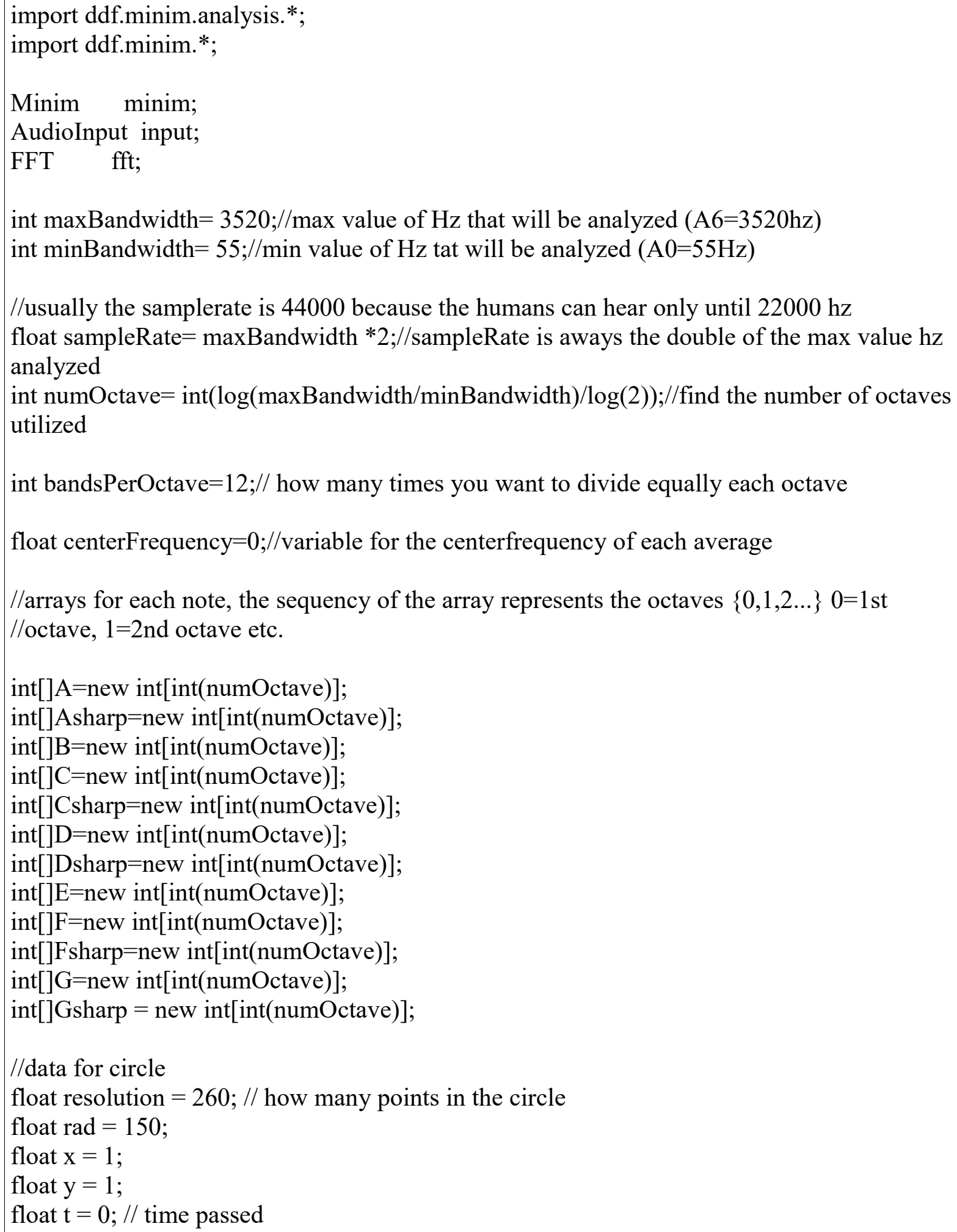




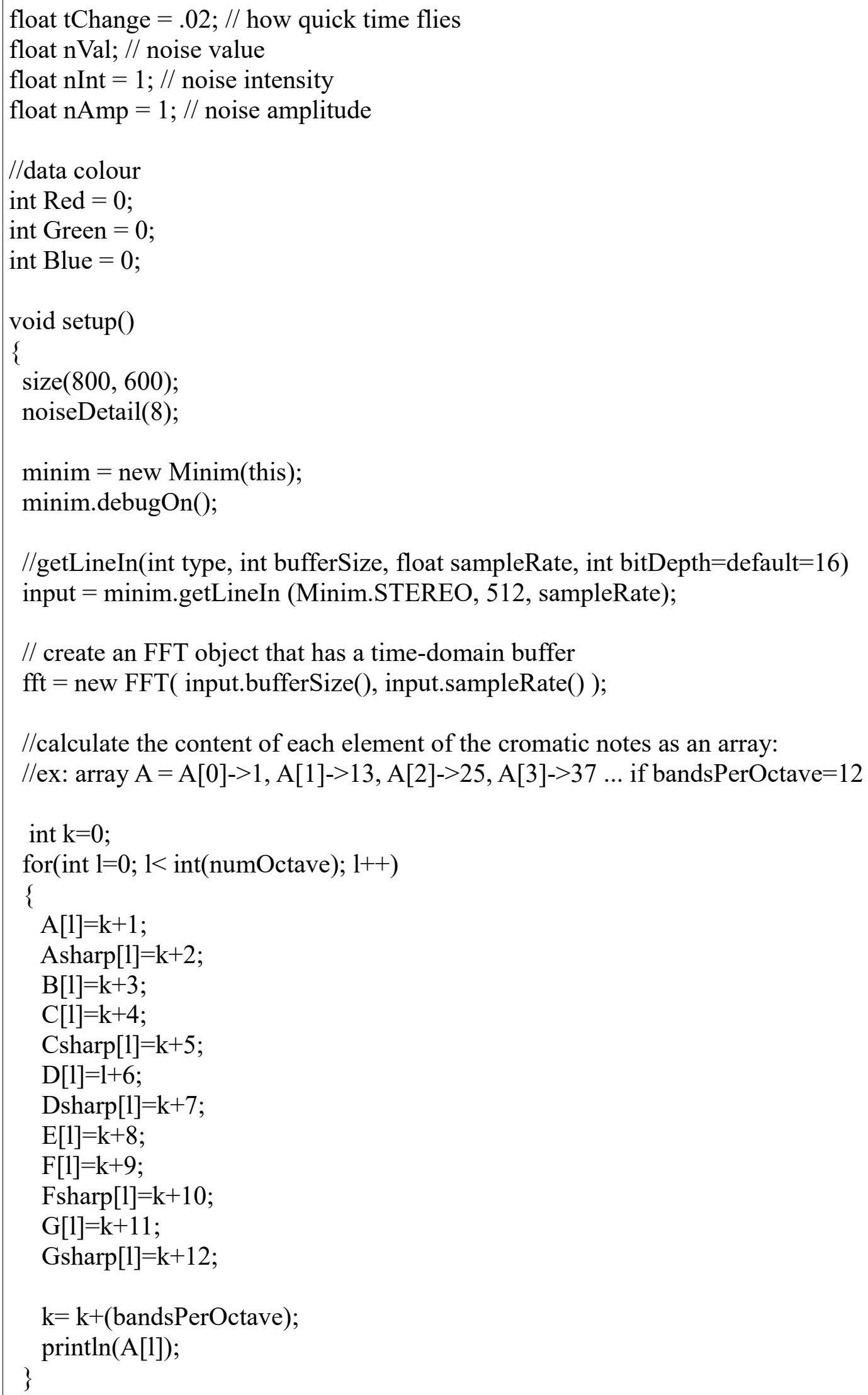




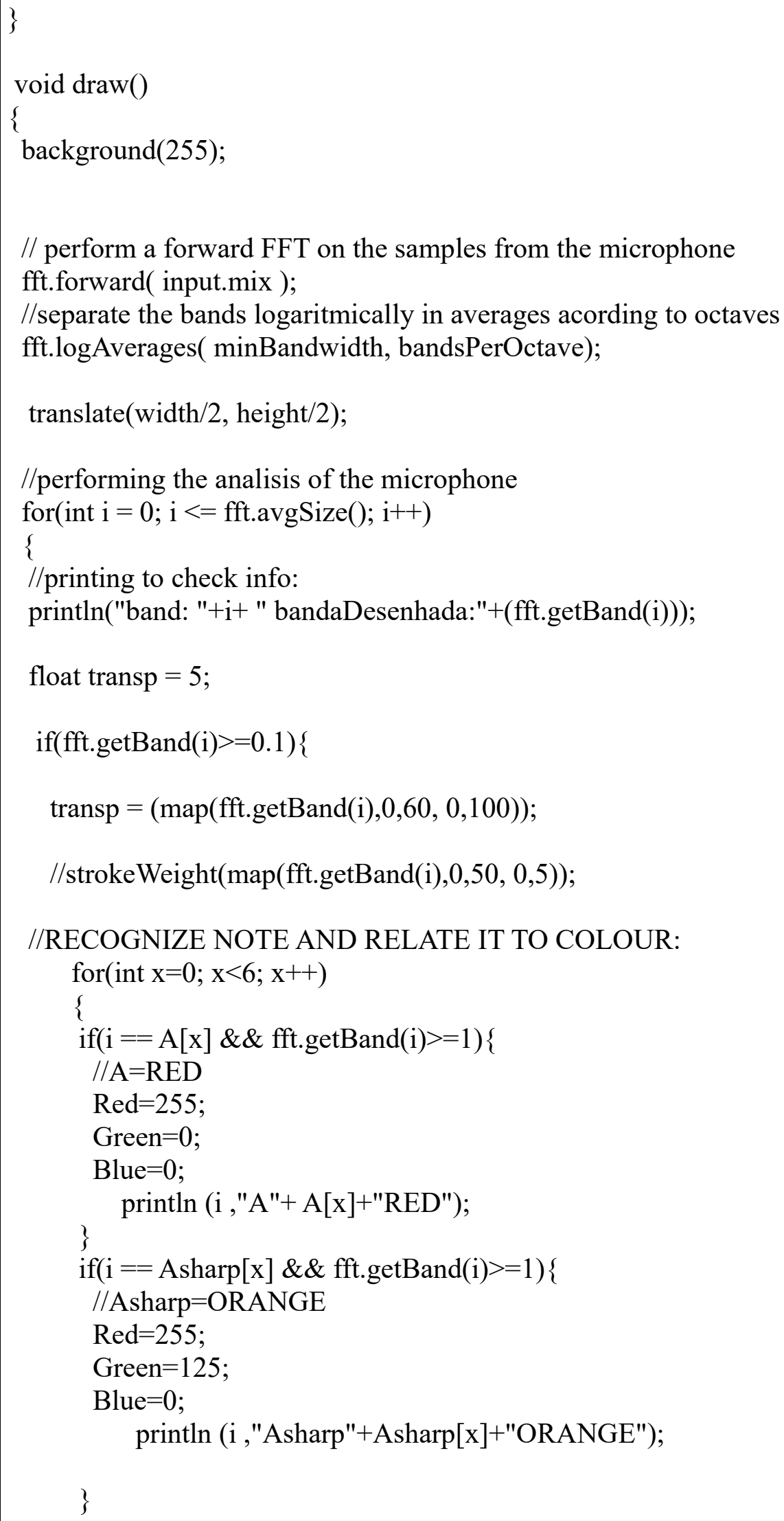


if $(\mathrm{i}==\mathrm{B}[\mathrm{x}] \& \&$ fft.getBand(i) $>=1)\{$

$/ / \mathrm{B}=$ YELLOW

$\mathrm{Red}=255$;

Green $=255$;

Blue $=0$;

if

println (i , "B"+B[x]+"YELLOW");

if $(\mathrm{i}==\mathrm{C}[\mathrm{x}] \& \&$ fft.getBand(i) $>=1)\{$

$/ / \mathrm{C}=$ SPRING GREEN

$\mathrm{Red}=200$;

Green $=255$;

Blue $=0$;

println (i , "C"+C[x]+"SPRING GREEN");

\}

if $(\mathrm{i}==$ Csharp $[\mathrm{x}] \& \&$ fft.getBand(i) $>=1)\{$

$/ /$ Csharp $=$ GREEN

$\mathrm{Red}=0$;

Green=255;

Blue $=0$; println (i , "Csharp"+Csharp[x]+"GREEN");

\}

if $(\mathrm{i}==\mathrm{D}[\mathrm{x}] \& \&$ fft.getBand(i) $>=1)\{$

$/ / \mathrm{D}=\mathrm{CYANE}$

$\mathrm{Red}=0$;

Green $=255$;

Blue $=255$;

println (i , "D"+D[x]+"CYANNE");

\}

if $(\mathrm{i}==\operatorname{Dsharp}[\mathrm{x}] \& \&$ fft.getBand(i) $>=1)\{$

//Dsharp=TURQUOISE

Red $=0$;

Green $=160$;

Blue $=255$;

println (i , "Dsharp"+Dsharp[x]+"TUQUOISE");

\}

if $(\mathrm{i}==\mathrm{E}[\mathrm{x}] \& \&$ fft.getBand(i) $>=1)\{$

$/ / \mathrm{E}=\mathrm{BLUE}$

$\mathrm{Red}=0$;

Green $=0$;

Blue $=255$;

println (i , "E"+ E[x]+"BLUE");

\}

if $(\mathrm{i}==\mathrm{F}[\mathrm{x}] \& \&$ fft.getBand(i) $>=1)\{$

$/ / \mathrm{F}=\mathrm{OCEAN}$

$\mathrm{Red}=80$;

Green $=0$; 


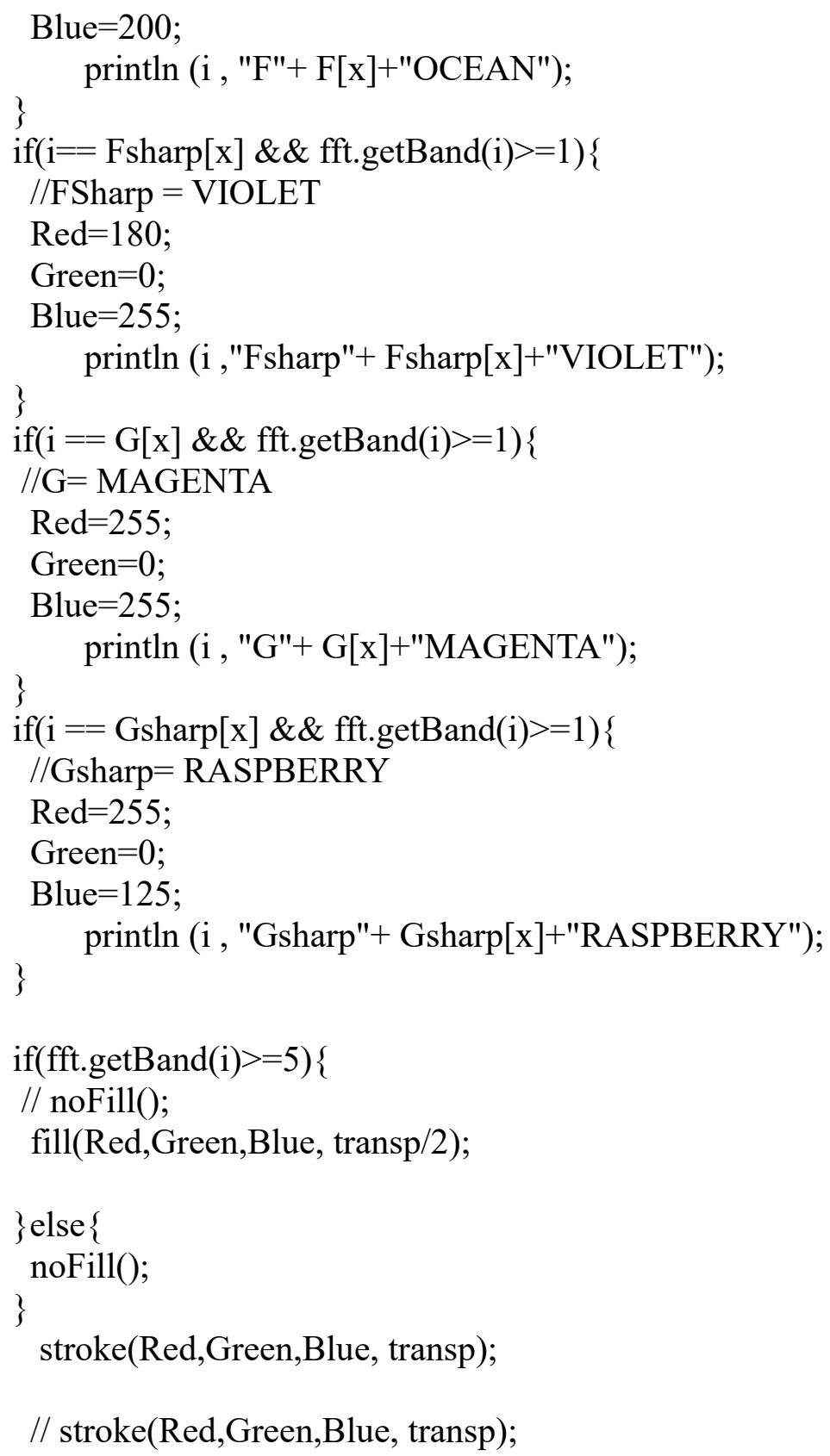

//data for the circle

nInt $=\operatorname{map}(\mathrm{i}, 0,72,0.1,30) ; / /$ map mouseX to noise intensity (how rough) nAmp = map(fft.getBand(i), 0, 30, 0.0, 1.0); // map mouseY to noise amplitude (how big) //begining circle beginShape(); 


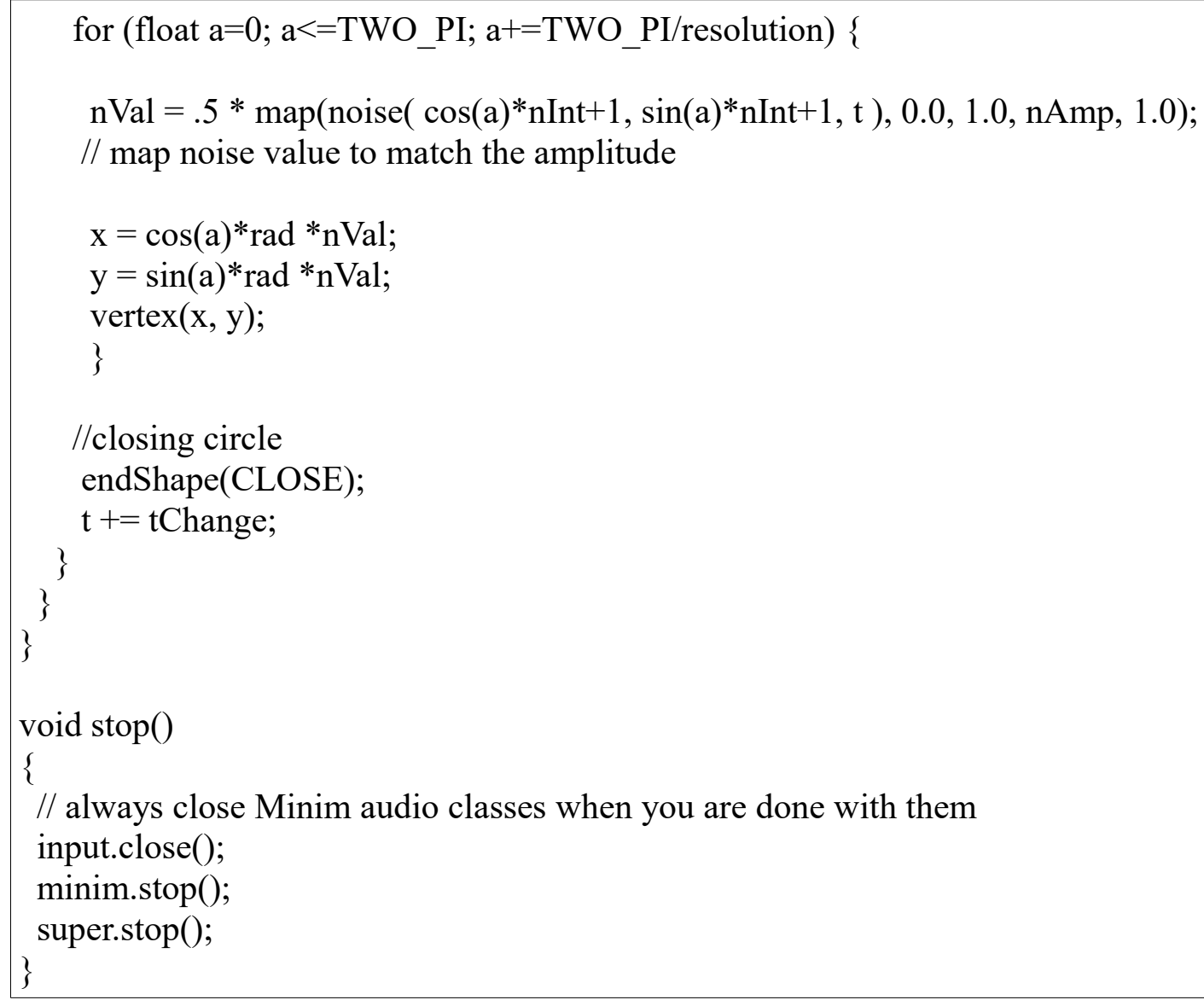


ANEXOS 


\section{Programa Híbrida}

Prototipagem EXPERIMENTAL DE AMPLiAdores DE PERCEPÇÃO

\section{Simulador de Sinestesia}

Autor:

Rafael V. RiBEIRo

11 de fevereiro de 2014 


\section{O que é sinestesia?}

Sinestesia é um fenômeno neurológico/psicológico que consiste na percepção cruzada de estímulos entre sentidos físicos. De modo simples, um sinesteta (aquele que possui sinestesia) interpreta com mais de um sentido um estímulo sobre outro sentido. Ou seja, um estímulo sonoro, como o timbre de um trompete, pode produzir em sua mente visões de círculos azuis ou triângulos amarelos. Do mesmo modo, ver uma paisagem ou um quadro, ou assistir a um filme, pode produzir experiências sonoras, táteis, ou mesmo de sabor ou cheiro no cérebro de um sinesteta. Indivíduos com tal condição (ou melhor, habilidade, ou dom, como eles próprios preferem chamá-lo) em um nível mais complexo podem também associar formas e elementos temporais (dias, horas, estações) entre si ou a características como alto, baixo, estreito, largo, etc.

Um tipo específico de sinestesia pode ser denotado pela sintaxe $x \rightarrow y$, em que $x$ é o "indutor" ou "experiência-gatilho" que serve de estímulo à experiência, e y é a experiência adicional ou "induzida." Por exemplo, um tipo comum de sinestesia é a grafema $\rightarrow$ cor, que apresentam aqueles que costumam associar cores a grafemas (caracteres como letras e números). Sinestesia visual $\leftrightarrow$ sonora se refere à percepção sonora de formas (cores, movimento, etc) como possuindo "sons" e, do mesmo modo, à percepção visual de sons, que possuiriam suas próprias texturas ou cores/formas.

Ainda, as experiências sinestésicas reais variam de indivíduo para indivíduo. A letra A pode ser amarela para uma pessoa e azul para outra. Um círculo pode ser quente para um e frio para outro. Wassily Kandinsky, com pretensões científicas em seu Do Espiritual na Arte, explorou suas impressões sobre o assunto, e mais tarde Gaston Bachelard, em A Poética do Espaço, fez o mesmo, discordando do professor da Bauhaus em diversos pontos.

\section{Proposta \& especialização}

O intuito deste documento é propor a criação de um conjunto de aparelhagem física (hardware) e imaterial (software) que simule sinestesia. Uma vez que percepções como tato, paladar e olfato são ainda de difícil interpretação satisfatória por máquinas, optou-se por limitar o âmbito da proposta à sinestesia visual $\leftrightarrow$ 
sonora.

\subsection{Hardware}

No nível de (hardware, poucas inovações seriam necessárias. Seriam necessários aparelhos que proporcionassem (output audiovisual ao usuário e, ao mesmo tempo, fossem capazes de receber (input do ambiente. Para o (output visual, bastaria uma tela, preferencialmente um óculos com telas digitais (como os óculos de realidade virtual já existentes). Para a saída sonora,

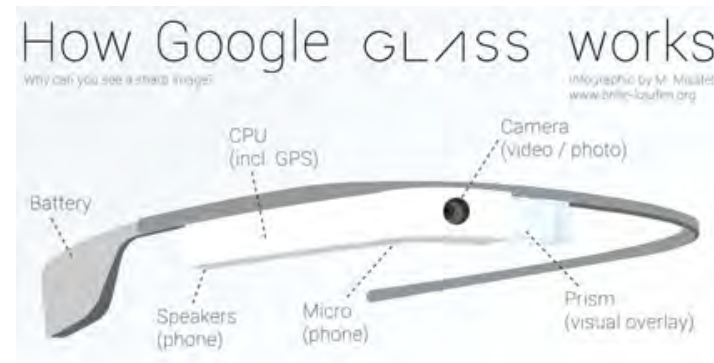

Figure 1: Google Glass um fone de ouvido comum serviria ao propósito - no entanto, os chamados bone-conducting headphones proporcionariam uma experiência ainda mais vívida ao não barrar a captação dos sons naturais por parte do usuário. Para o input, um pequeno microfone e uma câmera digital acoplada ao usuário de modo a "ver" o mesmo que ele seriam ideais. Seria necessário, ainda, um tipo de CPU para rodar o software proposto. Deve-se notar que o dispositivo Google Glass (fig. 1), recentemente lançado, possui todas estas funcionalidades e outras mais.

\subsection{Software}

A parte mais artística e tecnologicamente interessante desta proposta seria o software. Para um indivíduo sinesteta, a conversão de imagem a som e vice-versa é natural e imediata, como deve ser neste projeto. O que se propõe são dois algoritmos de conversão em tempo real de som para imagem e de imagem para som. No primeiro caso, o som ambiente (seja o ruído de uma rua, o falar de pessoas, ou uma canção) seria captado e extrairia-se dele informações que podem ser compreendidas por um computador, como a frequência, a amplitude, e o que mais puder ser utilizado. Tais dados seriam utilizados como parâmetros para a geração simultânea de uma sequência de imagens nos olhos do usuário. Um som constante e pouco variável geraria uma imagem praticamente estática. Uma melodia ou 
um ruído com grandes mudanças geraria uma sequência de imagens interessantes. De modo similar, na conversão de imagens para sons, a câmera analisaria características da paisagem vista pelo usuário, como a quantidade de vermelhos, verdes e azuis, ou o brilho e a saturação, bem como, se possível, a presença de formas geométricas básicas. Tais características, quantificadas, seriam submetidas como parâmetros para a geração (ou reprodução) de sons no ouvido do usuário. Samples de instrumentos -como em áudio MIDI- poderiam ser utilizadas. Novamente, caso uma imagem estática fosse vista, uma nota pura e constante seria gerada, e se o input consistisse de várias imagens em sucessão (como num filme), geraria-se uma sequência de notas: uma melodia.

Além disso, como dito, as experiências sinestésicas são pessoais. Uma das funcionalidades do projeto deve ser refletir essa individualidade, proporcionando uma experiência sensorial única para cada usuário. Alguns parâmetros nos algoritmos acima citados poderiam ter suas origens em características do próprio usuário, seja físicas (como a cor de seus olhos, sua altura, etc.), seja psicológicas (neste caso auferidas por meio de um breve quiz antes do uso do aparelho. Por outro lado, tão variância não pode entrar em conflito com a constância pessoal. É ideal que não se utilize randomização na geração dos sons/imagens, de modo que as experiências, para cada usuário, sejam repetíveis: um indivíduo que, ao olhar para a Monalisa, ouve um ré bemol de trompete, deve ouvir o mesmo ré bemol ao olhar para a mesma pintura, dado que seu input pessoal, acima descrito, seja o mesmo em ambas as situações. 

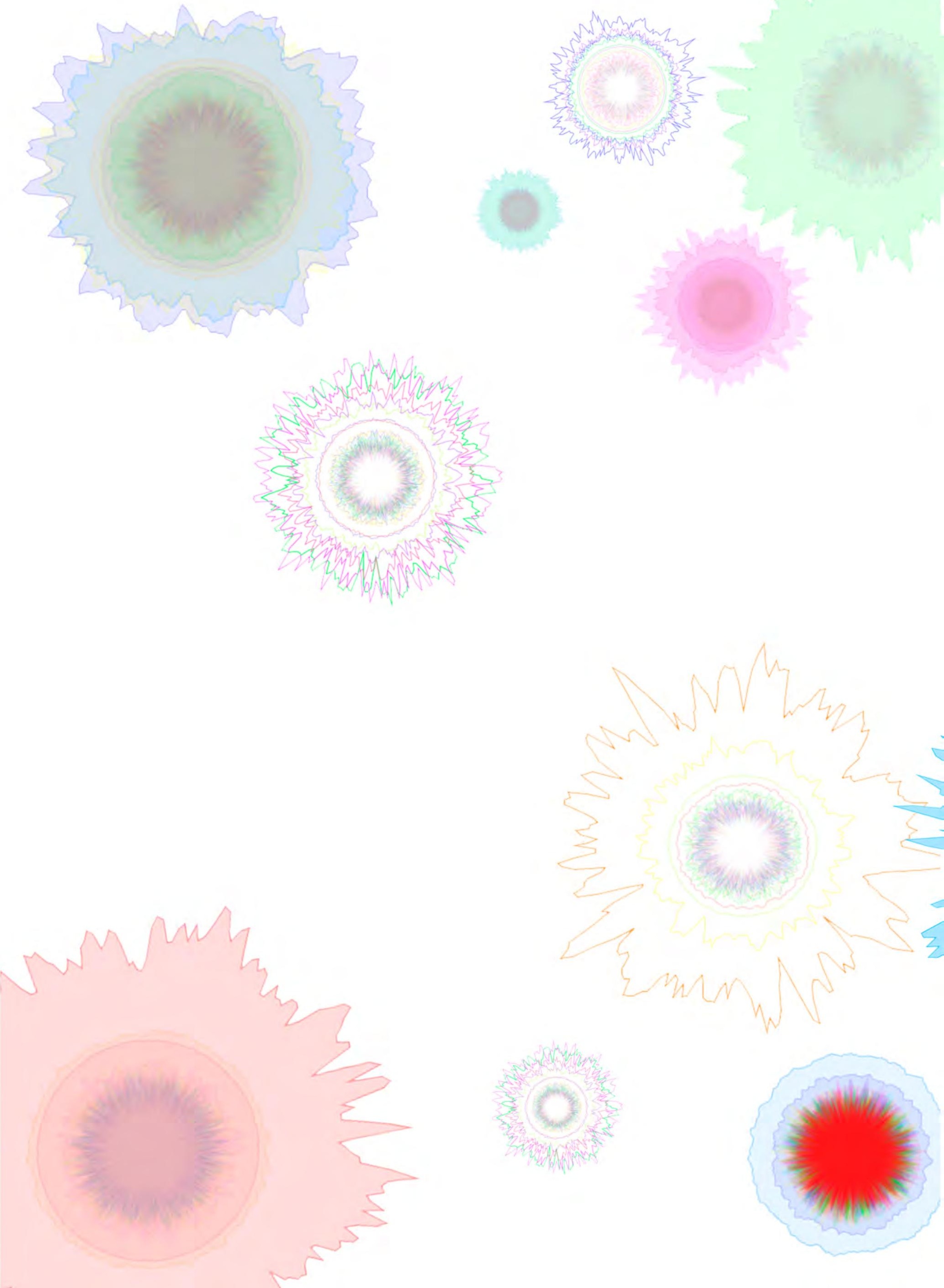